\title{
REVIEW OF THE GENUS PARAPLODERUS HERMAN, 1970 (COLEOPTERA: STAPHYLINIDAE: OXYTELINAE)
}

\author{
GYöRgY MAKRANCZY \\ Department of Zoology, Hungarian Natural History Museum \\ H-1088 Budapest, Baross utca 13, Hungary; E-mail: makranczy@zoo.nhmus.hu
}

The genus Paraploderus Herman, 1970 inhabits forested areas of the Afrotropical and Oriental regions and lives in wet, decaying plant material, most frequently leaf litter and is collected by sifting or at light. Fifteen species are recognized, the synonymies of Paraploderus parcepunctus (Fauvel, 1905) = Trogophloeus punctus Bernhauer, 1933, syn. n. and Paraploderus speculiventris (Fauvel, 1904) = Trogophloeus oxyteloides Cameron, 1925, syn. n. are proposed. Eleven species are described as new: Paraploderus fauveli sp. n. (Indonesia: Lombok), P. goergesae sp. n. (Indonesia: Maluku), P. grandis sp. n. (Kenya: Trans Nzoia), P. hammondi sp. n. (India: Tamil Nadu), P. leleupi sp. n. (Angola: Lunda Sul), P. loebli sp. n. (India: Uttarakhand), P. malgaceus sp. n. (Madagascar: Toamasina/Alaotra Mangoro), P. rufescens sp. n. (Uganda: Western prov.), P. schwendingeri sp. n. (Indonesia: West Sumatra prov.), P. thailandicus sp. n. (Thailand: Nakhon-Nayok prov.) and P. wittei sp. n. (D.R. Congo: Katanga). Lectotypes are designated for Trogophloeus oxyteloides Cameron, 1925, T. nigronitens Cameron, 1951, T. notabilis Cameron, 1950, Oxytelus parcepunctus Fauvel, 1905 and Haploderus speculiventris Fauvel, 1904. The genus is redescribed and relevant morphological details are illustrated. All fifteen species are shown on colour habitus photos, male and female genitalia plus certain details of male and female terminalia by line drawings. The suspected mature larva of Paraploderus rufescens is illustrated and discussed.

Key words: Coleoptera, Staphylinidae, Oxytelinae, Paraploderus, Afrotropical region, Oriental region, Palaearctic region, key, new species, synonymy, lectotypes, larva.

\section{INTRODUCTION}

Proportional to the number of species, the genus Paraploderus Herman, 1970 is without doubt one of the most poorly known in the staphylinid subfamily Oxytelinae. At the time of this writing there is not a single image on the internet and the low number of scattered illustrations in the literature barely allow recognition of this group. Species are rather uniform in appearance, without conspicuous colouration or modifications that would attract attention. Phylogenetic affiliation is controversial, in the original description of Paraploderus it is treated as a sister group of the Neotropical Parosus Sharp, 1887, a genus recently revised (MAKRANCZY 2014a).

During the 1970s and early 1980s a revisional treatment by Peter M. Hammond was in preparation, but it remained unpublished. Paraploderus is interesting phylogenetically as it possesses a number of unique traits (e.g. 
position of abdominal defensive gland openings, densely setose parameres) and in most hypotheses being placed with the more primitive groups of the tribe Oxytelini (sensu MaKranczy 2006), and it is the knowledge of these less speciose genera where a foundation of a more accurate reconstruction of phylogeny lies. By intention, only the most unique and unambiguously distinct species are dealt with (those for which sufficient material exists to allow appropriate descriptions). The lack of established and tested distinguishing characters makes interpretation of the previously described nominal taxa a rather challenging task. Therefore, the principal aim was to provide a solid basis for further studies.

The 15 species treated in the present account are known from the Oriental (7 species) and Afrotropical regions (8 species, including one exclusive to the Malgasy subregion). Quite likely more undescribed species exist.

\section{MATERIAL AND METHODS}

Specimens from every possible source were gathered, although identification of not all material was possible for either bad condition, singularity or poor separation from the species recognized here. Such dubious specimens are better left as they are until values of characters in the genitalia are further investigated and intraspecific variability assessed.

Abbreviations of collections used in the present study are: $\mathrm{BMNH}=$ The Natural History Museum, London, UK (R.G. Booth); CNCI = Canadian National Collection of Insects, Ottawa, ON, Canada; FMNH = Field Museum of Natural History, Chicago, IL, USA (J.H. Boone); HNHM = Hungarian Natural History Museum, Budapest, Hungary; ISNB = Institut Royal des Sciences Naturelles de Belgique, Bruxelles, Belgium (Y. Gérard); MHNG = Muséum d'Histoire Naturelle, Genève, Switzerland (G. Cuccodoro); MRAC = Musée Royal de l'Afrique central, Tervuren, Belgium (M. De Meyer, S. Hulot); MNHP = Muséum National d'Histoire Naturelle, Paris, France (T. Deuve, A. Taghavian); MZLU = Museum of Zoology, Lund University, Lund, Sweden (R. Danielsson, C. Fägerström); NHMW = Naturhistorisches Museum Wien, Austria (H. Schillhammer); NIBR = National Institute of Biological Resources, Incheon, South Korea (M-J. Jeon); NMPC = National Museum (Natural History), Prague, Czech Republic; RMNH = Nationaal Natuurhistorische Museum ("Naturalis") [formerly Rijksmuseum van Natuurlijke Historie], Leiden, The Netherlands (H. Huijbregts); SMNS = Staatliches Museum für Naturkunde, Stuttgart, Germany (W. Schawaller); ZFMK = Zoologisches Forschungsmuseum "Alexander Koenig", Bonn, Germany (D. Ahrens); ZMHB = Museum für Naturkunde der Humboldt Universität, Berlin, Germany (J. Willers, J. Frisch); JJRC = Jiří Janák, private collection, Rtyně nad Bílinou, Czech Republic.

For descriptions and measurements a Leica MZ 12.5 stereoscopic microscope was used. For the line drawings permanent preparations were made in Euparal mounting medium on plastic cards pinned with the specimens. The genital preparation techniques are detailed in Makranczy (2006). Drawing was done with a Jenalab (Carl Zeiss, Jena) compound microscope and attached drawing tube (camera lucida). For colour habitus photography a Nikon D4 camera with Mitutoyo PlanApo 5× ELDW or 10× ELDW lens were used and layers montaged with ZereneStacker. 
Measurements are defined as follows: EW = head width at eyes; ew = epicranium width; TW = head width at temples; $\mathrm{PW}=$ maximum width of pronotum; $\mathrm{SW}=$ approximate width of shoulders; $\mathrm{AW}=$ maximum width of abdomen; $\mathrm{HL}=$ head length at the middle-line from front margin of clypeus to the beginning of neck; EL = eye length; TL = length of temple; $\mathrm{PL}=$ length of pronotum at the middle-line; $\mathrm{SL}=$ length of elytra from shoulder; SC = length of elytra from hind apex of scutellum; FB = forebody length (combined length of head, pronotum and elytra); BL = approximate body length. All measured from dorsal view.

For the larval description, terminology in relevant works by STANIEC $(1997,1999$, 2003) was used.

Since obviously a previous revisional effort resulted in a labelling of both the type material for the earlier described species and the new species recognized by P. M. Hammond, it could be argued that a duplicate type labelling by the present writer may not be necessary. However, the concepts of the species as here presented, differ significantly from his, so it was decided that a uniform and consistent set of labels should be added to all material discussed here. The label data are cited verbatim for previously selected type specimens between " ", the symbol " $\backslash$ " is a separator between each individual label, while ";" means line breaks. Text within square brackets [ ] is explanatory and was not included in the original labels. Types of the here described species and specimens of the other species have their label data supplemented from secondary sources (internet, collection lists, other articles) as well as collectors. Yet, coordinates from Google Earth are often in square brackets to distinguish them from primary data: these should be considered "a best possible approximation". In determining position of historical localities, a gazetteer maintained at MRAC as electronic resource for collection users was consulted.

\section{TAXONOMY}

\section{Paraploderus Herman, 1970: 400}

Type species: Aploderus speculiventris Fauvel (by original designation).

Diagnosis - Paraploderus can be recognized by its rather shiny and sparsely setose body with weak sclerotization, abdomen and legs somewhat translucent but often also parts of forebody. Most species have varying degree of punctation at least on the forebody, but punctures are with indefinite edges, mostly contributing to body surface perceived as uneven. Head is rather short, broad and trapezoid, all species have bulging temples, evenly curved, though eye/temple ratio varies as also whether head is broadest at eye or temples. Neck is delimited by a distinct transversal groove (occipital groove). Abdomen is fusiform, sternite IX absent, abdominal defensive gland openings (in the form of a slot) are in unique position in tergites IX along the sides of tergite $X$. The peculiar form of tergite $X$ makes the abdominal apex reminiscent of a horizontal fish-tail (slightly incised and depressed in middle). 
Description - Small to medium sized $(1.8-4.0 \mathrm{~mm})$. Body rather shiny and often slightly translucent. Forebody sparsely, rather finely pubescent, most setae short, only few darker and slightly longer in the following positions: at inner edge of supraantennal prominences, upper anterior edge of eye, inner margin of eye, dorsal side of temple behind eye, middle of impressions on pronotal disc, pair of setae in proximity at and slightly behind anterior pronotal corner and one slightly before posterior corner (often a shorter one behind middle of side); darker setae on outer elytral edge so short that almost invisible in dorsal view, from lateral view more apparent for being more erect.

Head. Clypeus (Fig. 1) rather large (long and broad), rectangular, mostly shiny and slightly convex, delimited by a distinct, impressed epistomal suture, less marked on sides; anterior margin of clypeus truncate with thin marginal bead anteriorly and laterally. Dorsum of head usually with strong, but indistinct-bordered and scattered (unevenly distributed) punctures, rest of surface shiny. Supraantennal prominences well developed but moderately elevated from plane of vertex; latter delimited from them by a pair of longitudinal impressions starting from occipital groove and more or less vanishing anteriorly. Compound eyes vary less in size than in other related genera, always bulging, medium roughly faceted on almost entire surface, however with a shiny rim surrounding it posteriorly and forming a steplike ridge before temples. Gular sutures confluent anteriorly; sutures narrowly separate at anterior neck, sharply divergent from middle to posterior neck. Genal area (temples) more sculptured, gradually condensing punctures often turn to a rugged surface on the lateral parts. Base of head very strongly constricted to form a well defined neck, delimited by strongly impressed occipital groove; latter with side parts turning onto upper surface of head in slightly anterior direction, middle part sometimes slightly separated. Antenna slightly incrassate apically, first three segments quite elongate (articles 2 and 3 similar in length, together slightly shorter than scape), further articles with basal dish, sculptured and unlike rest of body strongly setose. Labrum (Fig. 2) divided in longitudinal midline, anterior edge rather truncate, lateral portions bearing membranous lobes with mesial margin fimbriate. Mandible (Fig. 4) denticulate, apex bifurcate, a further, smaller tooth between apex and a knob-like tooth (anteriorly demarcated by incision) at apical 1/3; prostheca extending from inner edge, almost as long as half the length of entire mandible, composed of rather long and slender processes. Maxilla (Fig. 9) with cardo semitriangular, stipes like perfect right-angled triangle, lacinia with slender lobe, galea larger, both with dense setation at apex. Maxillary palpus with first segment very small and ring-like, second large and apically incrassate, third even larger (and a little longer), more oval, about as wide at base as at apex, fourth almost as long as second but strongly narrowing towards middle and apically 


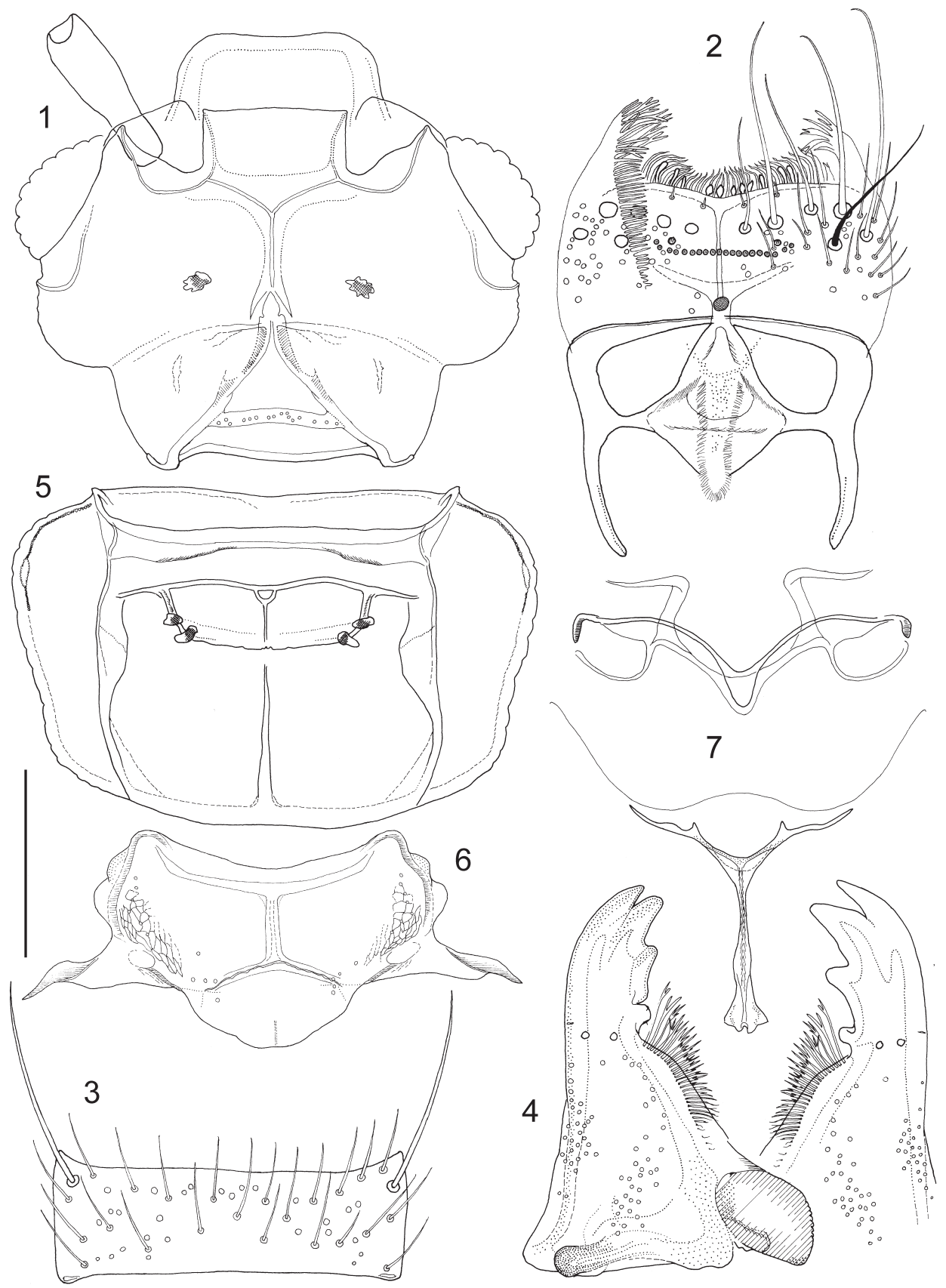

Figs 1-7. Paraploderus wittei sp. n. $1=$ head capsule, $2=$ labrum, $3=$ mentum, $4=$ mandibles, 5 = prothorax, $6=$ scutellum, $7=$ median pterothoracic parts. Scales: $0.04 \mathrm{~mm}$ for Fig. 3 , $0.045 \mathrm{~mm}$ for Fig. 2, $0.06 \mathrm{~mm}$ for Figs 4, 6, $0.1 \mathrm{~mm}$ for Figs 1, 5, 7. 
slender. In labium, mentum (Fig. 3) strongly transversally rectangular. Hypopharynx (Fig. 8) with a set of bulbous setae near apical edge. Labial palps three-segmented segments 1 and 3 almost of same length, segment 1 twice as thick as segment 3, segment 2 slightly longer than either of others, its thickness intermediate between other two. Apical article with group of short sensillae at apex. Plate-like armature in hypopharynx - introduced in MAKRANCZY (2006) and applied in recent works (MAKRANCZY 2014a,b,c) not only as a generic character but one diagnostic for species groups in larger genera - fully developed but rather simple.

Thorax. Pronotum (Fig. 5) widest near apex, lateral margins slightly convergent posteriorly, both anterior and posterior corners rounded, lateral margins often slightly concave anteriad posterior corners. Procoxal fissure absent, protrochantin concealed. Postprocoxal lobe absent, prohypomeron broad and strongly deflexed. Prosternal process as curved keel on transverse rectangular furcasternum, shortly extending between procoxae. Scutellum (Fig. 6) with basally transverse rhomboid shaped, apically more arcuate impression. Impression anteriorly connected to proscutum by a midlongitudinal internal ridge (externally as a dark line, a scratch-like impression on surface). Mesosternal process (Fig. 7) spiniform, metendosternite slender, furcal arms developed, anterior arms barely discernible. - Elytra. Disc of elytra with indistinctly bordered punctures arranged more or less randomly. Elytral epipleural ridge present, well-marked except extreme anterior, slightly fading at outer posterior corners. Suture marked by unpunctured, slightly elevated margin. - Legs. Tibiae with moderately developed mid-tibial spurs, distinct tibial spines absent except at apex. Tarsomeres 3-3-3, basal article longer than second, being three former segments fused as evident from their apical rings of setae still observable, apical article long, slender, slightly curved and only with a couple of setae. Formation of tarsal lobe out of apical setae of second tarsomere only evident in hind leg; this ventral modification characteristic of most oxytelines, but strongly expressed only in the Carpelimus group of genera.

Abdomen. Intersegmental membrane without brickwall pattern, second sternite fully developed, first sternite completely absent. Abdomen spindleshaped, somewhat flattened dorsally, two pairs of laterosclerites present. When abdomen light coloured, hind margin of tergal fold (basal ridge) on tergites III-VII with a darker line. Tergal basolateral ridges present, also darker marked, no longitudinal marks in midline. Fimbriate hind margin on tergite VII present, sternite VII without modifications. Tergite X similar in both sexes, dorsoventrally flattened, with medial depression, slight apical emargination forming two peculiar 'lobes' at apex; apex fimbriate, but a similar transversal fimbriate line running parallel to apex at about apical $1 / 4$. Secondary sexual differences slight, confined to somewhat different apical formation of sternites VIII between males and females. - Male terminalia. Tergite VIII without 


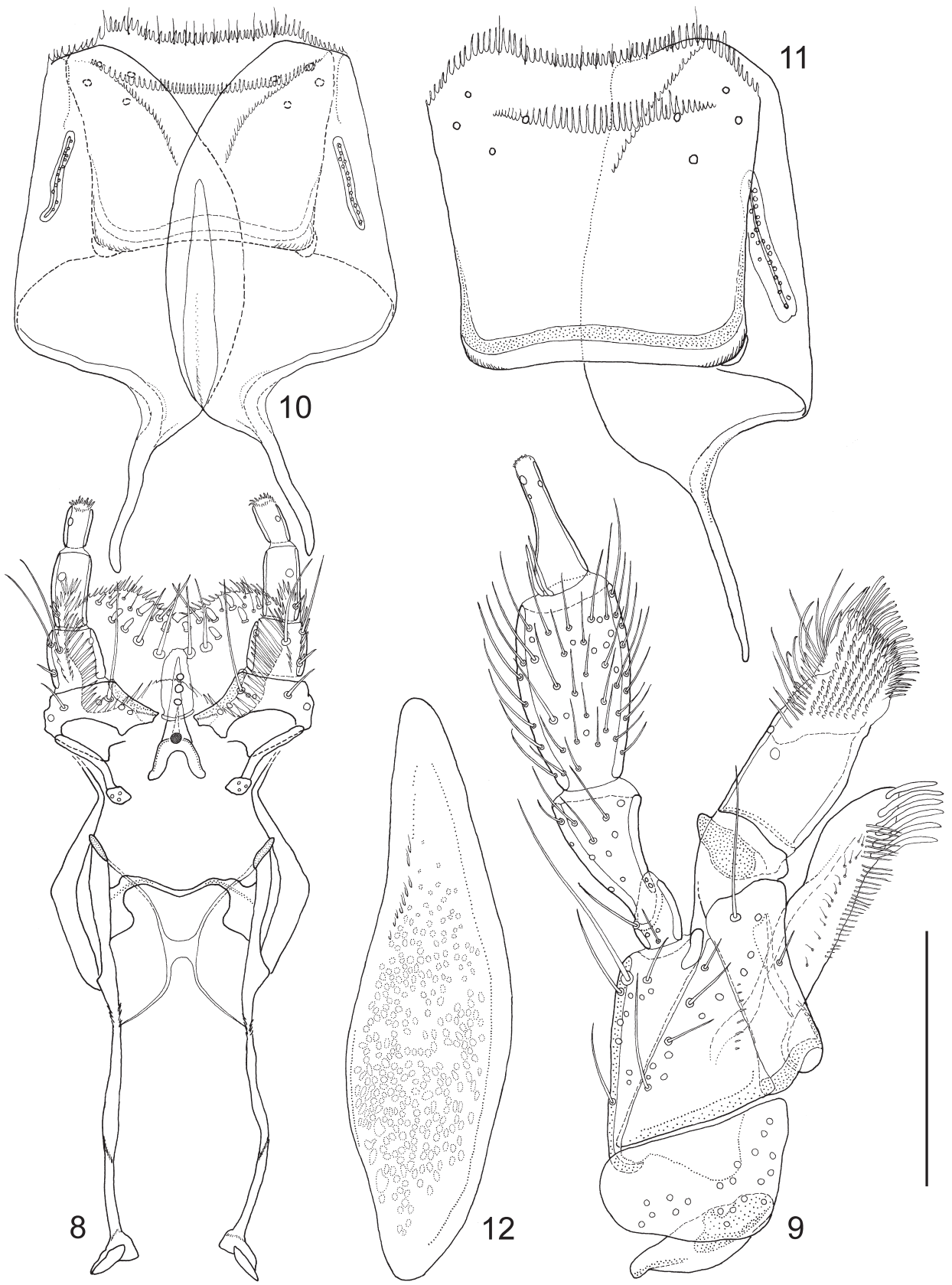

Figs 8-12. 8-9= Paraploderus wittei sp. n. $8=$ labium, $9=$ maxilla. $10=$ P. notabilis (Cameron, 1950) male tergites $I X$ and $X$, ventral view. $11=P$. nigronitens (Cameron, 1951) male tergite $I X$ and $X$, dorsal view (defensive gland opening magnified $2 \times$ ). $12=P$. grandis sp. $n$. male sternite IX. Scales: $0.1 \mathrm{~mm}$ for Fig. 9, $0.12 \mathrm{~mm}$ for Fig. 8, $0.17 \mathrm{~mm}$ for Fig. 12, $0.2 \mathrm{~mm}$ for Figs 10-11. 
peculiar modification, apex truncate; Tergite IX paired, with slender but not too elongate, ventral struts', plate laterally strongly fused to tergite X (Fig. 11), forming a compact structure (Fig. 10), defensive gland openings longitudinal, slightly oblique in tergite IX, near, but discrete from plate fusion line. Sternite IX very weakly developed, entirely lost setation, desclerotized and membranous, absolutely inconspicuous (it is, however, more apparent, spindleshaped, slightly asymmetric and densely porous in Paraploderus grandis, Fig. 12). - Male genitalia. Aedeagus trilobed, median lobe bulb-like, sclerites and sclerotized parts confined mostly to apical part: with one paired blade-like opening processes and in between one unpaired appendage - latter reminiscent to and perhaps precursor of apicomedial hook in Oxytelus Gravenhorst, 1802 (MaKranczy 2006, etc.) and more recently discovered within Anotylus Thomson, 1859 (MaKRANCZy 2013). Apical part with a variously wide, sclerotized, reverse U-shaped sclerite (length of median lobe in key measured from apex of this sclerite), others much less conspicuous, more membranous. Parameres extremely setose on much of length (usually apical 2/3; unique trait in the subfamily). Size of aedeagus varying often disproportionally to differences in body size. - Female terminalia very similar to that of male, but tergites IX missing elongate 'ventral strut'. - Female genitalia. Spermatheca sclerotized, receptacle divided into a small, slender tubular portion and a more bulky bladder-like part sometimes constricted near middle. No sclerotized spermathecal gland observable, umbilicus absent.

Diversity - Only 6 names have been proposed for species that were later included in or transferred to Paraploderus, two of them have now fallen into synonymy; with the current contribution the count rises to 15 . Other species may exist but most of them are hard to distinguish due to the rather simple and uniform body built and genitalia with very few diagnostic traits. It is believed that the differences between species are rather subtle and subject to considerable variation.

Distribution - Localities of the examined material lay in forested areas across almost the entire Afrotropical and Oriental regions, although records are rather scattered; presence of material indicates intensive collecting activity using the appropriate methods to find Paraploderus rather than a distribution pattern. Only one species is recognized to be bound to higher altitudes and have somewhat reduced wings.

Natural history - Available information preserved on specimen labels and collecting event lists indicates that these species live in wet, decaying plant materials, primarily leaf litter. Preferred habitats are forested, often river banks or waterfalls. Most frequently specimens were collected by sifting, but many flew to light. 
The mature $\left(\mathrm{L}_{3}\right)$ larva (of Paraploderus rufescens) - Length (in $\mathrm{mm}$ ): 4.20 [ew =0.50] (Fig. 79) and 3.45 [ew =0.46] (specimen on Figs 105-116); the third larval specimen is interpreted as $\mathrm{L}_{2}$ larva, length 2.83 [ew $=0.48$ ] (Fig. 78). Head. Head capsule (Fig. 105) dorso-ventrally flattened, rounded but slightly transverse, a single large stemma on each side, supraantennal prominences transversely elongate. Stemma (Fig. 115) as clear spherical calotte, dark (blackish) pigment variously moved away from the lens in preserved specimens (artifact of preservation). Dorsum of head with frontal setae (frontal dorsal $=\mathrm{fd}$, frontal lateral $=\mathrm{fl}$, frontal marginal $=\mathrm{fm})$, epicranial setae $($ epicranial dorsal $=$ ed, epicranial lateral $=$ el, epicranial marginal $=e m)$ temporal $(t)$ and lateral $(l)$ setae plus two pairs of posterior setae (p). Antenna (Fig. 114) three segmented, three sensory appendages (sa) on penultimate, solenidia (so) on apical. Labrum (Fig. 108) trapeziform, half as long as wide, frontal margin with a pair of stout, spine-like setae. Mandible (Fig. 113) bifid, narrow triangular shaped but thick at base, gradually narrowing towards bifurcate apex; a more basal tooth on dorsal side of mandible observable in one specimen only: either an aberration or possibly a remnant of the molar lobe of more primitive staphylinoids. Maxilla (Fig. 112) with triangular cardo, moderately wide stipes, mala with ctenidium on adoral margin somewhat interrupted in middle. Labium (Fig. 109) with mentum saddle-shaped, prementum quite elongate, ligula short and small, labial palps two segmented. Thorax. Tergites with short and long setae arranged more or less along transversal lines; prothorax as in Fig. 106, mesothorax as in Fig. 107, metanotum with setation identical to that of mesonotum. Pronotal discal setae in rows (a-e) (terminology explained in Staniec (2003)). Legs with five articles. Anterior leg (Fig. 110) with proximal pair of tibial setae uneven in size (one stout, other thin and longer), meso- and metatibiae with setae even in size within pair. Tarsungulus with two small setae in basal position, one on each side. Abdomen. Segments I-VIII composed of tergites and sternites. First tergum with a small, island-like sclerite (pleurite) separated laterally (Fig. 116), weakly sclerotized but marked by three setae, spiracles situated between pleurite and tergite, separate from both. Segments II-VIII with spiracles in tergites. Abdominal segments IX and X (Fig. 111) forming tergosternite (dorsal and ventral sclerites fused). Urogomphi one articled, black and distally narrowed, extended beyond segment X. Anal lobes not everted in examined specimens but without conspicuous structures.

\section{Key to species of Paraploderus}

1 Afrotropical species.

- Oriental species. 
2 Eyes large, conspicuously wider than head width at temples (TW:EW = 0.91-0.95). Aedeagus (Figs 48-49) median lobe $0.27 \mathrm{~mm}$ [D.R. Congo].

- $\quad$ Head width at eyes (EW) never significantly exceeding width at temples (TW:EW > 0.95), even if eyes relatively large.

3 Temples much shorter than eyes $(\mathrm{TL}=0.07-0.09 \mathrm{~mm})$.

- $\quad$ Temples about as long as eyes, sometimes slightly larger $(\mathrm{TL}=0.10-0.15$ $\mathrm{mm})$.

4 Pronotum sometimes even narrower than head. In fully coloured specimens, head conspicuously darker (dark brown, sometimes blackish) than pronotum (light brown, often distinctly yellowish). Aedeagus (Figs 38-39) median lobe $0.27 \mathrm{~mm}$ [Guinea to R. Centrafr. and Congo Rep., D.R. Congo to Angola].

$P$. parcepunctus

- Pronotum at least as wide as head. Pronotum not significantly brighter coloured than elytra, although there may be slight contrast to darker head. Aedeagus (Figs 18-19) median lobe $0.31 \mathrm{~mm}$ [Angola, Burundi, D.R. Congo].

P. leleupi

5 Rather large species $(\mathrm{PW}=0.62-0.69 \mathrm{~mm}$ ) with somewhat reduced wings. Aedeagus (Figs 13-14) median lobe 0.46 mm [Kenya, Uganda, D.R. Congo].

P. grandis

- $\quad$ Medium sized species $(\mathrm{PW}=0.51-0.59 \mathrm{~mm})$ with fully developed wings ( $\mathrm{TL}=0.07-0.09 \mathrm{~mm}$ ).

6 Pronotal sculpture (punctation) shallow and indisctinct bordered to absent.

- Pronotal sculpture pronounced, punctures often smaller but deeper and more distinct.

$7 \quad$ Pronotal punctation almost entirely absent. Mostly dark coloured, dark brown. Aedeagus (Figs 28-29) median lobe 0.32 mm [Angola, D.R. Congo].

P. nigronitens

- Pronotal punctation sparse, on large surfaces missing. Lighter coloured, medium brown to ochre, orangish. Aedeagus (Figs 33-34) median lobe $0.30 \mathrm{~mm}$ [Angola, D.R. Congo].

P. notabilis

8 Unicolorous dark brown with reddish tint. Occipital suture somewhat divided, medial portion bending posteriorly (Fig. 99). Aedeagus (Figs 23-24) median lobe $0.36 \mathrm{~mm}$ [Madagascar].

P. malgaceus 
- $\quad$ Pronotum and elytra distinctly reddish medium brown, other main body parts occasionally darker. Occipital suture undivided, medial portion straight or slightly bending anteriorly (Fig. 90). Aedeagus (Figs 43-44) median lobe $0.32 \mathrm{~mm}$ [Kenya, Uganda, D.R. Congo]. P. rufescens

9 Large species ( $\mathrm{PW}=0.61-0.76 \mathrm{~mm})$ with large eyes $(\mathrm{EL}=0.155-0.17 \mathrm{~mm})$ and short temples. Ridge on posterior edge of elytra absent. Aedeagus (Figs 83-84) median lobe $0.58 \mathrm{~mm}$ [Indonesia: Sumatra, Java].

P. speculiventris

- $\quad$ Eyes smaller $(E L=0.09-0.15 \mathrm{~mm})$. Ridge on posterior edge of elytra present.

10 Very small species $(\mathrm{PW}=0.46-0.51 \mathrm{~mm})$. Eyes short $(\mathrm{EL}=0.09-0.11 \mathrm{~mm})$, width (EW $=0.42-0.46)$ less than those of temples (TW $=0.43-0.48)$. Aedeagus (Figs 58-59) median lobe $0.28 \mathrm{~mm}$ [Indonesia: Moluccas, New Guinea].

P. goergesae

- $\quad$ Larger species $(\mathrm{PW}>0.51 \mathrm{~mm})$.

11 Medium sized species ( $\mathrm{PW}=0.51-0.60 \mathrm{~mm}$ ). 12

- $\quad$ Rather large species ( $\mathrm{PW}=0.60-0.68 \mathrm{~mm}$ ).

12 Eyes smaller $(\mathrm{EL}=0.11-0.12 \mathrm{~mm}$ ). Parameres shorter (extending beyond median lobe by approx. 1/5 of latter's length). Aedeagus (Figs 53-54) median lobe $0.31 \mathrm{~mm}$ [Indonesia: Sumatra, Java, Sulawesi, Lombok].

P. fauveli

- $\quad$ Eyes larger $(E L=0.12-0.14 \mathrm{~mm}$ ). Parameres longer (extending beyond median lobe by approx. 1/3 of latter's length). Aedeagus (Figs 68-69) median lobe $0.28 \mathrm{~mm}$ [N-India, Thailand].

P. loebli

13 Temple at least as wide as eyes. Aedeagus (Figs 63-64) median lobe 0.36 mm [S-India].

P. hammondi

- $\quad$ Temples less wide than eyes

14 Sternite VIII with apical edge slightly concave and conspicuously fimbriate in middle (Figs 96-97). Aedeagus (Figs 94-95) median lobe $0.37 \mathrm{~mm}$, with apicomedial appendage $0.48 \mathrm{~mm}$ [N-Thailand]. P. thailandicus

- Sternite VIII with apical edge always convex (Figs 75-76). Aedeagus (Figs 73-74) median lobe $0.43 \mathrm{~mm}$ [Indonesia: Sumatra].

P. schwendingeri 


\title{
I. AFROTROPICAL SPECIES
}

\section{Paraploderus grandis sp. $\mathrm{n}$.}

\author{
(Figs 12-17, 89)
}

Type material - Holotype (ð): KENYA: Mt. Elgon, [Kaptega river], $2380 \mathrm{~m}\left[01^{\circ} 10^{\prime} \mathrm{N}\right.$, 34 ${ }^{\circ} 3^{\prime}$ E], 17.I.1979, leg. Th. Palm, [sifting moist grass litter] (MZLU); Paratypes (34): same data as holotype (1 Ĵ, 1 o, MZLU); Mt. Elgon, 1900-2500 m, 12.I.-5.II.1979, leg. Th. Palm (1 万̃, 8, MZLU, 4, MHNG, 1, HNHM); Mt. Aberdares près entrée du Park National, 2300 m [00 $\left.27.5^{\prime} \mathrm{S}, 36^{\circ} 51.0^{\prime} \mathrm{E}\right], 25 . X I .1974$, leg. V. Mahnert \& J-L. Perret (45), tamisage feuilles mortes et bois mort (5, MHNG, 1, SDEI, 1, ZMHB, 1, NHMW, 1, SMNS, 1, AMNH, 1, FMNH, 1, NMPC, 1, MNHP, 1, CNCI, 1, ISNB); UGANDA: Mt. Elgon, Kapkwata, 2250 m

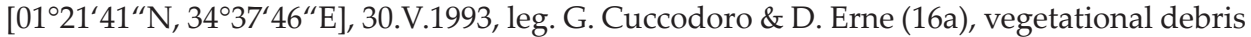
and old rotting trunk in pine plantation, sifted (1, MHNG); D. R. CONGO: Parc National

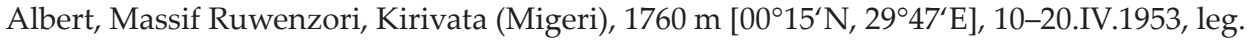
P. Vanschuytbroeck \& J. Kekenbosch (3171-3202) (1, MRAC, 1 §, BMNH).

Description - Measurements (in mm, $\mathrm{n}=10)$ : $\mathrm{EW}=0.56(0.54-0.58)$; $\mathrm{TW}=0.59(0.56-$ $0.62) ; \mathrm{PW}=0.66(0.62-0.69) ; \mathrm{SW}=0.65(0.62-0.68) ; \mathrm{AW}=0.85(0.81-0.90) ; \mathrm{HL}=0.39$ (0.38$0.41) ; \mathrm{EL}=0.12(0.11-0.13) ; \mathrm{TL}=0.14(0.13-0.15) ; \mathrm{PL}=0.46(0.43-0.49) ; \mathrm{SL}=0.56(0.53-0.62)$; $\mathrm{SC}=0.52(0.49-0.57) ; \mathrm{FB}=1.51$ (1.42-1.63); $\mathrm{BL}=3.16$ (2.89-3.42). Habitus as in Fig. 89. Pronotum and elytra dark brown with reddish tint. Head blackish dark brown, towards clypeus lighter, epistomal suture darker. Abdomen dark brown, with more reddish apices of tergites. Legs, basal antennomeres and mouthparts medium brown, antennal articles 3-10 dark brown, ultimate antennomere lighter at apex. Head transverse with rounded, bulging temples wider than eyes. Clypeus almost impunctate with only feeble traces of microsculpture and the finest punctures on surface. Epistomal suture between tips of supraantennal prominences or only a little behind imaginary line connecting them. Medial portion of occipital groove bending anteriorly, neck medially shiny, laterally with traces of coriaceous microsculpture with isodiametric cells. Vertex with indefinite-bordered but large and deep punctures only on impressed parts, elevated middle unpunctured; some also near temples but ventrally punctation turning into ruggedness around eyes, obscuring a postocular ridge. Faint longitudinal impressions running on both sides of vertex from epistomal suture to occipital groove, becoming more marked posteriorly. Head surface otherwise shiny, without microsculpture. Pronotum with complete, thin marginal bead. Surface shiny, without any microsculpture but punctured like head, with scattered, indefinite-bordered, mostly rather large pits, slightly umbilicate. Longitudinal midline unmarked but punctures missing on a broad stripe on both sides and partly along hind margin. On both sides of midline middle-posterior 3/5 of disc slightly impressed. Elytra with disc gently convex, slightly impressed anteriorly, two very thin and shallow longitudinal impressions along suture behind scutellum. Epipleural ridge present on almost entire length. Thin marginal bead with obscure connection to epipleural ridge continuing along posterior margin, not reaching sutural corner, slightly curving anteriorly before it. Along suture very fine marginal bead conspicuous only because of darker colour. Elytral punctation moderately deep, equally spaced, moderately sparse, missing on a thin, slightly elevated stripe along suture. Abdomen shiny and smooth with only tiny insertion points of setae and extremely faint coriaceous microsculpture with isodiametric cells. Male sternite VIII as in Fig. 15, aedeagus as in Figs 13-14, female sternite VIII as in Fig. 16, spermatheca as in Fig. 17.

Distribution - The present (restricted) selection of type material is partly due to the fact that this taxon has somewhat reduced wings and is apparently found at higher al- 


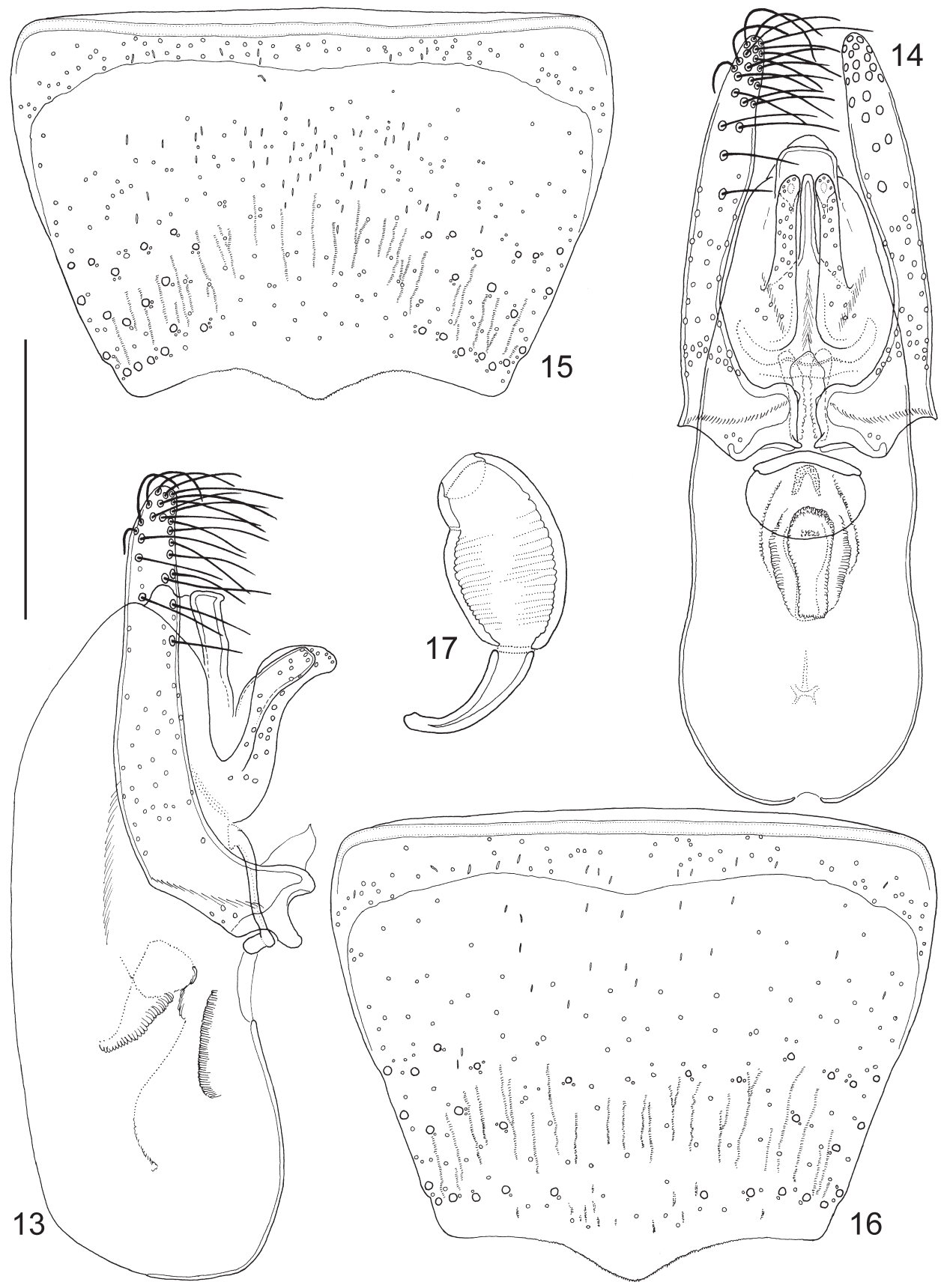

Figs 13-17. Paraploderus grandis sp. n. $13=$ aedeagus, lateral view, $14=$ aedeagus, frontal view (parameral setation shown on left), 15 = sternite VIII, male, 16 = sternite VIII, female, 17 = spermatheca. Scales: $0.1 \mathrm{~mm}$ for Fig. 17, $0.16 \mathrm{~mm}$ for Figs 13-14, $0.3 \mathrm{~mm}$ for Figs 15-16. 
titudes. A more narrow range of specimens and localities perhaps ensures a more clear identity for this taxon; the previous type series in fact may be a mixture of several closely related species. As recognized here, the distribution of $P$. grandis is confined to the Ruwenzori range, Mt. Aberdares and Mt. Elgon. At the latter location the recorded habitat was "primeval forest area uphill Mount Elgon at Kaptega river, deciduous forests, shrub- and tall herbaceous vegetation" - this does not suggest a very narrow distribution, but further material and work is necessary to clarify the exact distribution and variability.

Etymology - Named after the rather large size of the species.

Remarks - The species was first recognized by P. M. Hammond, who labelled a series of specimens with the name 'grandis' in the 1970s, but it remained unpublished - his series, however, appears rather heterogenous. At least it is difficult to decide whether the specimens from a variety of localities really belong to the same species or represent closely allied distinct forms. A further complication is caused by the fact that the present author used this Paraploderus species for a phylogenetic analysis in 2005 (MAKRANCZY 2006) misidentified as " $P$. parcepunctus". A decade later it is impossible to determine what circumstances led to this confusion of identities. Having considered these facts, while keeping his name 'grandis', only the two specimens from Hammond's original type locality of his manuscript name are included in the new type series (including the former 'holotype'), and as the holotype exactly the same specimen (collected by Thure Palm in 1979 at Kaptega river, tributary of Suam r.) that was used in the analysis (aedeagus illustrated in fig. 92, p. 76, Makranczy 2006) is chosen. Almost all of Hammond's other specimens are females, the two males found were in less than perfect condition, one has the aedeagus dissected (parameres detached), the other has a weakly sclerotized aedeagus, making it very tricky to draw solid conclusion on the identities of these specimens.

\section{Paraploderus leleupi sp. $\mathrm{n}$.}

(Figs 18-22, 81)

Type material - Holotype (đ): ANGOLA: Saurimo, Forêt-galerie, chutes R. Chicapa [09²9'S, 20²0’E, $1050 \mathrm{~m}], 28 . V I .1964$, leg. Luna de Carvalho (FMHD\#64-242) (FMNH); Paratypes (8): Alto Cuílo, Cuílo river, Poste de Cacolo, 1200 m [1008'42"S, 19¹5'58'E], V.1954, leg. A. de Barros Machado (4072-2) (1, MRAC), same but (4082-4) (1 , MRAC, $1 \mathrm{BMNH}$ ); Tcha-Pemba, gallery forest of the Lunguena river, tributary of the Luangue, Poste de Xá-Cassau, $1050 \mathrm{~m}$ [08 $\left.56^{\prime} 02^{\prime \prime} \mathrm{S}, 2^{\circ} 16^{\prime 2} 28^{\prime \prime} \mathrm{E}\right]$, V.1954, leg. A. de Barros Machado (4077.5) (1, MRAC); BURUNDI[Urundi]: terr. Bururi, $900 \mathrm{~m}$, Nyamurembe [0401‘s, 29³1‘E], 7.III.1953, leg. P. Basilewsky (1 ${ }^{\circ}$, MRAC); D. R. CONGO: Kivu, territoire de

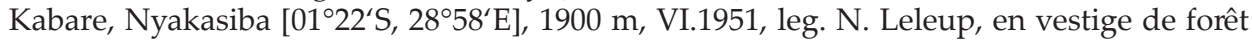
ombrophile (1 +, MRAC, 1 ㅇ, NHMW); Parc National Garamba II/dd/4 [cellule biologique II, $\left.03^{\circ} 58^{`} \mathrm{~N}, 2^{\circ} 22^{`} \mathrm{E}\right]$, 17.I.1952, leg. J. Verschuren (3035) (1, MRAC). 
Description - Measurements (in mm, $\mathrm{n}=9)$ : $\mathrm{EW}=0.47(0.44-0.50) ; \mathrm{TW}=0.47(0.45-$ $0.51) ; \mathrm{PW}=0.51(0.48-0.53) ; \mathrm{SW}=0.56(0.55-0.60) ; \mathrm{AW}=0.61(0.56-0.64) ; \mathrm{HL}=0.30(0.28-$ $0.32) ; \mathrm{EL}=0.12(0.11-0.12) ; \mathrm{TL}=0.08(0.07-0.09) ; \mathrm{PL}=0.36(0.35-0.38) ; \mathrm{SL}=0.51(0.48-0.54)$; $\mathrm{SC}=0.48(0.45-0.51) ; \mathrm{FB}=1.22(1.15-1.30) ; \mathrm{BL}=2.39(2.09-2.83)$. Habitus as in Fig. 81. Head reddish dark brown, pronotum medium to dark brown with slight orangish tint, elytra and abdomen slightly darker, dark brown. Legs, antennae and mouthparts medium brown to ochre, apices of mandibles infuscate. Head transverse with rounded, bulging temples just slightly wider than eyes. Clypeus with very scattered, minute punctures only, with feeble traces of microsculpture and unevenness laterally on surface. Epistomal suture between tips of supraantennal prominences or only a little behind imaginary line connecting them. Medial portion of occipital groove bending anteriorly, neck laterally with traces of coriaceous microsculpture with isodiametric cells, medially only with traces of it, mostly shiny. Vertex with very scattered, indefinite-bordered and variously sized (some large and deep) punctures; punctation near temples much denser and obscures postocular ridge. Faint longitudinal impressions running on both sides of vertex from epistomal suture to occipital groove, becoming more marked posteriorly. Head surface otherwise shiny, without microsculpture. Pronotum with complete, thin marginal bead. Surface shiny, without any microsculpture but punctured like head, with scattered, indefinite-bordered, mostly rather large pits, slightly umbilicate. Longitudinal midline unmarked but punctures missing on a broad stripe on both sides and partly along hind margin. On both sides of midline middle-posterior 3/5 of disc slightly impressed. Elytra with disc gently convex, two longitudinal impressions behind scutellum extending along suture. Epipleural ridge present on almost entire length. Thin marginal bead with obscure connection to epipleural ridge continuing along posterior margin, not reaching sutural corner, slightly curving anteriorly before it. Along suture very fine marginal bead only conspicuous because of darker colour. Elytral punctation rather deep, obscured by uneven surface, more or less equally spaced, moderately dense, missing on a thin, slightly elevated stripe along suture. Abdomen shiny and smooth with only tiny insertion points of setae and extremely faint coriaceous microsculpture with isodiametric cells. Male sternite VIII as in Fig. 20, aedeagus as in Figs 18-19, female sternite VIII as in Fig. 21, spermatheca as in Fig. 22.

Distribution - Currently only known from Angola, Burundi and the D. R. Congo.

Etymology - Named after Narcisse Leleup (1912-2001), who made a major contribution to the knowledge of African staphylinids and collected some of the paratypes.

Remarks - The Angolan specimens are somewhat lighter coloured, while the other 3 paratypes are darker - this could be due to variation or artifact of preservation.

\section{Paraploderus malgaceus sp. n.}

(Figs 23-27, 92)

Type material - Holotype (ð): MADAGASCAR: E-, Andilamena pr., 5 km S of Am-

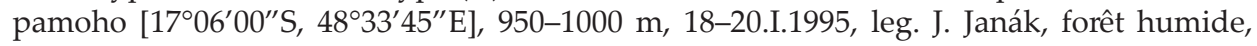
tamisages (NMPC); Paratypes (7): same data as holotype (4 ㅇ, JJRC, 1 ㅇ, NHMW, 1 , MHNG, 1 , HNHM). 


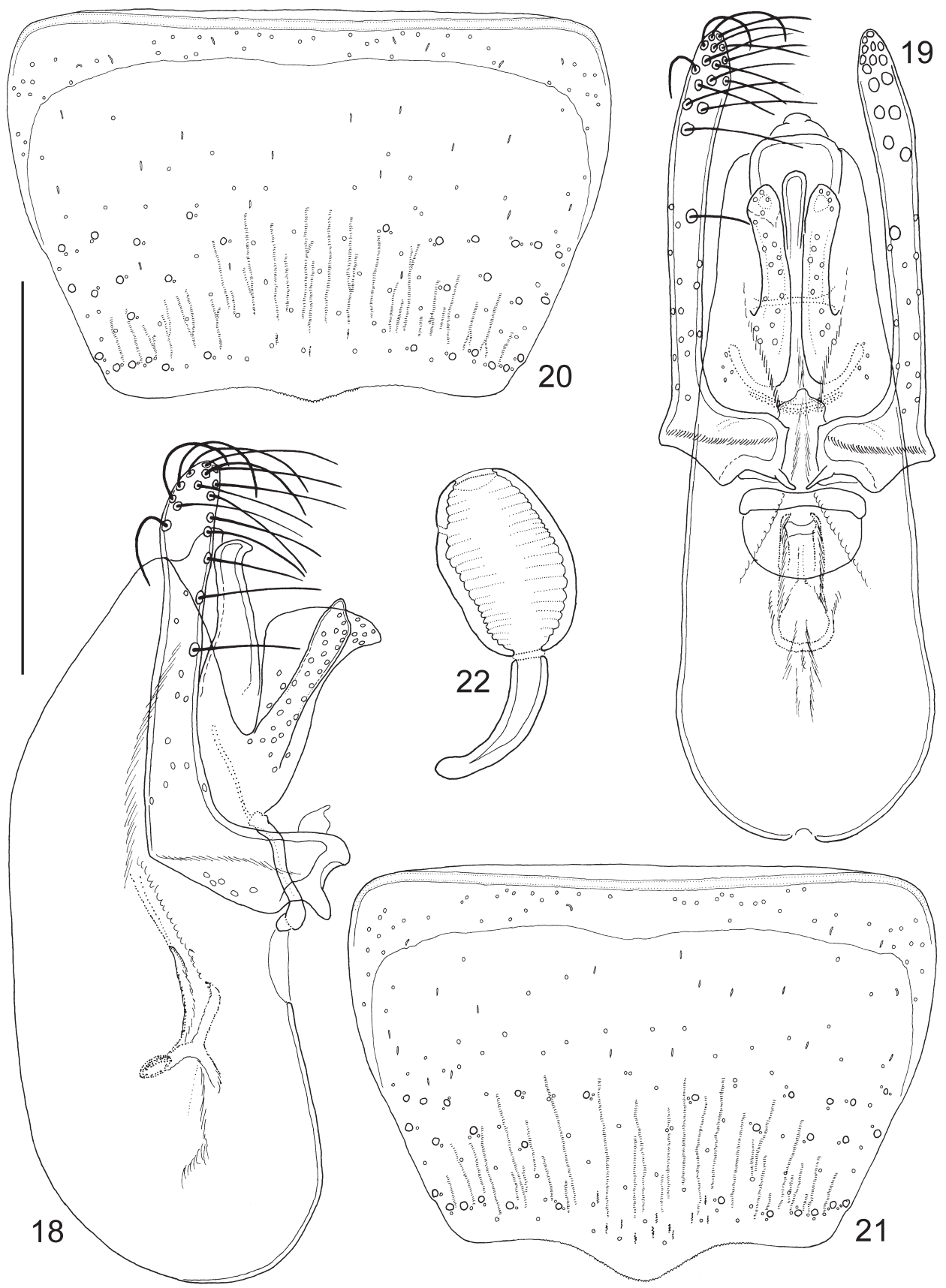

Figs 18-22. Paraploderus leleupi sp. n. $18=$ aedeagus, lateral view, $19=$ aedeagus, frontal view (parameral setation shown on left), $20=$ sternite VIII, male, $21=$ sternite VIII, female, $22=$ spermatheca. Scales: 0.14 mm for Fig. 22, 0.16 mm for Figs 18-19, 0.3 mm for Figs 20-21. 
Description - Measurements (in mm, $\mathrm{n}=8)$ : $\mathrm{EW}=0.51(0.49-0.53) ; \mathrm{TW}=0.54(0.51-$ $0.55) ; \mathrm{PW}=0.55(0.52-0.58) ; \mathrm{SW}=0.58(0.55-0.59) ; \mathrm{AW}=0.73(0.70-0.75) ; \mathrm{HL}=0.35(0.33-$ $0.37) ; \mathrm{EL}=0.11(0.10-0.11) ; \mathrm{TL}=0.125(0.12-0.13) ; \mathrm{PL}=0.38(0.36-0.40) ; \mathrm{SL}=0.51(0.50$ $0.53) ; \mathrm{SC}=0.48(0.47-0.50) ; \mathrm{FB}=1.31(1.23-1.38) ; \mathrm{BL}=2.48(2.33-2.65)$. Habitus as in Fig. 92. Forebody reddish dark brown, abdomen dark brown but slightly translucent. Legs, mouthparts and basal antennomeres medium brown, antennal articles 3-10 dark brown, but terminal antennomere somewhat lighter, mandibles more reddish with apex infuscate. Head transverse with rounded, bulging temples just slightly wider than eyes. Clypeus virtually unpunctured and unsculptured, shiny. Epistomal suture posterior to imaginary line connecting supraantennal prominences. Medial portion of occipital groove bending posteriorly (not anteriorly), neck covered by coriaceous microsculpture with isodiametric cells. Vertex with very scattered, indefinite bordered and variously sized punctures; punctation near temples much denser and obscures postocular ridge. Faint longitudinal impressions running on both sides of vertex from epistomal suture to occipital groove, becoming more marked posteriorly. Head surface otherwise shiny, without microsculpture. Pronotum with complete, thin marginal bead. Surface shiny, without any microsculpture but more strongly punctured than head, indefinite-bordered, mostly rather large pits (slightly umbilicate) almost everywhere on surface except along midline and narrowly along posterior margin. Longitudinal midline marked in posterior $1 / 3$. On both sides of midline middle-posterior $3 / 5$ of disc strongly impressed. Elytra with disc gently convex, two very thin and shallow longitudinal impressions along suture behind scutellum, anterior half of disc longitudinally impressed in middle. Epipleural ridge present on almost entire length. Thin marginal bead with obscure connection to epipleural ridge continuing along posterior margin, not reaching sutural corner, slightly curving anteriorly before it. Along suture very fine marginal bead only conspicuous because of darker colour. Elytral punctation very shallow, more or less equally spaced, moderately sparse, missing on a thin, slightly elevated stripe along suture. Abdomen shiny and smooth with only tiny insertion points of setae and extremely faint coriaceous microsculpture with isodiametric cells. Male sternite VIII as in Fig. 25, aedeagus as in Figs 23-24, female sternite VIII as in Fig. 26, spermatheca as in Fig. 27.

Distribution - The species is only known from one locality in Madagascar and is probably endemic to the island.

Etymology - The name of the species refers to its being from Madagascar, the people and the language both called Malgasy.

Remarks - All the specimens are in somewhat decayed condition, some legs and antennae are missing. No other material from Madagascar was found. The species stands out for the median lobe being porous on apical half opposite basal orifice.

\section{Paraploderus nigronitens (Cameron, 1951)}

$$
\text { (Figs 11, 28-32, 88) }
$$

Trogophloeus (Taenosoma) nigronitens Cameron, 1951: 47.

Paraploderus nigronitens; Herman, 1970: 401, Herman, 2001: 1463.

Type material examined - Lectotype ( $\sigma^{\lambda}$, here designated): “Lecto-; type [lilac margined disc, curator label] \Para-; type [yellow margined disc, curator label] $\backslash$ ANGOLA; 


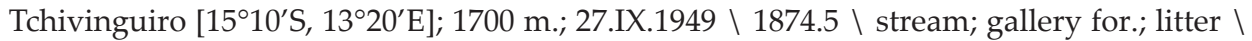
M. Cameron.; Bequest.; B.M. 1955-147. \ M. Cameron det., 19..; Trogophloeus; nigronitens; Cam; Cotype \Trogophloeus; nigronitens Cam.; P.M. Hammond; det. 1971; Lectotype $\widehat{\delta}$ $\backslash$ Lectotypus; Trogophloeus; nigronitens Cameron; des. Makranczy, $2014 \backslash$ Paraploderus; nigronitens (Cameron); det. Makranczy, 2014" (BMNH); Paralectotype (1): “q [on mounting card] \Para-; lecto; type [light blue margined disc, curator label] \ Type [red margined disc, curator label] \Museu do Dundo; Tchivinguiro; 27.IX.1949; Reg. Ang. 1874.5 \M. Cameron.; Bequest.; B.M. 1955-147. \M. Cameron det., 19..; Trogophloeus; nigronitens; Cam; Type \Trogophloeus; nigronitens Cam.; P.M. Hammond; det. 1971; Paralectotype q \ Paralectotypus; Trogophloeus; nigronitens Cameron; des. Makranczy, $2014 \backslash$ Paraploderus; nigronitens (Cameron); det. Makranczy, 2014" (1 ㅇ, BMNH).

Other material - D. R. CONGO: Tanganika, Moba [0703`S, $29^{\circ} 47^{\prime} \mathrm{E}$ ], 780 m, IV.1953, leg. H. Bomans, à la lumière (1 + , MRAC).

Redescription - Measurements (in mm, $\mathrm{n}=3$ ): $\mathrm{EW}=0.52(0.50-0.53) ; \mathrm{TW}=0.53$ (0.51-0.54); $\mathrm{PW}=0.55$ (0.53-0.57); $\mathrm{SW}=0.61(0.60-0.63) ; \mathrm{AW}=0.69(0.68-0.70) ; \mathrm{HL}=0.37$ (0.34-0.39); $\mathrm{EL}=0.115(0.11-0.12) ; \mathrm{TL}=0.12(0.12-0.13) ; \mathrm{PL}=0.40(0.39-0.41) ; \mathrm{SL}=0.56$ $(0.55-0.58) ; \mathrm{SC}=0.52(0.51-0.54) ; \mathrm{FB}=1.37(1.33-1.41) ; \mathrm{BL}=2.98$ (2.78-3.11). Habitus as in Fig. 88. Head brownish black with slight reddish tint anteriorly on clypeus. Pronotum and elytra blackish dark brown, former occasionally as dark as head while elytra slightly brighter. Abdomen dark brown, basal ridges marked black. Legs medium brown/ochre, apices of femora and both ends of tibiae sometimes darker. Mouthparts medium brown, antennae dark brown, blackish, except 11th article and first antennomeres lighter, medium brown, article 3 transitional. Head transverse with rounded, bulging temples wider than eyes. Clypeus impunctate with only slight unevenness on surface. Epistomal suture posterior to imaginary line connecting supraantennal prominences. Occipital groove somewhat divided and less conspicuous, medial portion slightly bending posteriorly, neck smooth with slight isodiametric microsculpture. Vertex with only traces of punctures, around eyes punctures with increasing density and exceptionally broad postocular rim. Temples laterally with some ruggedness, longitudinal impressions connecting epistomal suture with occipital groove (more distinct posteriorly). Head surface otherwise shiny, without microsculpture. Pronotum with complete, thin marginal bead. Surface shiny, without any microsculpture and only traces of punctation still appearing umbilicate. Longitudinal midline practically invisible, but without any trace of punctation around it and along hind margin. On both sides of midline posterior 2/3 of disc obliquely impressed. Elytra with disc gently convex, impressed obliquely only on both sides of scutellum, anterior half of disc gently, longitudinally impressed. Epipleural ridge present on almost entire length. Thin marginal bead along posterior margin broadening and vanishing at inner posterior corners. Along suture very fine marginal bead only conspicuous because of darker colour. Elytral punctation shallow, equally spaced, moderately sparse, missing on a thin, slightly elevated stripe along suture. Abdomen shiny and smooth with only tiny insertion points of setae and no microsculpture observable except segments IX-X with shallow coriaceous microsculpture with isodiametric cells. Male sternite VIII as in Fig. 30, aedeagus as in Figs 28-29, female sternite VIII as in Fig. 31, spermatheca as in Fig. 32.

Distribution - The species is known from its types from Angola and a female specimen from the D. R. Congo.

Remarks - The single female specimen P. M. Hammond identified in MRAC as 'nigronitens' is slightly smaller than the types. The spermatheca of 


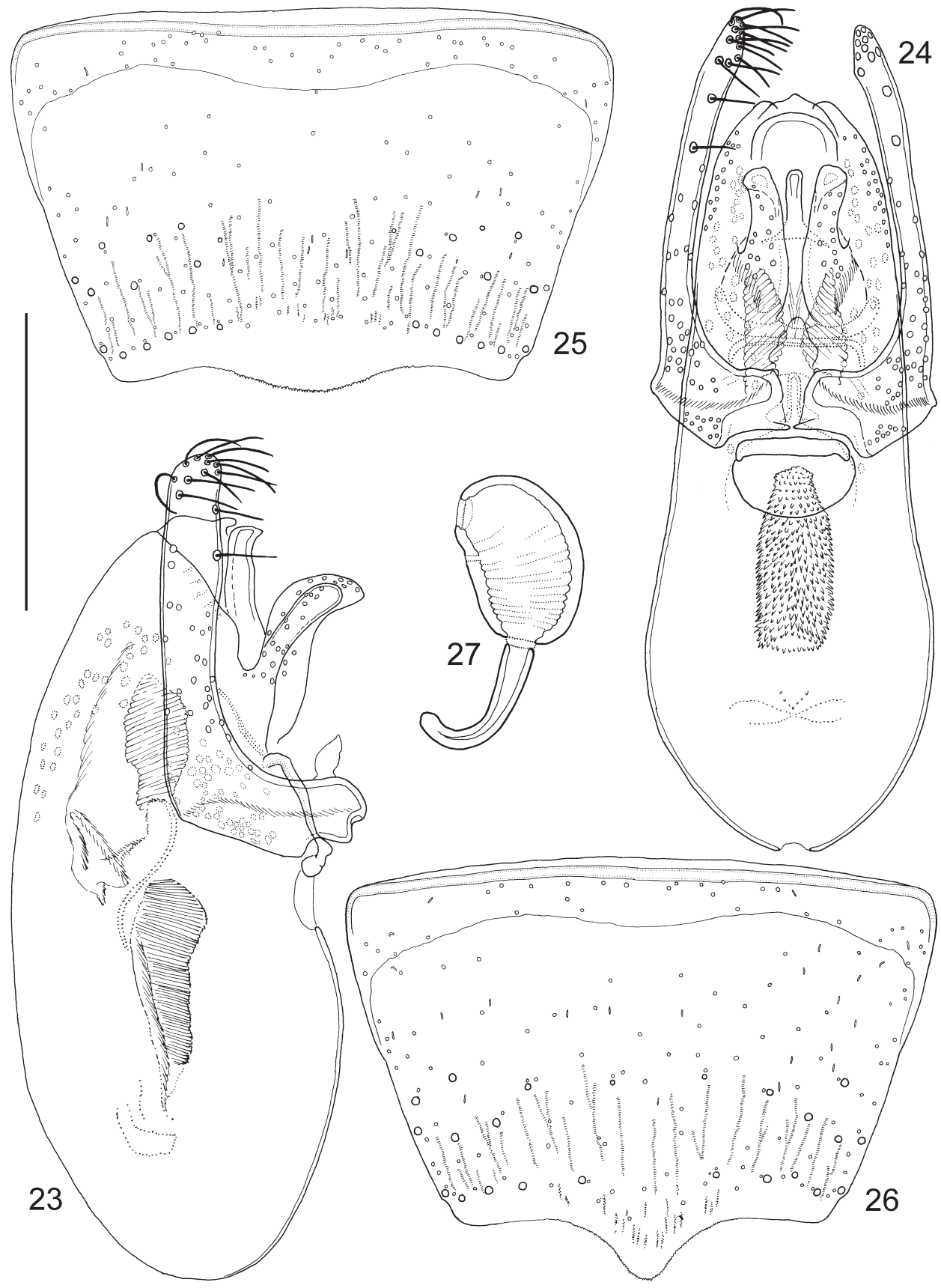

Figs 23-27. Paraploderus malgaceus sp. n. 23 = aedeagus, lateral view, 24 = aedeagus, frontal view (parameral setation shown on left), 25 = sternite VIII, male, 26 = sternite VIII, female, 27 = spermatheca. Scales: $0.1 \mathrm{~mm}$ for Fig. 27, $0.14 \mathrm{~mm}$ for Figs 23-24, 0.25 mm for Figs 25-26. 


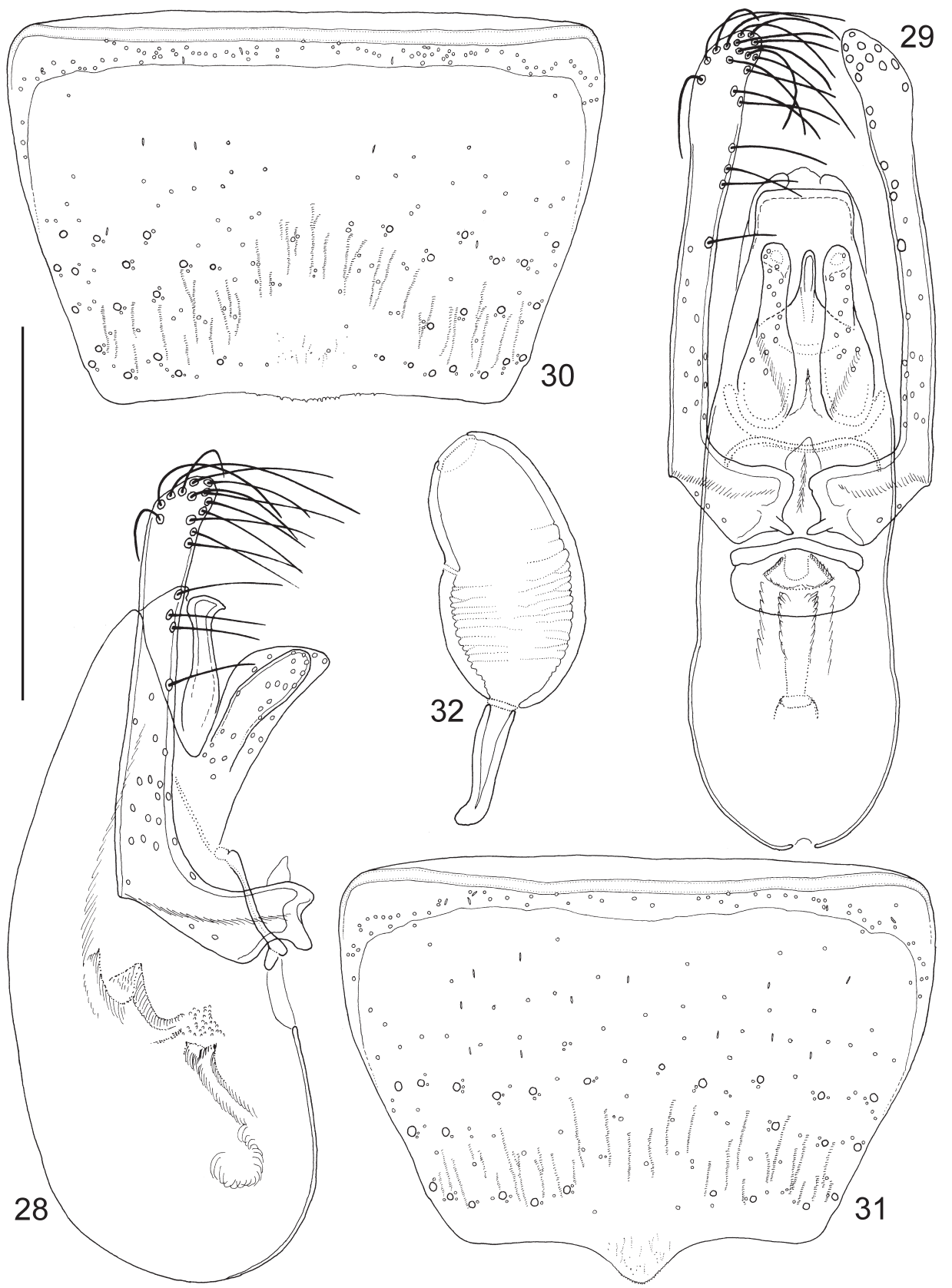

Figs 28-32. Paraploderus nigronitens (Cameron, 1951). 28 = aedeagus, lateral view, $29=$ aedeagus, frontal view (parameral setation shown on left), 30 = sternite VIII, male, $31=$ sternite VIII, female, 32 = spermatheca. Scales: $0.1 \mathrm{~mm}$ for Fig. 32, $0.18 \mathrm{~mm}$ for Figs 28-29, 0.32 mm for Figs 30-31. 
the paralectotype was embedded on the mounting card of the specimen in an unknown medium. Considering the risk of damage, no attempt was made to dissolve this mounting of the spermatheca which has an air bubble inside.

\section{Paraploderus notabilis (Cameron, 1950)}

(Figs 10, 33-37, 82)

Trogophloeus (Taenosoma) notabilis Cameron, 1950: 113.

Paraploderus notabilis; Herman, 1970: 401, Herman, 2001: 1463.

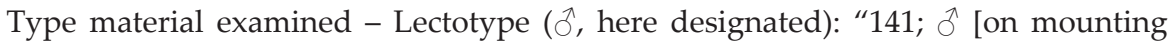
card] \ Holo-; type [paper disc, curator label with red frame] \Angola:; Camissombo [0809’S, 2040’E]; 17.V.[19]49 \Angola; Dundo; 17.V.[19]49 \ M. Cameron.; Bequest.; B.M. 1955-147. \veg.[etational] refuse; in forest \Trog.; notabilis; Cam. i.l; Type \ Lectotypus; Trogophloeus; notabilis Cameron; des. Makranczy, $2014 \backslash$ Paraploderus; notabilis (Cameron); det. Makranczy, 2014" (BMNH).

Other material - "ANGOLA; $1385.10 \backslash$ W. Steel coll.; B.M. 1969-552." (1 ð̂, 1 ㅇ, 2, $\mathrm{BMNH}$ ); Alto Chicapa, riv. Tchirimbo [1055’S, 19²0’E, 1300 m], VII-1954, leg. A. de Barros Machado (4323-4) (2, BMNH, 1, NHMW); Calunda (Alto Zambeze), chutes Luisavo [waterfall] [1150'S, 2337' E], II-1955, leg. A. de Barros Machado (Ang. 4965A-3) (1, MRAC); D. R.

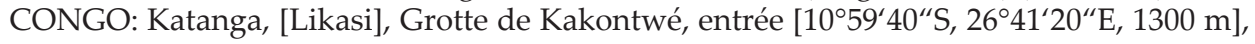
1.VIII.1948, leg. N. Leleup, récolté sous des pierres (1, MRAC).

Redescription - Measurements (in mm, $\mathrm{n}=8)$ : EW $=0.50(0.47-0.52) ; \mathrm{TW}=0.49(0.45-$ $0.51) ; \mathrm{PW}=0.54(0.52-0.55) ; \mathrm{SW}=0.61(0.58-0.64) ; \mathrm{AW}=0.68(0.59-0.71) ; \mathrm{HL}=0.33(0.31-$ $0.35) ; \mathrm{EL}=0.12(0.11-0.13) ; \mathrm{TL}=0.11(0.10-0.12) ; \mathrm{PL}=0.38(0.36-0.39) ; \mathrm{SL}=0.58(0.55-0.60)$; $\mathrm{SC}=0.54(0.52-0.56) ; \mathrm{FB}=1.33(1.27-1.39) ; \mathrm{BL}=2.61(2.30-2.78)$. Habitus as in Fig. 82. Head dark brown but lighter (medium brownish) anteriorly. Pronotum medium brown, marginal bead sometimes slightly darker. Elytra medium to light brown/ochre, abdomen medium to dark brown with black lines along basal ridges. Legs and mouthparts light brown to ochre, apices of femora and tibiae sometimes darker, antennae medium brown (slightly reddish). Head transverse with rounded, bulging temples almost as wide as eyes. Clypeus almost impunctate with only traces of microsculpture/unevenness on surface. Epistomal suture between tips of supraantennal prominences or only a little behind imaginary line connecting them. Medial portion of occipital groove bending anteriorly, neck shiny with superficial coriaceous microsculpture with isodiametric cells. Vertex with scattered, indefinite-bordered but large and deep punctures; some also near temples but ventrally punctation turning into ruggedness around eyes. On both sides of vertex more shallow longitudinal impressions running from epistomal suture to occipital groove. Head surface otherwise shiny, without microsculpture. Pronotum with complete, thin marginal bead. Surface shiny, without any microsculpture but punctured like head, scattered, indefinitebordered, mostly rather large pits, slightly umbilicate. Longitudinal midline inconspicuously marked but punctures missing on a broad stripe on both sides and partly along hind margin. On both sides of midline posterior $2 / 3$ of disc slightly impressed. Elytra with disc gently convex, impressed obliquely only on both sides of scutellum, anterior half of disc with inconspicuous longitudinal impression in middle. Epipleural ridge present on almost entire length. Thin marginal bead along posterior margin broadening and vanishing at 


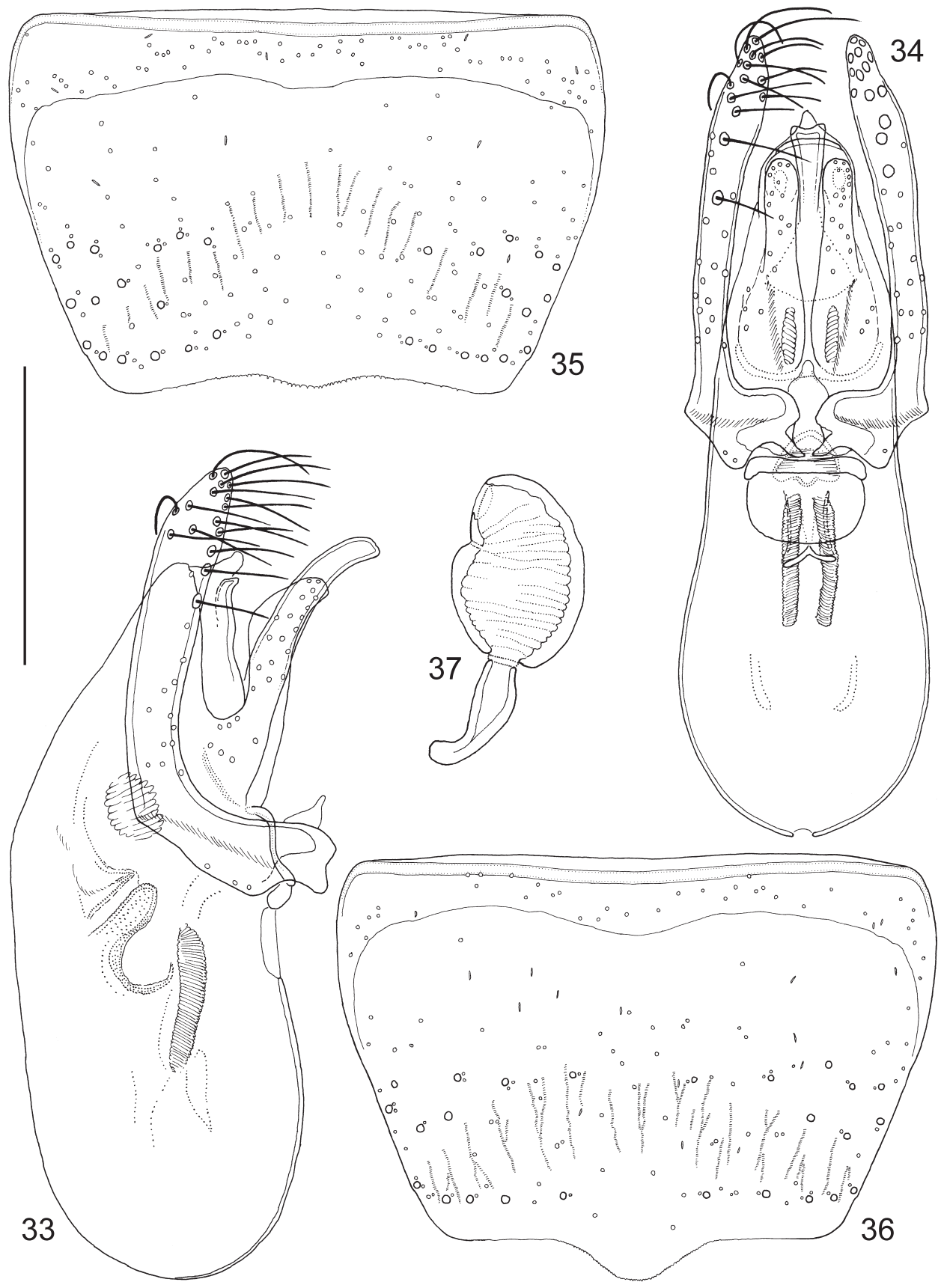

Figs 33-37. Paraploderus notabilis (Cameron, 1950). $33=$ aedeagus, lateral view, $34=$ aedeagus, frontal view (parameral setation shown on left), 35 = sternite VIII, male, 36 = sternite VIII, female, 37 = spermatheca. Scales: $0.1 \mathrm{~mm}$ for Fig. 37, $0.125 \mathrm{~mm}$ for Figs 33-34, $0.24 \mathrm{~mm}$ for Figs 35-36. 
inner posterior corners. Along suture very fine marginal bead only conspicuous because of darker colour. Elytral punctation rather deep, equally spaced, moderately sparse, missing on a thin, slightly elevated stripe along suture. Abdomen shiny and smooth with only tiny insertion points of setae and no microsculpture observable except segments IX-X with shallow coriaceous microsculpture with isodiametric cells. Male sternite VIII as in Fig. 35, aedeagus as in Figs 33-34, female sternite VIII as in Fig. 36, spermatheca as in Fig. 37.

Distribution - Although a wide range of material was identified by P. M. Hammond as 'notabilis', this may be a confusion of several closely allied species; here the name is applied in a very strict sense. Therefore, the species is known from Angola and southern D. R. Congo.

Remarks - The type designation in the original article is somewhat controversial. It could be argued that the noting of "(Type)" after the collecting data (locality and date) is aimed at the unambiguous assignment of type locality rather than the designation of a primary type specimen, and in fact it does not refer to a single specimen (numbers of specimens not noted anywhere). In this situation it was felt better to designate a lectotype even if other workers may consider the holotype selection valid by the description. On the type specimen the locality data were supplied long after the description, probably substituting a code number; it is believed that the series of specimens from the collection of W. O. Steel (code number without locality) are from the same event.

\section{Paraploderus parcepunctus (Fauvel, 1905)}

(Figs 38-42, 80)

Oxytelus parcepunctus Fauvel, 1905: 121.

Trogophloeus punctus Bernhauer, 1933: 291, syn. n.

Paraploderus parcepunctus Herman, 1970: 401, Herman, 2001: 1463.

Paraploderus punctus Gildenkov, 2004: 341.

Type material examined - (parcepunctus) Lectotype (here designated): “Lecto-; type [lilac margined disc, curator label] \Kinchassa; Congo 2, 4 [February, April] \ parcepunctus; Fvl. \ Coll. et det. A. Fauvel; Oxytelus; parcepunctatus[sic!]; Fauv.; R.I.Sc.N.B. 17.479 \ G. Fagel elig., 1956; Oxytelus; parcepunctatus[sic!]; Fauv.; Lectotype \ G. Fagel det., 1956; Trogophloeopsis; gen. nov. \Oxytelus; parcepunctus Fvl.; P.M. Hammond; det. 1972; Lectotype \Lectotypus; Oxytelus; parcepunctus Fauvel; des. Makranczy, $2013 \backslash$ Paraploderus; parcepunctus (Fauvel); det. Makranczy, 2013" (ISNB); Paralectotype (1): "Para-; lecto-; type [light blue margined disc, curator label] \Kinchassa; Congo; 2-4 \Coll. et det. A. Fauvel; Oxytelus; parcepunctatus[sic!]; Fauv.; R.I.Sc.N.B. $17.479 \backslash$ Ex-Typis \Para-; type \Oxytelus; parcepunctus Fvl.; P.M. Hammond; det. 1972; Paralectotype \ Paralectotypus; Oxytelus; parcepunctus Fauvel; des. Makranczy, 2013 \Paraploderus; parcepunctus (Fauvel); det. Makranczy, 2013" (ISNB). (punctus) Lectotype: "Lecto-; type [lilac margined disc, curator label] \Typus; $\widehat{O} \backslash$ Musée du Congo; Léopoldville; 1930; Eg. Devroye \Trogophloeus; punctus Bernh.; P.M. Hammond; det. 1972; Lectotype \ Paraploderus; punctus (Bh.); det. M. Gildenkov $2003 \backslash$ Paraploderus; punctus (Bernh.); comb. n. Gildenkov \Lectotypus; Trogophloeus; punctus Bernhauer; ver. Makranczy, $2013 \backslash$ Paraploderus; parcepunctus 
(Fauvel); det. Makranczy, 2013" (MRAC); Paralectotypes (4): “Para-; lecto-; type [light blue margined disc, curator label] \Tr.; Type; punctus Brnh. \Musée du Congo; Léopoldville; 1930; E. Devroey \R. dét.; C; $2271 \backslash$ Trogophloeus; punctus Bernh.; P.M. Hammond; det. 1972; Paralectotype \Paraploderus; punctus (Bh.); det. M. Gildenkov $2003 \backslash$ Paralectotypus; Trogophloeus; punctus Bernhauer; ver. Makranczy, $2013 \backslash$ Paraploderus; parcepunctus (Fauvel); det. Makranczy, 2013" (MRAC); "Para-; lecto-; type [light blue margined disc, curator label] \Tr.; Type; punctus Brnh. \Musée du Congo; Léopoldville; 1930; E. Devroey \R. dét.; C; $2271 \backslash$ Trogophloeus; punctus; Brnh. Typ. \Trogophloeus; punctus Bernh.; P.M. Hammond; det. 1972; Paralectotype \ Paraploderus; punctus (Bh.); det. M. Gildenkov 2003 \Paralectotypus; Trogophloeus; punctus Bernhauer; ver. Makranczy, $2013 \backslash$ Paraploderus; parcepunctus (Fauvel); det. Makranczy, 2013” (MRAC); “Musée du Congo \Léopoldville; 1930; E. Devroey \ punctus; Brh. Typ. \ punctus; Brnh. Typus; Trogophloeus \Chicago NHMus; M. Bernhauer; Collection \Trogophloeus; punctus Bnh.; P.M. Hammond; det. 1974 đ̊; Paralectotype \ Paraploderus; parcepunctus (Fvl.); P.M. Hammond; det. $1974 \backslash$ Paralectotype; teste A. Westrich 2015; GDI Imaging Project" (1 $\jmath^{\text {, }}$ FMNH); "Musée du Congo \Léopoldville; 1930; E. Devroey \punctus; Brnh.; Cotypus $\backslash$ Chicago NHMus; M. Bernhauer; Collection \Trogophloeus; punctus Bnh.; P.M. Hammond; det. 1974 क ; Paralectotype \Paralectotype; teste A. Westrich 2015; GDI Imaging Project" $(1$,, $\mathrm{FMNH})$.

Other material - GUINEA: Sérédou [08 $23^{\prime} \mathrm{N}, 09^{\circ} 18^{\prime} \mathrm{W}$ ], 5.IV.1975, leg. Zott, lux (1, ZMHB), same but 7-8.IV.1975 (1, ZMHB), same but 4.V.1975 (1, ZMHB); CÔTE D'IVOIRE: Adiopo-doumé $\left[05^{\circ} 20^{\prime} \mathrm{N}, 04^{\circ} 07^{\prime} \mathrm{W}\right], 1975$, leg. P. Dessart (1, MRAC), same but 7-8.IV.1975 (1, ZMHB), same but 4.V.1975 (1, ZMHB); CENTRAL AFRICAN REPUBLIC: Bozo [0508'N, $\left.18^{\circ} 29^{\prime} \mathrm{E}\right], 8 . X \mathrm{XI} .1980$, leg. N. Degallier, at light (1, ZMHB), same but 21.V.1981 (1, ZMHB); CONGO REP.: Odzala, 0³1’N , 14³3’E, X.1963, exp. Descarpentries \& Villiers (5, coll. Levasseur, MNHP); Bouenza, $04.30^{\circ} \mathrm{S}, 13.96^{\circ} \mathrm{E}$, 3.V.1985, leg. Bremer, lux (1, ZMHB); Méya near Kindamba, 0350'19"S, 14³0’08”'E, 03.XI.1963, leg. S. Endrődy-Younga (no. 92), by lamplight at settlement (3, HNHM); same but 05.XI.1963, leg. J. Balogh \& A. Zicsi (no. 111) (1, HNHM), same but leg. S. Endrődy-Younga (no. 112) (1, HNHM); Méya near Kindamba, Louolo river, $03^{\circ} 50^{\prime} 19^{\prime \prime}$ S, $1^{\circ} 29^{\prime} 00^{\prime \prime} \mathrm{E}, 05 . X I .1963$, leg. S. Endrődy-Younga (no. 110), beaten from shrubs in multilayer gallery forest (1, HNHM), same but 12.XI.1963, leg. S. Endrődy-Younga (no. 185), by lamplight in gallery forest, on riverside (1, HNHM); Mt. Fou-

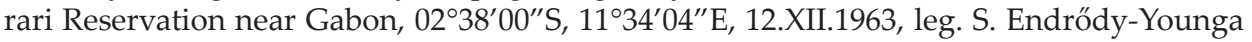
(no. 456), collected by lamplight on hillside facing savannah (271, HNHM, 1, NHMW, 1, JJRC, 1, SDEI, 1, FMNH, 1, MHNG, 1, MZLU, 1, NMPC, 1, SMNS, 1, CNCI, 1, AMNH, 1, ZFMK); Loudima, park of the SAGRO Institution, $04^{\circ} 10^{\prime} 00^{\prime \prime} \mathrm{S}, 13^{\circ} 00^{\prime} 39^{\prime \prime} \mathrm{E}, 06 . \mathrm{XII.1963}$, leg. S. Endrődy-Younga (no. 378), by lamplight, on hillside facing savannah (2, HNHM), same but leg. J. Balogh \& A. Zicsi (no. 379) (1, HNHM), same but 07.XII.1963, leg. S. EndrődyYounga (no. 403) (1, HNHM), same but 10.XII.1963 (no. 431) (2, HNHM); Brazzaville, park of the ORSTOM Institution, $04^{\circ} 10^{\prime} 38^{\prime \prime} S, 15^{\circ} 10^{\prime} 28^{\prime \prime} \mathrm{E}, 19 . X \mathrm{XI} 1963$, leg. S. Endrődy-Younga (no. 214), light trap (1, HNHM), same but 22.XI.1963, leg. J. Balogh \& A. Zicsi (no. 220) (1, HNHM), same but 21.XII.1963, leg. S. Endrődy-Younga (no. 491), light trap (1, HNHM), same but 22.XII.1963 (no. 495) (1, HNHM); GABON: Mt. Fourari Reservation, 02³8'00"S, $11^{\circ} 33^{\prime} 00^{\prime \prime}$ E, 14.XII.1963, leg. S. Endrődy-Younga (no. 465), singled and sifted from buffalo dung (2, HNHM); D. R. CONGO: Elisabethville, 1953-55, leg. Ch. Seydel, à la lumière (1, MRAC); Eala, XI.1929, leg. H. J. Brédo (1, MRAC); Kidada (Kitobola) [05²2'S, 14³1'E], II.1922, leg. H. Schouteden (1, MRAC); terr. Mwenga, Kitutu [031'S, 2805’E], 650 m, IV.1958, leg. N. Leleup, lumière (1, MRAC); Tshuapa, terr. Bikoro, Mabali [00 53'S, $\left.18^{\circ} 17^{\prime} \mathrm{E}\right]$, IX-X.1959, leg. N. Leleup, Esobe de M-Bolo, à la lumière (1 ㅇ, 1, MRAC, 1 ô, HNHM); Parc 
National Garamba II/gd/4 [cellule biologique II, $03^{\circ} 58^{\prime} \mathrm{N}, 2^{\circ} 22^{\prime} \mathrm{E}$ ], 3.XII.1951, leg. H. De Saeger (2843) (1, MRAC); ANGOLA: Chianga, 6.III.1972, exp. B.M. Southern Africa (A21), damp leaf litter by stream (1, BMNH); lac Lundo, $105 \mathrm{~km}$ N Vila Luso, I.1954, leg. A. de Barros Machado \& E. Luna de Carvalho (Ang.4652.1) (1, MRAC); lac Calundo, $105 \mathrm{~km}$ E Vila Luso, [1150 m], XII.1954, leg. A. de Barros Machado \& E. Luna de Carvalho (4544.13), lumière (1, MRAC), same but (4623.2) (1, BMNH); rives du lac Calundo, XII.1954, leg. A. de Barros Machado (4595.1), lumière (1, MRAC).

Redescription - Measurements (in $\mathrm{mm}, \mathrm{n}=10)$ : $\mathrm{EW}=0.45(0.42-0.47) ; \mathrm{TW}=0.44$ (0.41-0.46); $\mathrm{PW}=0.45$ (0.42-0.48); $\mathrm{SW}=0.50(0.47-0.54) ; \mathrm{AW}=0.55(0.50-0.60) ; \mathrm{HL}=0.30$ (0.28-0.31); $\mathrm{EL}=0.12(0.11-0.13) ; \mathrm{TL}=0.08(0.07-0.09) ; \mathrm{PL}=0.33(0.30-0.35) ; \mathrm{SL}=0.46(0.45-$ $0.48) ; \mathrm{SC}=0.43(0.42-0.45) ; \mathrm{FB}=1.15(1.09-1.20) ; \mathrm{BL}=2.04(1.86-2.38)$. Habitus as in Fig. 80. Head reddish dark brown, epistomal suture blackish. Pronotum yellowish medium to light brown, as well as abdominal base; rest of abdomen medium brown with basal ridges of tergites marked in dark brown, legs, antennae and mouthparts light brown, but mandibles dark reddish brown. Head transverse with rounded temples almost as wide as eyes. Clypeus with very scattered, minute punctures only, with a thin anterior rim also on sides, only feeble traces of microsculpture and unevenness laterally on surface. Epistomal suture between tips of supraantennal prominences or only a little behind imaginary line connecting them. Medial portion of occipital groove bending anteriorly, neck medially shiny, laterally with traces of coriaceous microsculpture with isodiametric cells. Vertex with very scattered, indefinite-bordered and variously sized punctures; punctation near temples much denser and obscures a postocular ridge. Faint longitudinal impressions running on both sides of vertex from epistomal suture to occipital groove, becoming more marked posteriorly. Head surface otherwise shiny, without microsculpture. Pronotum with complete, thin marginal bead. Surface shiny, without any microsculpture but more strongly punctured than head, indefinite-bordered, mostly rather large pits (slightly umbilicate) almost everywhere on surface except along midline and narrowly along posterior margin. Longitudinal midline unmarked. On both sides of midline middle-posterior 3/5 of disc moderately strongly impressed. Elytra with disc gently convex, two very thin and shallow longitudinal impressions along suture behind scutellum. Epipleural ridge present on almost entire length. Thin marginal bead with obscure connection to epipleural ridge continuing along posterior margin, not reaching sutural corner, slightly curving anteriorly before it. Along suture very fine marginal bead only conspicuous because of darker colour. Elytral punctation mostly rather shallow, obscured by uneven surface, more or less equally spaced, moderately dense, missing on a thin, slightly elevated stripe along suture. Abdomen shiny and smooth with only tiny insertion points of setae and extremely faint coriaceous microsculpture with isodiametric cells. Male sternite VIII as in Fig. 40, aedeagus as in Figs 38-39, female sternite VIII as in Fig. 41, spermatheca as in Fig. 42.

Distribution - The species is known to have a rather wide distribution from Guinea to the Central African Republic and to Angola in the south.

Remarks - The article with the lectotype designation of "Trogophloeus punctus" (Gildenkov, 2004) includes a figure of the aedeagus without parameres, unwarranted. The aedeagal structures as well as the external characters of the type series of 'punctus' are totally consistent with the concept of $P$. parcepunctus, hence the synonymy between the two names is here proposed. 


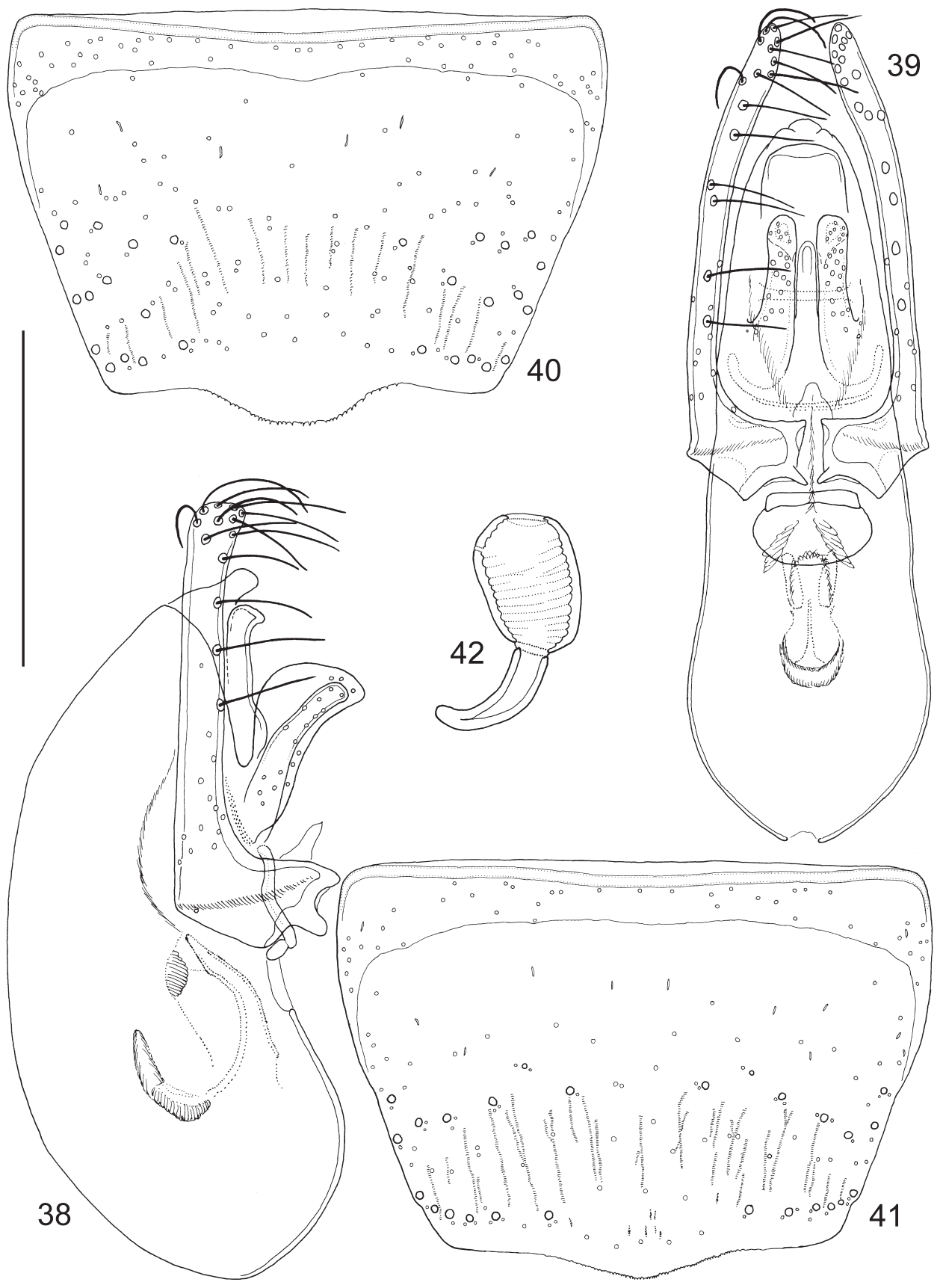

Figs 38-42. Paraploderus parcepunctus (Fauvel, 1905). 38 = aedeagus, lateral view, $39=$ aedeagus, frontal view (parameral setation shown on left), 40 = sternite VIII, male, 41 = sternite VIII, female, 42 = spermatheca. Scales: $0.1 \mathrm{~mm}$ for Fig. 42, $0.13 \mathrm{~mm}$ for Figs 38-39, $0.2 \mathrm{~mm}$ for Figs 40-41. 


\section{Paraploderus rufescens sp. $\mathrm{n}$.}

(Figs 43-47, 78-79, 90, 105-116)

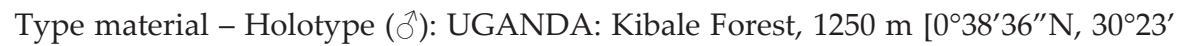
38"E], 25.V.1993, leg. G. Cuccodoro \& D. Erne (14a), leaflitter in forest near river, sifted (MHNG); Paratypes (386 adults): same data as holotype (2, MHNG); Kibale Forest, $1250 \mathrm{~m}$, 23.V.1993, leg. G. Cuccodoro \& D. Erne (12b), moist leaflitter in forest, sifted (1 ô, 2 ㅇ, 3, MHNG), same but (12d) old rotting trunk, sifted (2, MHNG); KENYA: M'laba Forest, 1660 m, 2.II.1979, leg. Th. Palm (5, MZLU); Kakamega Forest, 1500 m, II.1977, leg. Deharveng (Ken12) (1, MHNG); Kakamega Forest, 1650 m, 27.I.1979, leg. Th. Palm (9, MZLU); Western prov., Kakamega Forest Nat., Kaimosi, $0^{\circ} 07^{\prime} 42^{\prime \prime}$ N, 34 50’27"E, 03.I.2006, leg. G. Fischer (\#3/ T1-400) (1, MHNG); Western prov., Kakamega Forest Nat., Yala, 0¹2'08”N, 34 52'47"E, 06.I.2006, leg. G. Fischer (\#6/T3-200) (3, MHNG, 2, HNHM); Western prov., Kakamega Forest Nat., Colobus, $0^{\circ} 21^{\prime} 17^{\prime \prime} \mathrm{N}, 34^{\circ} 51^{\prime} 41^{\prime \prime} \mathrm{E}, 09 . \mathrm{I} .2006$, leg. G. Fischer (\#7/T2-0) (1, MHNG, 1, HNHM); Western prov., Kakamega Forest Nat., Colobus, $0^{\circ} 21^{\prime} 20^{\prime \prime} \mathrm{N}, 34^{\circ} 51^{\prime} 39^{\prime \prime} \mathrm{E}$, 10.I.2006, leg. G. Fischer (\#8/T2-100) (2, MHNG); Western prov., Kakamega Forest Nat., Malava East, $0^{\circ} 27^{\prime} 09^{\prime \prime} \mathrm{N}, 34^{\circ} 51^{\prime} 49^{\prime \prime} \mathrm{E}, 12 . \mathrm{I} .2006$, leg. G. Fischer (\#9/T1-100) (22, MHNG, 2, HNHM); Western prov., Kakamega Forest Nat., Ikuywa, $0^{\circ} 12^{\prime} 40^{\prime \prime} \mathrm{N}, 34^{\circ} 55^{\prime} 52^{\prime \prime} \mathrm{E}, 19 . \mathrm{I} .2006$, leg. G. Fischer (\#11/T1-200) (33, MHNG); Western prov., Kakamega Forest Nat., Ikuywa, $0^{\circ} 12^{\prime} 42^{\prime \prime} \mathrm{N}, 34^{\circ} 55^{\prime} 53^{\prime \prime} \mathrm{E}, 20 . \mathrm{I} .2006$, leg. G. Fischer (\#12/T1-300) (10, MHNG, 6, HNHM); Western prov., Kakamega Forest Nat., Salasar, $0^{\circ} 18^{\prime} 00^{\prime \prime}$ N, 34 $4^{\circ} 2^{\prime} 04^{\prime \prime}$ E, 25.I.2006, leg. G. Fischer (\#14/T3-500) (4, MHNG, 4, HNHM); Western prov., Kakamega Forest Nat., Salasar, $0^{\circ} 19^{\prime} 02^{\prime \prime} \mathrm{N}, 34^{\circ} 52^{\prime} 06^{\prime \prime} \mathrm{E}, 27 . \mathrm{I} .2006$, leg. G. Fischer (\#16/T3-400) (1, MHNG, 1, HNHM); Western prov., Kakamega Forest Nat., Isecheno A, $0^{\circ} 14^{\prime} 24^{\prime \prime} \mathrm{N}, 34^{\circ} 52^{\prime} 05^{\prime \prime} \mathrm{E}, 01 . \mathrm{II} .2006$, leg. G. Fischer (\#18/T2-400) (10, MHNG, 1, HNHM); Western prov., Kakamega Forest Nat., Isecheno B, $0^{\circ} 15^{\prime} 20^{\prime \prime} \mathrm{N}, 34^{\circ} 52^{\prime} 06^{\prime \prime} \mathrm{E}, 02 . I I .2006$, leg. G. Fischer (\#19/T2-400) (7, MHNG); Western prov., Kakamega Forest Nat., Isecheno B, $0^{\circ} 15^{\prime} 23^{\prime \prime} \mathrm{N}, 34^{\circ} 52^{\prime} 04^{\prime \prime} \mathrm{E}, 26 . \mathrm{VI} .2006$, leg. G. Fischer (\#20/T1-400) (10, MHNG); Western prov., Kakamega Forest Nat., Kisere, $0^{\circ} 23^{\prime} 00^{\prime \prime} \mathrm{N}$, 3453'41"E, 30.VI.2006, leg. G. Fischer (\#22/T4-300) (6, MHNG); Western prov., Kakamega Forest Nat., Malava West, $0^{\circ} 27^{\prime} 17^{\prime \prime} \mathrm{N}, 34^{\circ} 50^{\prime} 38^{\prime \prime}$ E, 06.VII.2006, leg. G. Fischer (\#23/T3-200) (2, MHNG, 3, HNHM); Western prov., Kakamega Forest Nat., Buyangu Hill, 0²0’59”N, 3451'58”E, 31.VII.2006, leg. G. Fischer (\#25/T2-200) (1, MHNG); Western prov., Kakamega Forest Nat., Buyangu Hill, $0^{\circ} 20^{\prime} 56^{\prime \prime} \mathrm{N}$, 3451'56”'E, 01.VIII.2006, leg. G. Fischer (\#26/T2300) (13, MHNG, 1, HNHM); Western prov., Kakamega Forest Nat., Kaimosi, $0^{\circ} 07^{\prime} 46^{\prime \prime} \mathrm{N}$, 3450’38”E, 05.VIII.2006, leg. G. Fischer (\#28/T2-200) (1, MHNG); Western prov., Kakamega Forest Nat., Ikuywa, $0^{\circ} 13^{\prime} 19^{\prime \prime} \mathrm{N}, 34^{\circ} 55^{\prime} 51^{\prime \prime} \mathrm{E}, 07 . V I I I .2006$, leg. G. Fischer (\#29/T3-500) (24, MHNG, 1, SDEI, 1, ZMHB, 1, NHMW, 1, SMNS, 1, AMNH, 1, BMNH, 1, NMPC, 1, MNHP, 1, CNCI, 1, ISNB); Western prov., Kakamega Forest Nat., Ikuywa, $0^{\circ} 13^{\prime} 14^{\prime \prime} \mathrm{N}, 34^{\circ} 55^{\prime} 52^{\prime \prime} \mathrm{E}$, 09.VIII.2006, leg. G. Fischer (\#30/T3-300) (12, MHNG, 3, HNHM); Western prov., Kakamega Forest Nat., Salasar, 0`19'22"N , 3452'14"E, 14.VIII.2006, leg. G. Fischer (\#32/T2-100) (27, MHNG, 3, HNHM); Western prov., Kakamega Forest Nat., Salasar, $0^{\circ} 19^{\prime} 40^{\prime \prime} \mathrm{N}, 34^{\circ} 52^{\prime} 14^{\prime \prime} \mathrm{E}$, 17.VIII.2006, leg. G. Fischer (\#34/T1-100) (3, MHNG); Western prov., Kakamega Forest Nat., Malava East, $0^{\circ} 27^{\prime} 20^{\prime \prime} \mathrm{N}$, 34 $51^{\prime} 45^{\prime \prime} \mathrm{E}$, 23.VIII.2006, leg. G. Fischer (\#35/T2-100) (4, MHNG, 1, HNHM); Western prov., Kakamega Forest Nat., Kisere, 0²3’13”N , 34 $53^{\circ} 42^{\prime \prime}$, 28.VIII.2006, leg. G. Fischer (\#37/T5-400) (13, MHNG); Western prov., Kakamega Forest Nat., Kisere, $0^{\circ} 23^{\prime} 17^{\prime \prime} N$, 34 $4^{\circ} 53^{\prime} 42^{\prime \prime}$ E, 31.VIII.2006, leg. G. Fischer (\#38/T5-500) (3, MHNG); Western prov., Kakamega Forest Nat., Buyangu Hill, 0²0'49"N N, 3451'56" E, 07.IX.2006, leg. G. Fischer (\#40/T3-100) (8, MHNG); Western prov., Kakamega Forest Nat., Yala, $0^{\circ} 12^{\prime} 07^{\prime \prime} \mathrm{N}$, 34 52'53"E, 08.IX.2006, leg. G. Fischer (\#41/T1-400) (12, MHNG, 3, HNHM); Western 
prov., Kakamega Forest Nat., Yala, $0^{\circ} 12^{\prime} 10^{\prime \prime}$ N, 3452'53”E, 09.IX.2006, leg. G. Fischer (\#42/ T1-300) (3, MHNG); Western prov., Kakamega Forest Nat., Yala, $0^{\circ} 12^{\prime} 20^{\prime \prime} \mathrm{N}, 34^{\circ} 52^{\prime} 52^{\prime \prime} \mathrm{E}$, 26.IX.2006, leg. G. Fischer (\#47/T1-0) (8, MHNG, 2, HNHM); Western prov., Kakamega Forest Nat., Yala, $0^{\circ} 12^{\prime} 16^{\prime \prime} \mathrm{N}, 34^{\circ} 52^{\prime} 52^{\prime \prime} \mathrm{E}, 27 . \mathrm{IX} .2006$, leg. G. Fischer (\#48/T1-100) (15, MHNG, 1, HNHM); Western prov., Kakamega Forest, Colobus, $0^{\circ} 21^{\prime} 18.5^{\prime \prime} \mathrm{N}, 34^{\circ} 51^{\prime} 30.1^{\prime \prime} \mathrm{E}, 1650$ m, 14.VI.2007, leg. M. Peters (T1) primary forest habitat, leaf litter Winkler extraction (6, MHNG, 6, ZFMK); Western prov., Kakamega Forest, Salazar, $0^{\circ} 19^{\prime} 36^{\prime \prime} \mathrm{N}, 34^{\circ} 52^{\prime} 14.6^{\prime \prime} \mathrm{E}$, $1650 \mathrm{~m}$ 21.VI.2007, leg. M. Peters (T6) primary forest habitat, leaf litter Winkler extraction (5, ZFMK); Western prov., Kakamega Forest, Ikuywa, $0^{\circ} 12^{\prime} 42.6^{\prime \prime} \mathrm{N}, 34^{\circ} 55^{\prime} 52.3^{\prime \prime} \mathrm{E}, 1650 \mathrm{~m}$, 16.VIII.2007, leg. F. Hita Garcia (T20) primary forest habitat, leaf litter Winkler extraction (26, MHNG, 12, ZFMK); Western prov., Kakamega Forest, Yala, $0^{\circ} 12^{\prime} 43^{\prime \prime} \mathrm{N}, 34^{\circ} 55^{\prime} 52^{\prime \prime} \mathrm{E}$, 1650 m, V.2008, leg. M. Peters (T28) forest fragment, primary forest (1, ZFMK); Kakamega Forest, Udo's Bandas, $00^{\circ} 21^{\prime} 38.2^{\prime \prime} \mathrm{N}, 34^{\circ} 51^{\prime} 24.9^{\prime \prime} \mathrm{E}, 14 . \mathrm{XI} .2001$, leg. V. Grebennikov, under bark (2, 1 larva/L $\mathrm{L}_{2}, 2$ larva/L $\mathrm{z}^{\prime}$ FMNH); D.R. CONGO: Kibali-Ituri, terr. Epulu, MambasaMungbere [02 $\left.38^{\prime} \mathrm{N}, 28^{\circ} 30^{\prime} \mathrm{E}\right], 900 \mathrm{~m}$, II.1954, leg. N. Leleup (8, MRAC).

Description - Measurements (in mm, $\mathrm{n}=10)$ : $\mathrm{EW}=0.50(0.45-0.52)$; $\mathrm{TW}=0.51(0.44-$ $0.54) ; \mathrm{PW}=0.56(0.51-0.59) ; \mathrm{SW}=0.60(0.58-0.64) ; \mathrm{AW}=0.72(0.68-0.77) ; \mathrm{HL}=0.33$ (0.33$0.35) ; \mathrm{EL}=0.11(0.10-0.11) ; \mathrm{TL}=0.11(0.10-0.13) ; \mathrm{PL}=0.39(0.35-0.41) ; \mathrm{SL}=0.54(0.50-0.59)$; $\mathrm{SC}=0.50$ (0.46-0.54); $\mathrm{FB}=1.32(1.23-1.46) ; \mathrm{BL}=2.54$ (2.30-2.87). Habitus as in Fig. 90. Pronotum, elytra and abdominal base reddish medium brown; head and rest of abdomen reddish dark brown but anterior part of head lighter, epistomal suture partly blackish. Antennae, legs and mouthparts reddish medium brown, tips of mandibles and antennomeres 3-10 often darker. Head transverse with rounded, bulging temples just slightly wider than eyes. Clypeus with very scattered, minute punctures only, with a thin anterior rim also on sides, only feeble traces of microsculpture and unevenness laterally on surface. Epistomal suture posterior to imaginary line connecting supraantennal prominences. Medial portion of occipital groove bending anteriorly, neck medially shiny, laterally with traces of coriaceous microsculpture with isodiametric cells. Vertex with very scattered, indefinite-bordered and variously sized punctures; punctation near temples much denser and obscures a postocular ridge. Faint longitudinal impressions running on both sides of vertex from epistomal suture to occipital groove, becoming more marked posteriorly. Head surface otherwise shiny, without microsculpture. Pronotum with complete, thin marginal bead. Surface shiny, without any microsculpture but more strongly punctured than head, indefinite-bordered, mostly rather large pits (slightly umbilicate) almost everywhere on surface except along midline and narrowly along posterior margin. Longitudinal midline marked in posterior $1 / 2$. On both sides of midline middle-posterior $3 / 5$ of disc moderately strongly impressed. Elytra with disc gently convex, two very thin and shallow longitudinal impressions extending along suture behind scutellum, anterior half of disc slightly impressed in middle. Epipleural ridge present on almost entire length. Thin marginal bead with obscure connection to epipleural ridge continuing along posterior margin, not reaching sutural corner, slightly curving anteriorly before it. Along suture very fine marginal bead only conspicuous because of darker colour. Elytral punctation mostly rather deep, somewhat obscured by uneven surface, more or less equally distributed, moderately sparse, missing on a thin, slightly elevated stripe along suture. Abdomen shiny and smooth with only tiny insertion points of setae and extremely faint coriaceous microsculpture with isodiametric cells. Male sternite VIII as in Fig. 45, aedeagus as in Figs 43-44, female sternite VIII as in Fig. 46, spermatheca as in Fig. 47.

Distribution - Currently known from Uganda, Kenya and the D. R. Congo. 


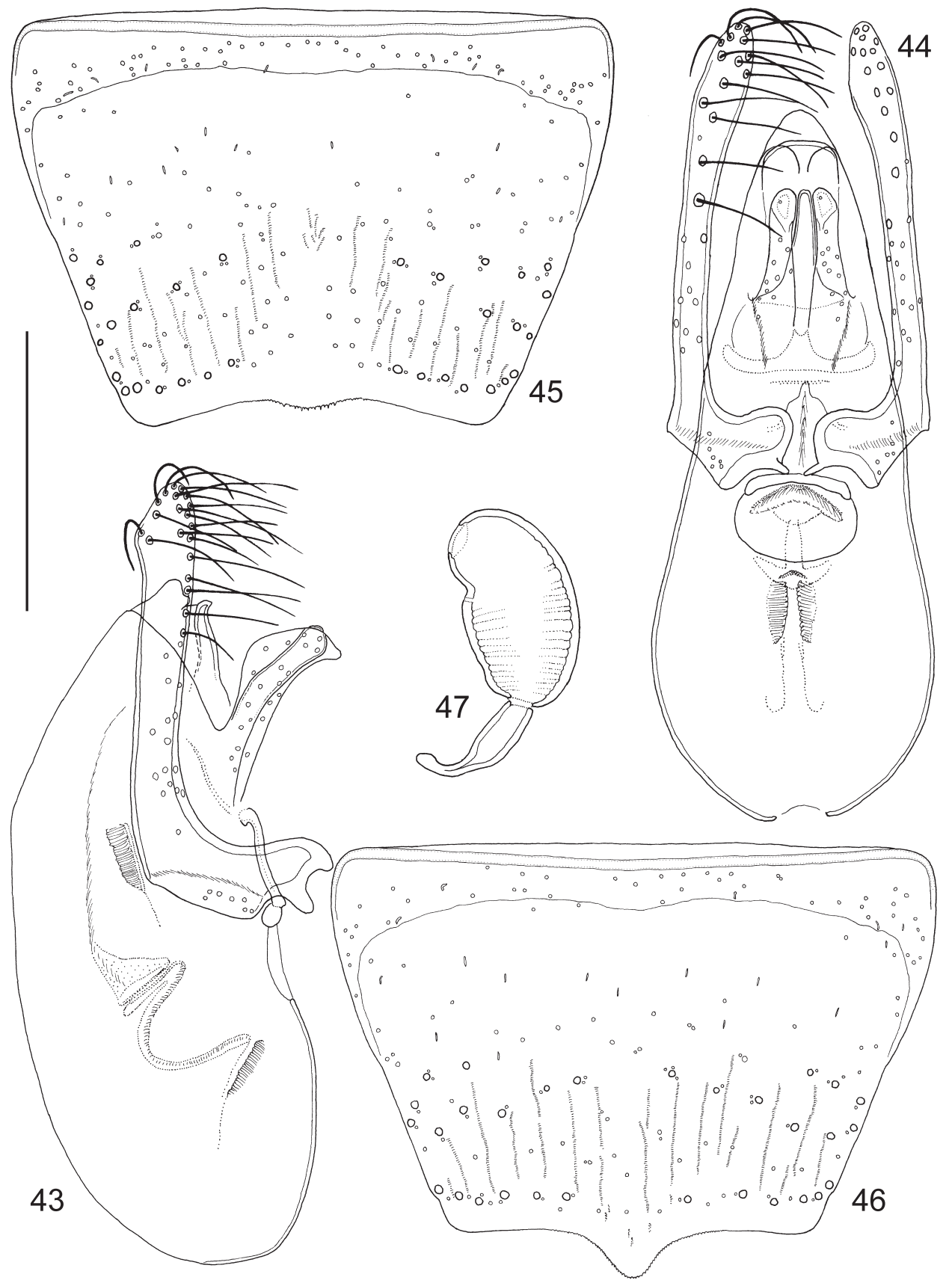

Figs 43-47. Paraploderus rufescens sp. n. $43=$ aedeagus, lateral view, $44=$ aedeagus, frontal view (parameral setation shown on left), 45 = sternite VIII, male, 46 = sternite VIII, female, 47 = spermatheca. Scales: $0.1 \mathrm{~mm}$ for Fig. 47, $0.13 \mathrm{~mm}$ for Figs 43-44, 0.24 mm for Figs 45-46. 
Etymology - Named after the distinctive orangish-reddish colouration of the pronotum and elytra.

Remarks - This is currently the only species for which a larva is known. In the vial that is associated by a dry-mounted voucher specimen there were three larvae and an adult Paraploderus rufescens in ethanol; the three larval specimens are placed in individual vials and identified according to their treatments in this article.

\section{Paraploderus wittei sp. $\mathrm{n}$.}

(Figs 1-9, 48-52, 91)

Type material - Holotype (ð): D. R. CONGO: Parc National Upemba, Mabwe [rive Est du lac Upemba, 08³9`S, 26³1'E], 585 m, 6.III.1949, leg. G.F. De Witte (2417) tamisage humus humide (MRAC); Paratypes (28): same data as holotype (13, MRAC, 7, BMNH, 1, FMNH, 1, NHMW, 1, CNCI, 1, SMNS, 1, MHNG, 1 q, ISNB, 1, AMNH, 1, HNHM).

Description - Measurements (in $\mathrm{mm}, \mathrm{n}=10)$ : $\mathrm{EW}=0.55(0.51-0.59) ; \mathrm{TW}=0.51(0.46-$ $0.55) ; \mathrm{PW}=0.55(0.51-0.58) ; \mathrm{SW}=0.61(0.56-0.66) ; \mathrm{AW}=0.69(0.64-0.74) ; \mathrm{HL}=0.34(0.32-$ $0.37) ; \mathrm{EL}=0.15(0.14-0.16) ; \mathrm{TL}=0.09(0.08-0.10) ; \mathrm{PL}=0.38(0.35-0.40) ; \mathrm{SL}=0.58(0.54-0.63)$; $\mathrm{SC}=0.54(0.50-0.59) ; \mathrm{FB}=1.36(1.26-1.46) ; \mathrm{BL}=2.72$ (2.46-3.00). Habitus as in Fig. 91. Body almost unicolorous dark brown, head darker, blackish but clypeus lighter. Legs, antennae and mouthparts medium brown, middle of antenna sometimes darker, apices of mandibles infuscate. Epistomal suture and basal ridges of tergites marked as thin blackish line. Head transverse with rounded temples significantly narrower than eyes. Clypeus almost unpunctured, only feeble traces of microsculpture and unevenness laterally on surface. Epistomal suture posterior to imaginary line connecting supraantennal prominences. Medial portion of occipital groove more or less straight, neck medially shiny, laterally with traces of coriaceous microsculpture with isodiametric cells. Middle of vertex unpunctured; punctation confined to grooves and near temples, postocular ridge thin and inconspicuous. Faint longitudinal impressions running on both sides of vertex from epistomal suture to occipital groove, becoming more marked posteriorly. Head surface otherwise shiny, without microsculpture. Pronotum with complete, thin marginal bead. Surface shiny, without any microsculpture but much more strongly punctured than head, indefinite-bordered, mostly rather large pits (slightly umbilicate) almost everywhere on surface except along midline and narrowly along posterior margin. Longitudinal midline marked in posterior $1 / 2$. On both sides of midline middle of disc strongly impressed to the middle of sides. Elytra with disc more or less flat, two very thin and shallow longitudinal impressions along suture behind scutellum, anterior half of disc gently impressed in middle. Epipleural ridge present on almost entire length. Thin marginal bead with obscure connection to epipleural ridge continuing along posterior margin, not reaching sutural corner, slightly curving anteriorly before it. Along suture very fine marginal bead only conspicuous because of darker colour. Elytral punctation mostly rather shallow, but not obscured by other sculpture, more or less equally spaced, moderately sparse, missing on a thin, slightly elevated stripe along suture. Abdomen shiny and smooth with only tiny insertion points of setae and extremely faint coriaceous microsculpture with isodiametric cells. Male sternite VIII as in Fig. 50, aedeagus as in Figs 48-49, female sternite VIII as in Fig. 51, spermatheca as in Fig. 52. 


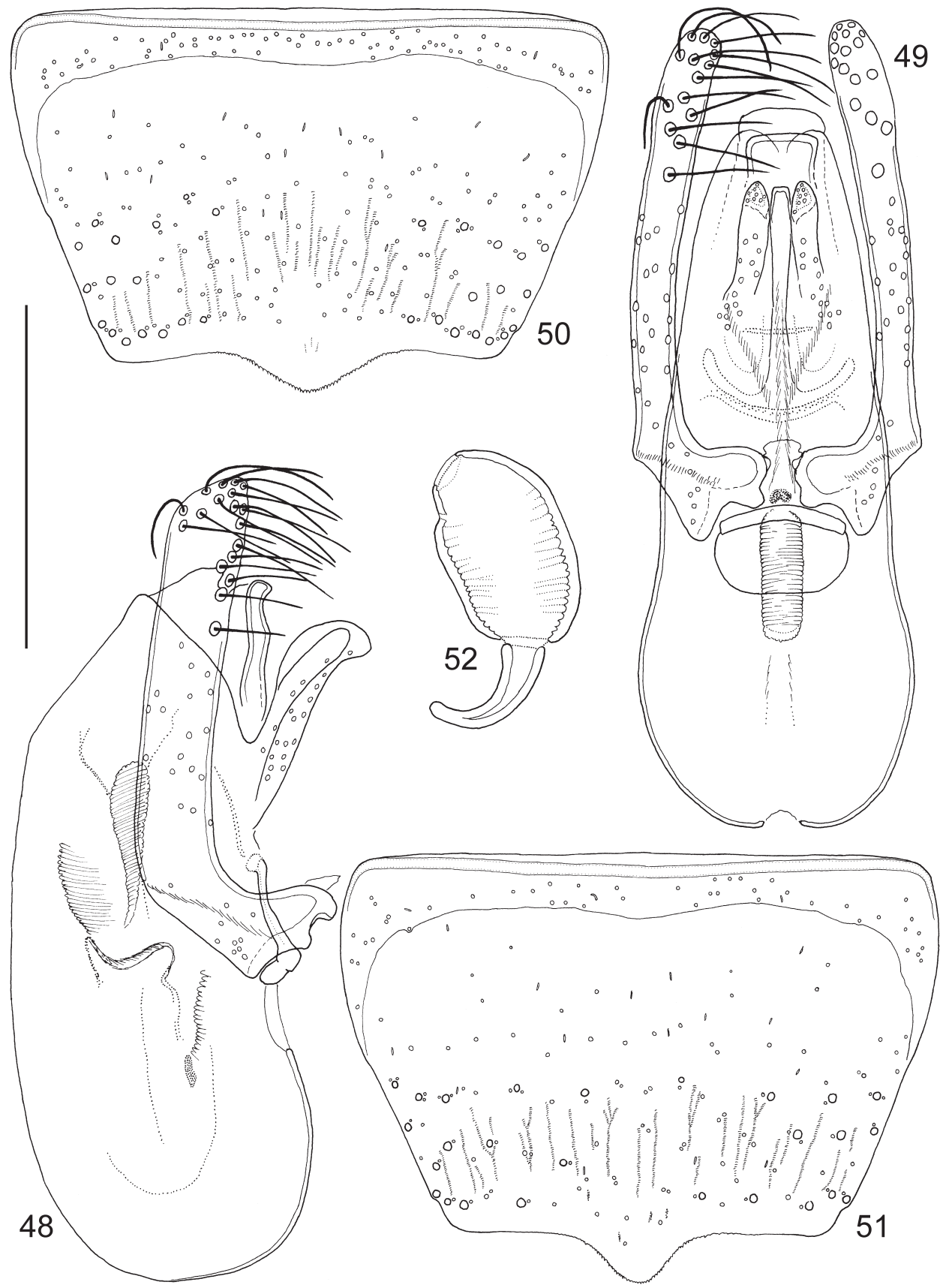

Figs 48-52. Paraploderus wittei sp. n. 48 = aedeagus, lateral view, $49=$ aedeagus, frontal view (parameral setation shown on left), 50 = sternite VIII, male, 51 = sternite VIII, female, $52=$ spermatheca. Scales: $0.1 \mathrm{~mm}$ for Fig. 52, $0.135 \mathrm{~mm}$ for Figs 48-49, $0.27 \mathrm{~mm}$ for Figs 50-51. 
Distribution - The species is known from only one locality in the D.R. Congo.

Etymology - Named after Gaston-François de Witte (1897-1980), ichtyologist and herpetologist who worked both in MRAC and ISNB, and was head of the scientific section in the Institution of National Parks in Belgian Congo in 1937-1951.

Remarks - The original material contained a fragmentary 'paratype' which was cleared and mounted on microscopic slide; the illustration plates with mouthparts and general (head, pronotum) morphology are based on this specimen, but the specimen of Paraploderus grandis used in the phylogenetic analysis (MAKRANCZY 2006), was also checked (only sketches made).

\section{ORIENTAL SPECIES}

\section{Paraploderus fauveli sp. n. \\ (Figs 53-57, 99)}

Type material - Holotype (đ̊): INDONESIA: Lombok, Aik Bukkak, 780 m [8³0’20”S $\left.116^{\circ} 20^{\prime} 41^{\prime \prime} \mathrm{E}\right], 10 . \mathrm{III} .1991$, leg. D. Agosti (2), secondary forest without any tall trees, clay soil (MHNG); Paratypes (8): same data as holotype (1, MHNG, 1 ते, NHMW, 1, NIBR); Lombok, Gn. Rinjani, 1000 m [8¹9'50”S, 116²4'03"E] (F91562), 16.III.1991, leg. D. Agosti, montane forest, at the base of a Ficus sp., with high infection of Mycorrhiza in a thick leaf litter

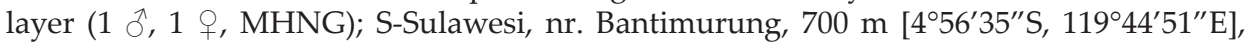
9-12.V.1997, leg. S. Kurbatov (1, MHNG); “Lecto-; type [lilac margined disc, curator label] $\backslash$ Bandoeng; [W-]Java \speculiventris; Fvl. \Coll. et det. A. Fauvel; Haploderus; speculiventris; Fauv.; R.I.Sc.N.B. $17.479 \backslash$ G. Fagel det., 19; Trogophloeopsis; gen. nov. m. in litt. \Syntype \Haploderus; speculiventris Fvl.; P.M. Hammond; det. 1972; Lectotype q" (1 +, ISNB); "Para-; lecto-; type [light blue margined disc, curator label] \ Palembang [02 59'10"S, $104^{\circ} 45^{\prime} 20^{\prime \prime}$ E]; Sumatra \Coll. et det. A. Fauvel; Haploderus; speculiventris; Fauv.; R.I.Sc.N.B. $17.479 \backslash$ G. Fagel det., 19; Trogophloeopsis; gen. nov. m. in litt. \Syntype $\backslash$ Haploderus; speculiventris Fvl.; P.M. Hammond; det. 1972; Paralectotype $\emptyset^{\prime \prime}(1$, ISNB).

Description - Measurements (in mm, $\mathrm{n}=9)$ : $\mathrm{EW}=0.51(0.47-0.54)$; $\mathrm{TW}=0.51(0.46-$ $0.55) ; \mathrm{PW}=0.56(0.52-0.60) ; \mathrm{SW}=0.59(0.55-0.62) ; \mathrm{AW}=0.70(0.64-0.74) ; \mathrm{HL}=0.34$ (0.31$0.36) ; \mathrm{EL}=0.115(0.11-0.12) ; \mathrm{TL}=0.11(0.10-0.13) ; \mathrm{PL}=0.38(0.37-0.40) ; \mathrm{SL}=0.54(0.50-0.57)$; $\mathrm{SC}=0.50(0.46-0.53) ; \mathrm{FB}=1.31(1.22-1.36) ; \mathrm{BL}=2.60$ (2.36-2.82). Habitus as in Fig. 99. Body more or less unicolorous reddish medium brown, head sometimes slightly darker than rest. Legs, mouthparts and antennae medium to light brown. Impressed lines laterally bordering clypeus blackish, apices of mandibles often darker, infuscate. Head transverse with rounded, bulging temples just slightly wider than eyes. Clypeus appears almost impunctate, with a thin anterior rim also on sides, almost no traces of microsculpture, smooth and shiny. Epistomal suture very gently curving posteriorly, slightly posterior to imaginary line connecting supraantennal prominences. Medial portion of occipital groove more or less straight, neck medially shinier but generally with slight coriaceous microsculpture with slightly transverse cells. Vertex with more dense punctation only in depressed parts, elevated areas with loosened punctation. Head rather shiny; smaller punctures plus ruggedness on lateral parts and temples obscuring postocular ridge. Faint longitudinal 


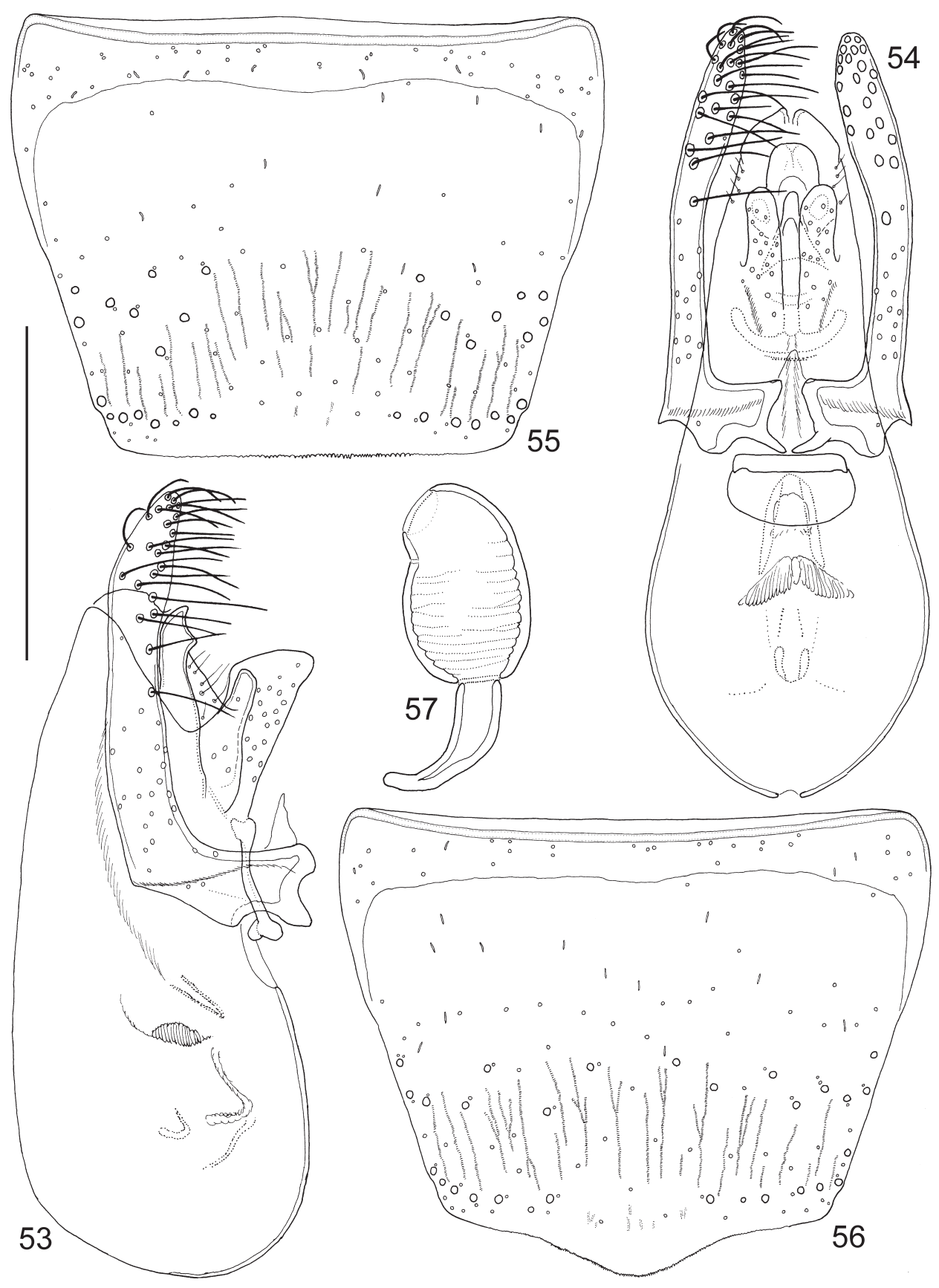

Figs 53-57. Paraploderus fauveli sp. n. 53 = aedeagus, lateral view, $54=$ aedeagus, frontal view (parameral setation shown on left), 55 = sternite VIII, male, 56 = sternite VIII, female, 57 = spermatheca. Scales: $0.1 \mathrm{~mm}$ for Fig. 57, $0.15 \mathrm{~mm}$ for Figs 53-54, 0.25 mm for Figs 55-56. 
impressions running on both sides of vertex from epistomal suture to occipital groove, becoming more marked posteriorly. Head surface otherwise shiny, without microsculpture. Pronotum with complete, thin marginal bead. Surface shiny, without any microsculpture. Punctures greatly vary in size and distinctness, sometimes slightly umbilicate, almost everywhere on surface except along midline and posterior margin. Longitudinal midline marked in posterior $1 / 2$. On both sides of midline middle of disc strongly impressed to the anterior $2 / 5$ of sides. Elytra with disc almost flat, two very thin and shallow longitudinal impressions along suture behind scutellum, anterior half of disc very gently impressed. Epipleural ridge present on almost entire length. Thin marginal bead with obscure connection to epipleural ridge continuing along posterior margin, not reaching sutural corner, slightly broadening before it. Along suture very fine marginal bead only conspicuous because of darker colour. Elytral punctation more shallow than punctate parts of pronotum, density similar (average interspaces slightly larger than puncture diameters) and more equally spaced. Abdomen shiny and smooth with only tiny insertion points of setae and no traces of microsculpture. Male sternite VIII as in Fig. 55, aedeagus as in Figs 53-54, female sternite VIII as in Fig. 56, spermatheca as in Fig. 57.

Distribution - The species has a remarkably wide distribution range within the Indonesian islands, currently known from Lombok, Sulawesi, Java and Sumatra.

Etymology - Named after C. A. Albert Fauvel (1840-1921), one of the giants of descriptive studies on Staphylinidae, who published the oldest species name in this genus.

Remarks - External morphology exhibits enormous variation. A nonconspecific syntype of Trogophloeus oxyteloides (without head) exists with labels: "Sebesi [0556’S, 105³0’E]; IV. 1921; Damm.[erman] \Trogophloeus; oxyteloides Cam \ paratype! [Cameron's handwriting] \ Paratype [printed on red card]" (RMNH). This fragmentary specimen cannot be identified with certainity, but at this point seems likely to be $P$. fauveli.

\section{Paraploderus goergesae sp. $\mathrm{n}$.}

(Figs 58-62, 93)

Type material - Holotype (ठ): INDONESIA: Moluccas/Maluku prov., Kai Islands, Kai Besar, kampung Bombai (E of Elat), Gunung Tukrau, 300 m [5³7'41"S, 13302'32"E] (F911074), 7.IX.1991, leg. D. Agosti (8), leaf litter, secondary forest on limestone (MHNG); Paratypes (83): same data as holotype (29, MHNG, 1, FMNH, 1, SDEI, 1, NMPC, 1, ZMHB, 1, NIBR, 1, NHMW, 1, BMNH, 1, MNHP, 1, CNCI, 1, AMNH, 1, ISNB, 1, HNHM); Moluccas/Maluku prov., Aru Islands, Wokam (Tanahbesar), $5 \mathrm{~km}$ E mouth of Sungai Tungu-

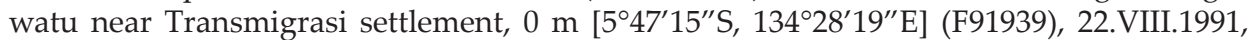
leg. D. Agosti (1), primary forest on limestone, leaf litter $(7,1 \hat{\jmath}, 1+9$, MHNG); Moluccas/ Maluku prov., Aru Islands, Kola isl. Wafan, 20 m (F91969), 27.VIII.1991, leg. D. Agosti (2), secondary forest, limestone (1, MHNG); Moluccas/Maluku prov., Aru Islands, Wohan isl., Bardefan, 50 m (F91979), 28.VIII.1991, leg. D. Agosti (3), rainforest on limestone, leaf litter (2, MHNG); Moluccas/Maluku prov., Kai Islands, Kai Besar, kampung Bombai (E of Elat), Gunung Dab, 300-480 m [5³9'10"S, 13301'28”E] (F911018), 3.IX.1991, leg. D. Agosti 
(4), limestone, secondary moist forest, leaf litter (3, 1 , MHNG); Moluccas/Maluku prov., Kai Islands, Kai Besar, kampung Bombai (E of Elat), Gunung Dab, 300-480 m (F911019), 3.IX.1991, leg. D. Agosti, leaf litter (1, HNHM); Moluccas/Maluku prov., Kai Islands, Kai Besar, kampung Bombai (E of Elat), Gunung Tukrau, south face, 300-400 m (F911034), 4.IX.1991, leg. D. Agosti (5), secondary moist forest on limestone, leaf litter (12, MHNG); Moluccas/Maluku prov., Kai Islands, Kai Besar, kampung Bombai (E of Elat), Gunung Dab, south face, $300 \mathrm{~m}$ (F911047), 5.IX.1991, leg. D. Agosti (6), secondary forest on limestone, leaf litter (10, MHNG, 1, HNHM); PAPUA NEW GUINEA: West Sepik prov., Vanimo, Denakerange, km 12, $500 \mathrm{~m}\left[2^{\circ} 44^{\prime} 58^{\prime \prime} \mathrm{S}, 141^{\circ} 14^{\prime} 54^{\prime \prime} \mathrm{E}\right], 28-29 . X .1992$, leg. A. Riedel (25B), roadside forest, sifting (1 $\overbrace{}^{\wedge}, \mathrm{SMNS})$.

Description - Measurements (in mm, $\mathrm{n}=10)$ : $\mathrm{EW}=0.44(0.42-0.46) ; \mathrm{TW}=0.46(0.43-$ $0.48) ; \mathrm{PW}=0.49$ (0.46-0.515); $\mathrm{SW}=0.51(0.47-0.54) ; \mathrm{AW}=0.63(0.60-0.66) ; \mathrm{HL}=0.30(0.27-$ $0.32) ; \mathrm{EL}=0.10(0.09-0.11) ; \mathrm{TL}=0.11(0.10-0.12) ; \mathrm{PL}=0.33(0.30-0.34) ; \mathrm{SL}=0.46(0.42-0.48)$; $\mathrm{SC}=0.42(0.38-0.44) ; \mathrm{FB}=1.14(1.04-1.21) ; \mathrm{BL}=2.02(1.78-2.30)$. Habitus as in Fig. 93. Whole body medium brown but head somewhat darker, epistomal suture dark brown, mandibles infuscate. Elytra sometimes a shade darker than pronotum, darker basal ridges of tergites not as consicuous as in other species. Basal antennomeres sometimes lighter than rest of antennal articles. Head transverse with rounded, bulging temples just slightly wider than eyes. Clypeus with very scattered, minute punctures only, with a thin anterior rim also on sides, only feeble traces of microsculpture and unevenness laterally on surface. Epistomal suture between tips of supraantennal prominences or only a little behind imaginary line connecting them. Medial portion of occipital groove bending anteriorly, neck medially shiny, laterally with traces of coriaceous microsculpture with isodiametric cells. Vertex with very scattered, indefinite-bordered and variously sized punctures; punctation near temples much denser and obscures postocular ridge. Faint longitudinal impressions running on both sides of vertex from epistomal suture to occipital groove, becoming more marked posteriorly. Head surface otherwise shiny, without microsculpture. Pronotum with complete, thin marginal bead. Surface shiny, without any microsculpture but more strongly punctured than head, indefinite-bordered, rather large pits equally distributed on surface except slightly impressed midline and two thin stripes along it plus narrowly along posterior margin. Longitudinal midline unmarked in colour. On both sides of midline centre of disc strongly impressed. Elytra with disc almost flat, with two thin longitudinal impressions extending along suture behind scutellum, anterior half of disc very gently impressed in middle. Epipleural ridge present on almost entire length. Thin marginal bead with obscure connection to epipleural ridge continuing along posterior margin, not reaching sutural corner, slightly curving anteriorly before it. Along suture very fine marginal bead only conspicuous because of darker colour. Elytral punctation mostly rather shallow, obscured by uneven surface, more or less equally spaced, moderately sparse, missing on a thin, slightly elevated stripe along suture. Abdomen shiny and smooth with only tiny insertion points of setae and extremely faint coriaceous microsculpture with isodiametric cells. Male sternite VIII as in Fig. 60, aedeagus as in Figs 58-59, female sternite VIII as in Fig. 61, spermatheca as in Fig. 62.

Distribution - The species is known from the Moluccas (Indonesia) and New Guinea. Since the latter record is very close to the arbitrarily drawn border of Irian Jaya, which is also the chosen border of zoogeographical regions, it is not considered to be an Australian species. 


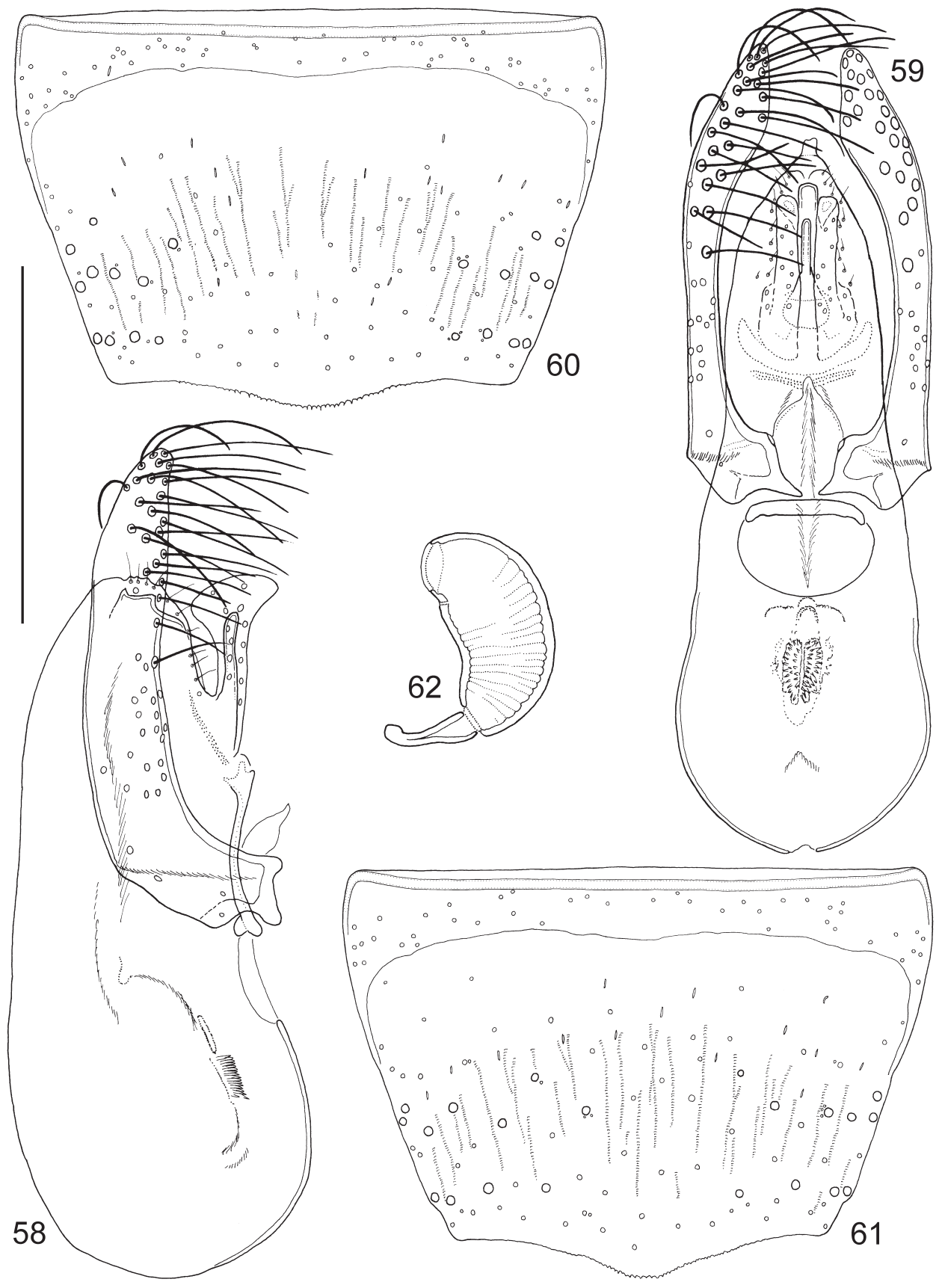

Figs 58-62. Paraploderus goergesae sp. n. $58=$ aedeagus, lateral view, $59=$ aedeagus, frontal view (parameral setation shown on left), 60 = sternite VIII, male, 61 = sternite VIII, female, 62 = spermatheca. Scales: $0.1 \mathrm{~mm}$ for Fig. 62, $0.13 \mathrm{~mm}$ for Figs 58-59, $0.25 \mathrm{~mm}$ for Figs 60-61. 
Etymology - Named after tennis player Julia Görges. I found her to be the only watchable attraction on French and German language television (some 30 channels) during the two weeks I spent at the Muséum d'histoire naturelle in Geneva. This new species was found on the same day (10 October 2012) when I saw the broadcast of her second match in Linz.

Remarks - This is the smallest known Oriental species of the genus.

\section{Paraploderus hammondi sp. $\mathrm{n}$.}

(Figs 63-67, 100)

Type material - Holotype (ठ): INDIA: Madras [= Tamil Nadu], Nilgiri, Coonoor, $1600 \mathrm{~m}\left[11^{\circ} 20^{\prime} 09^{\prime \prime} \mathrm{N}, 7^{\circ} 48^{\prime} 00^{\prime \prime} \mathrm{E}\right], 22 . X \mathrm{I} .1972$, leg. C. Besuchet, I. Löbl, R. Mussard (43), tamisages dans la forêt en dessous de la ville (MHNG); Paratypes (86): Kerala, Thekkady,

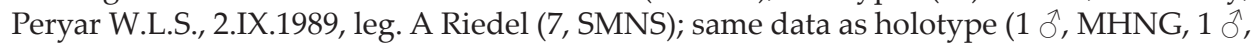
NHMW); Madras [= Tamil Nadu], Anaimalai Hills, $18 \mathrm{~km} \mathrm{~N}$ Valparai, $1250 \mathrm{~m}$ [10 $24^{\prime} 48^{\prime \prime} \mathrm{N}$, 7657'03"E], 18.XI.1972, leg. C. Besuchet, I. Löbl, R. Mussard (35), tamisages en forêt (1 ㅇ, MHNG), Kerala, Cardamom Hills, 5 km à l'ouest [W] de Kumily, 1000 m [9 $37^{\prime} 22^{\prime \prime} \mathrm{N}$, 7706'58"E], 6.XI.1972, leg. C. Besuchet, I. Löbl, R. Mussard (12), tamisages en forêt (1, MHNG); Kerala, Cardamom Hills, entre Pambanar et Peermade, 950 m [9 $34^{\prime} 35^{\prime \prime} \mathrm{N}$, 7701'21"E], 5.XI.1972, leg. C. Besuchet, I. Löbl, R. Mussard (11), tamisages en forêt, près d'une rivière (1, MHNG), same but 9.XI.1972 (18) (1, MHNG); Tamil Nadu, Anaimalai Hills, 700-1000 m, 17.I.1972, leg. R. Mussard (4) (2, MHNG, 1, FMNH); Tamil Nadu, Kodaikanal, 1200 m, 10.I.1972, leg. R. Mussard (1) (20, MHNG, 1, NIBR), same but (6) (53, MHNG, 1, BMNH, 1, AMNH).

Redescription - Measurements (in $\mathrm{mm}, \mathrm{n}=10$ ): $\mathrm{EW}=0.60(0.555-0.65) ; \mathrm{TW}=0.60$ (0.54-0.65); $\mathrm{PW}=0.63$ (0.58-0.68); $\mathrm{SW}=0.68$ (0.62-0.75); $\mathrm{AW}=0.75(0.67-0.83) ; \mathrm{HL}=0.39$ (0.36-0.43); $\mathrm{EL}=0.13(0.12-0.14) ; \mathrm{TL}=0.14(0.125-0.16) ; \mathrm{PL}=0.41(0.37-0.45) ; \mathrm{SL}=0.62$ $(0.56-0.67) ; \mathrm{SC}=0.58(0.52-0.62) ; \mathrm{FB}=1.49(1.36-1.60) ; \mathrm{BL}=3.02(2.58-3.43)$. Habitus as in Fig. 100. Body more or less unicolorous reddish medium brown, head sometimes slightly darker than rest, elytra a little lighter than pronotum, abdomen usually the same colour as elytra. Legs, mouthparts and antennae medium to light brown. Impressed parts on head and apices of mandibles often darker, infuscate. Head transverse with rounded, bulging temples just slightly wider than eyes. Clypeus appears impunctate, with a thin anterior rim also on sides, almost no traces of microsculpture, smooth and shiny. Epistomal suture posterior to imaginary line connecting supraantennal prominences. Medial portion of occipital groove more or less straight, neck medially often shiny, laterally with traces of coriaceous microsculpture with isodiametric cells. Vertex with very few punctures (or traces of them), almost totally shiny; variously sized (mostly small) punctures on lateral parts and temples obscuring postocular ridge. Faint longitudinal impressions running on both sides of vertex from epistomal suture to occipital groove, becoming more marked posteriorly. Head surface otherwise shiny, without microsculpture. Pronotum with complete, thin marginal bead. Surface shiny, without any microsculpture but much more strongly punctured than head, indefinite-bordered, mostly rather large pits (slightly umbilicate) almost everywhere on surface except along midline and along posterior and anterior margins. Longitudinal midline marked in posterior $1 / 2$. On both sides of midline middle of disc strongly impressed to the anterior $1 / 3$ of sides. Elytra with disc almost flat, two very thin and shallow longitudinal impressions along suture behind scutellum, anterior half of disc very gen- 


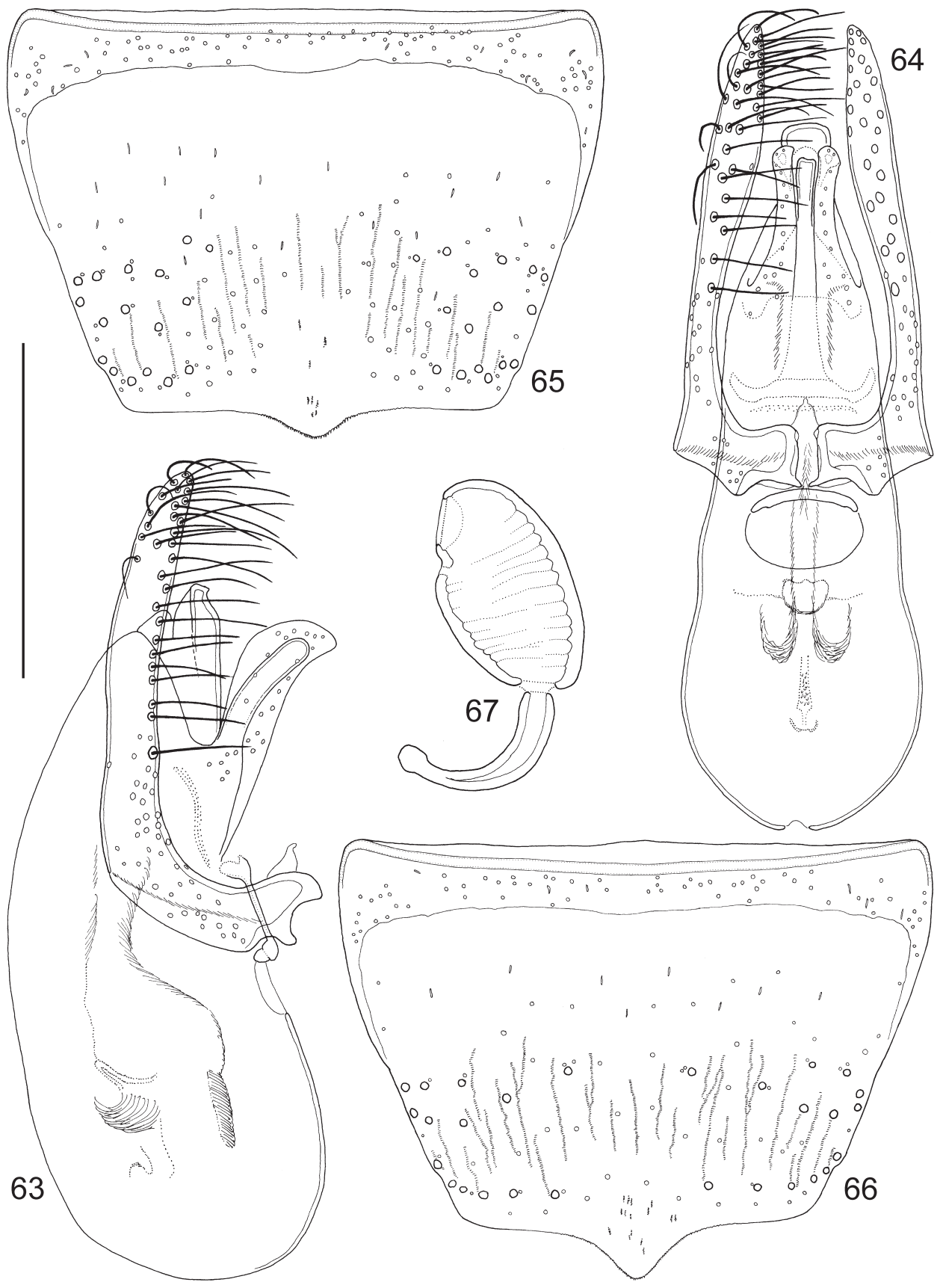

Figs 63-67. Paraploderus hammondi sp. n. 63 = aedeagus, lateral view, 64 = aedeagus, frontal view (parameral setation shown on left), 65 = sternite VIII, male, 66 = sternite VIII, female, 67 = spermatheca. Scales: $0.1 \mathrm{~mm}$ for Fig. 67, $0.165 \mathrm{~mm}$ for Figs 63-64, $0.3 \mathrm{~mm}$ for Figs 65-66. 
tly impressed. Epipleural ridge present on almost entire length. Thin marginal bead with obscure connection to epipleural ridge continuing along posterior margin, not reaching sutural corner, slightly curving anteriorly before it. Along suture very fine marginal bead only conspicuous because of darker colour. Elytral punctation similar to more punctate parts of pronotum, rather coarse and equally spaced, dense (interspaces about equal to puncture diameters). Abdomen shiny and smooth with only tiny insertion points of setae and no traces of microsculpture. Male sternite VIII as in Fig. 65, aedeagus as in Figs 63-64, female sternite VIII as in Fig. 66, spermatheca as in Fig. 67.

Distribution - The species is currently only known from southern India.

Etymology - Named after Peter M. Hammond who started this project many decades ago; he also recognized this species to be undescribed, evidenced by his handwritten note on one of the type specimens ("Paraploderus; sp. n.") without date.

Remarks - Most of the paratypes are heavily discoloured, appear to be dark brown to black, most likely a preservation artifact.

\section{Paraploderus loebli sp. $n$.}

(Figs 68-72, 101)

Type material - Holotype (ð): INDIA: Garhwal (Uttar Pradesh)[=Uttarakhand] La-

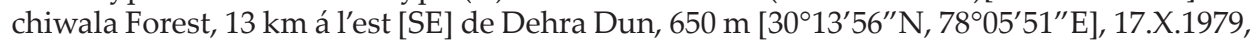
leg. I. Löbl (13), accumulation de feuilles et branches mortes dans un ravin (MHNG); Paratypes (20): same data as holotype (1 $\delta^{2}, 2$ ㅇ, 2, MHNG, 1, NHMW, 1, HNHM); THAILAND: Phetchaburi prov., Kaeng Krachan National Park, 25 à 30 km de „Headquarters“, 300-400 $\mathrm{m}\left[12^{\circ} 48^{\prime} 00^{\prime \prime} \mathrm{N}, 9^{\circ} 27^{\prime} 40^{\prime \prime} \mathrm{E}\right], 17 . X I .1985$, leg. D. Burckhardt \& I. Löbl (24), tamisage au pied de gros arbres $(1 \hat{\jmath}, 3$ q, 4, MHNG, $1 \hat{\jmath}, \mathrm{FMNH}, 1 \hat{\jmath}, \mathrm{NIBR}, 1, \mathrm{BMNH}, 1, \mathrm{AMNH})$; Phetchaburi prov., Kaeng Krachan National Park, à 30 km de "Headquarters", 450 m [1248'20"N, 99²5’30"E], 18.XI.1985, D. Burckhardt \& I. Löbl (25), tamisage au pied de gros arbres (1, MHNG).

Description - Measurements (in mm, $\mathrm{n}=10)$ : $\mathrm{EW}=0.53(0.51-0.555) ; \mathrm{TW}=0.53$ (0.50-0.555); $\mathrm{PW}=0.54(0.52-0.56) ; \mathrm{SW}=0.59(0.57-0.61) ; \mathrm{AW}=0.68(0.62-0.72) ; \mathrm{HL}=0.34$ (0.33-0.35); $\mathrm{EL}=0.13(0.12-0.14) ; \mathrm{TL}=0.115(0.105-0.12) ; \mathrm{PL}=0.36(0.35-0.38) ; \mathrm{SL}=0.55$ (0.52-0.58); $\mathrm{SC}=0.51(0.48-0.54) ; \mathrm{FB}=1.29(1.25-1.35) ; \mathrm{BL}=2.47(2.16-2.82)$. Habitus as in Fig. 101. Body more or less unicolorous medium brown or ochre, except scutellar area and anterior part of head somewhat darker. Legs, mouthparts and antennae light to medium brown or ochre, tips of femora very narrowly darker. Impressed parts on head and apices of mandibles often darker, infuscate. Head transverse with rounded, bulging temples about as wide as eyes. Clypeus with only scattered tiny punctures, with a thin anterior rim also on sides, only slight traces of microsculpture, smooth and shiny. Epistomal suture very gently curving posteriorly, slightly posterior to imaginary line connecting supraantennal prominences. Medial portion of occipital groove more or less straight, neck medially partly shiny, laterally with slight coriaceous microsculpture with isodiametric cells. Vertex with smaller but rather dense punctures, punctation more loosening on more elevated parts, almost totally shiny; small but dense punctures plus some ruggedness on lateral parts and temples obscuring postocular ridge. Faint longitudinal impressions running on both 


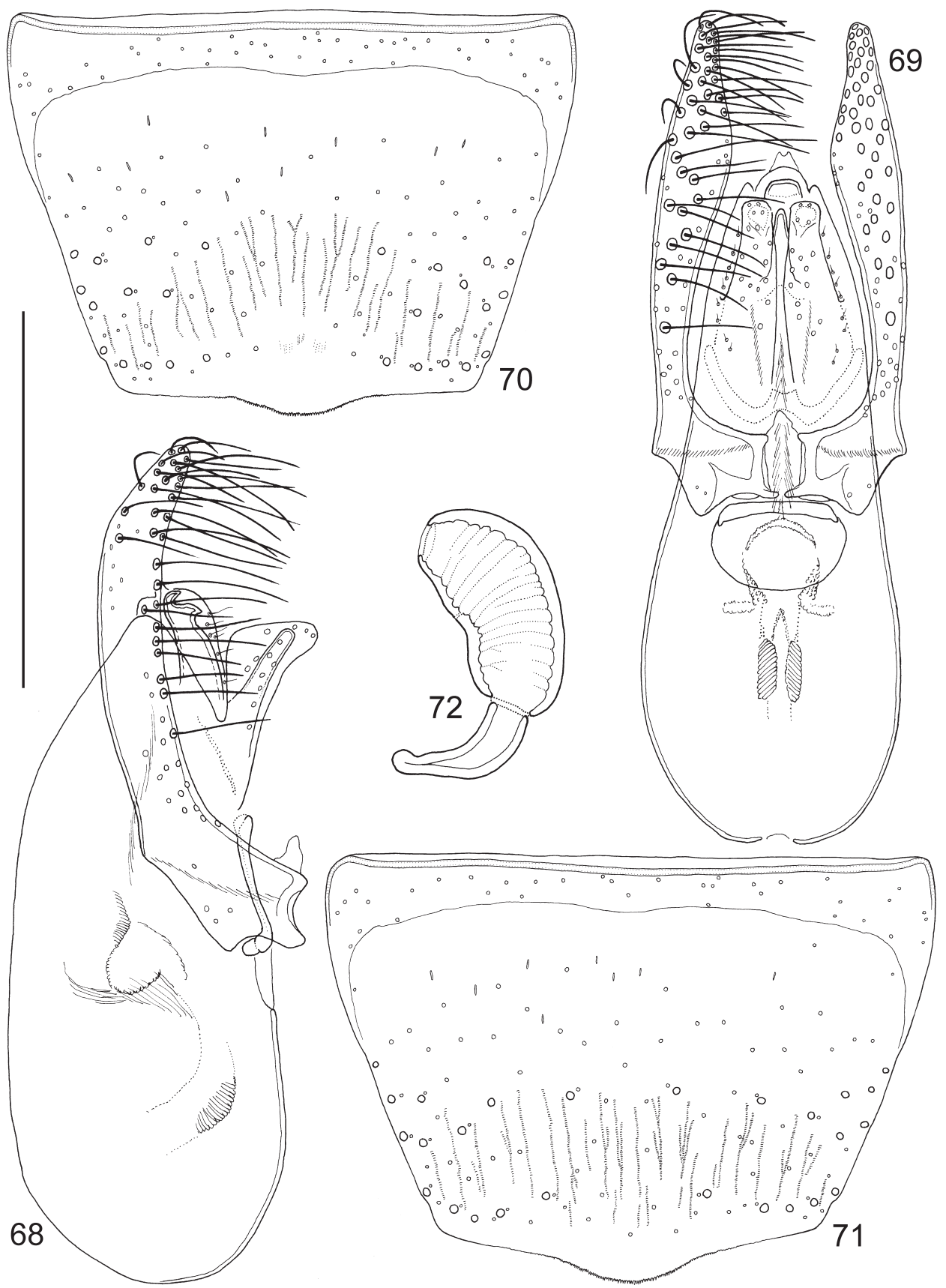

Figs 68-72. Paraploderus loebli sp. n. 68 = aedeagus, lateral view, $69=$ aedeagus, frontal view (parameral setation shown on left), $70=$ sternite VIII, male, 71 = sternite VIII, female, $72=$ spermatheca. Scales: $0.1 \mathrm{~mm}$ for Fig. 72, $0.15 \mathrm{~mm}$ for Figs 68-69, 0.3 mm for Figs 70-71. 
sides of vertex from epistomal suture to occipital groove, becoming more marked posteriorly. Head surface otherwise shiny, only slight traces of microsculpture. Pronotum with complete, thin marginal bead. Surface shiny, with only traces of microsculpture, punctation similar to that of head but more evenly sized and distributed covering almost entire surface; puncture more or less distinct-bordered, slightly umbilicate. Longitudinal midline marked in posterior $1 / 2$. On both sides of midline middle of disc strongly impressed to the anterior $1 / 3$ of sides. Elytra with disc almost flat, two very thin and shallow longitudinal impressions along suture behind scutellum, anterior half of disc inconspicuously impressed. Epipleural ridge present on almost entire length. Thin marginal bead with obscure connection to epipleural ridge continuing along posterior margin, almost reaching sutural corner, broadening and vanishing before it. Along suture very fine marginal bead marked mostly by puncture-free stripe. Elytral punctation similar to punctate parts of pronotum but more shallow, with punctures more indistinct-bordered, some surface unevenness and traces of microsculpture (average interspaces about equal to or slightly larger than puncture diameters). Abdomen shiny and smooth with only tiny insertion points of setae and extremely faint coriaceous microsculpture with isodiametric cells. Male sternite VIII as in Fig. 70, aedeagus as in Figs 68-69, female sternite VIII as in Fig. 71, spermatheca as in Fig. 72.

Distribution - The species is currently known from northern India (a disputed area that is more often treated under the Palaearctic rather than the Oriental region) and from Thailand (Phetchaburi prov.).

Etymology - Named after the collector of the holotype, Ivan Löbl (MHNG).

Remarks - The only other similarly sized Oriental congener has much shorter parameres, distributions do not seem to overlap with $P$. fauveli sp. $\mathrm{n}$.

\section{Paraploderus schwendingeri sp. $\mathrm{n}$.}

(Figs 73-77, 102)

Type material - Holotype (ð): INDONESIA: West Sumatra prov., Lake Maninjau, waterfall above Gasang, $720 \mathrm{~m}\left[0^{\circ} 17^{\prime} 10^{\prime \prime}\right.$ S, 100 $\left.14^{\prime} 10^{\prime \prime} \mathrm{E}\right]$, 9.II.2000, P. Schwendinger (Sum00/04) sifting forest soil at sides of stream below a small waterfall in patch of primary rain forest, Winkler extracted (MHNG); Paratypes (3): West Sumatra, Padangpanjan, 600 $\mathrm{m}\left[0^{\circ} 28^{\prime} 38^{\prime \prime} \mathrm{S}, 100^{\circ} 21^{\prime} 53^{\prime \prime} \mathrm{E}\right], 17 . X \mathrm{X} .1989$, leg. D. Agosti, I. Löbl \& D. Burckhardt (20), sifted rotten bamboos (1 $\left.\delta^{\lambda}, \mathrm{MHNG}\right)$; Aceh, Mt. Leuser National Park, Ketambe research station, 800 m [3³9‘51“N, 97³4‘40“E], 28.XI.1989, leg. D. Agosti, I. Löbl \& D. Burckhardt (26a), transition of lowland dipterocarp to lower montane Castanopsis-Lithocarpus forest, sifting of vegetational debris ( 1 , MHNG, 1, NIBR).

Description - Measurements (in mm, $\mathrm{n}=4)$ : EW $=0.59(0.51-0.61)$; $\mathrm{TW}=0.57(0.54-$ $0.59) ; \mathrm{PW}=0.65$ (0.63-0.68); $\mathrm{SW}=0.70(0.68-0.73) ; \mathrm{AW}=0.77(0.74-0.80) ; \mathrm{HL}=0.37(0.36-$ $0.38) ; \mathrm{EL}=0.135(0.13-0.14) ; \mathrm{TL}=0.11(0.10-0.12) ; \mathrm{PL}=0.44(0.43-0.45) ; \mathrm{SL}=0.62(0.60-0.66)$; $\mathrm{SC}=0.57(0.55-0.61) ; \mathrm{FB}=1.48(1.42-1.55) ; \mathrm{BL}=2.84(2.51-3.11)$. Habitus as in Fig. 102 . Head slightly reddish dark brown, pronotum reddish medium brown, elytra and abdomen more or less medium brown. Legs, mouthparts and antennae medium to light brown. Impressed lines laterally bordering clypeus blackish, apices of mandibles often darker, infuscate. Head transverse with rounded, slightly bulging temples not as wide as eyes. 


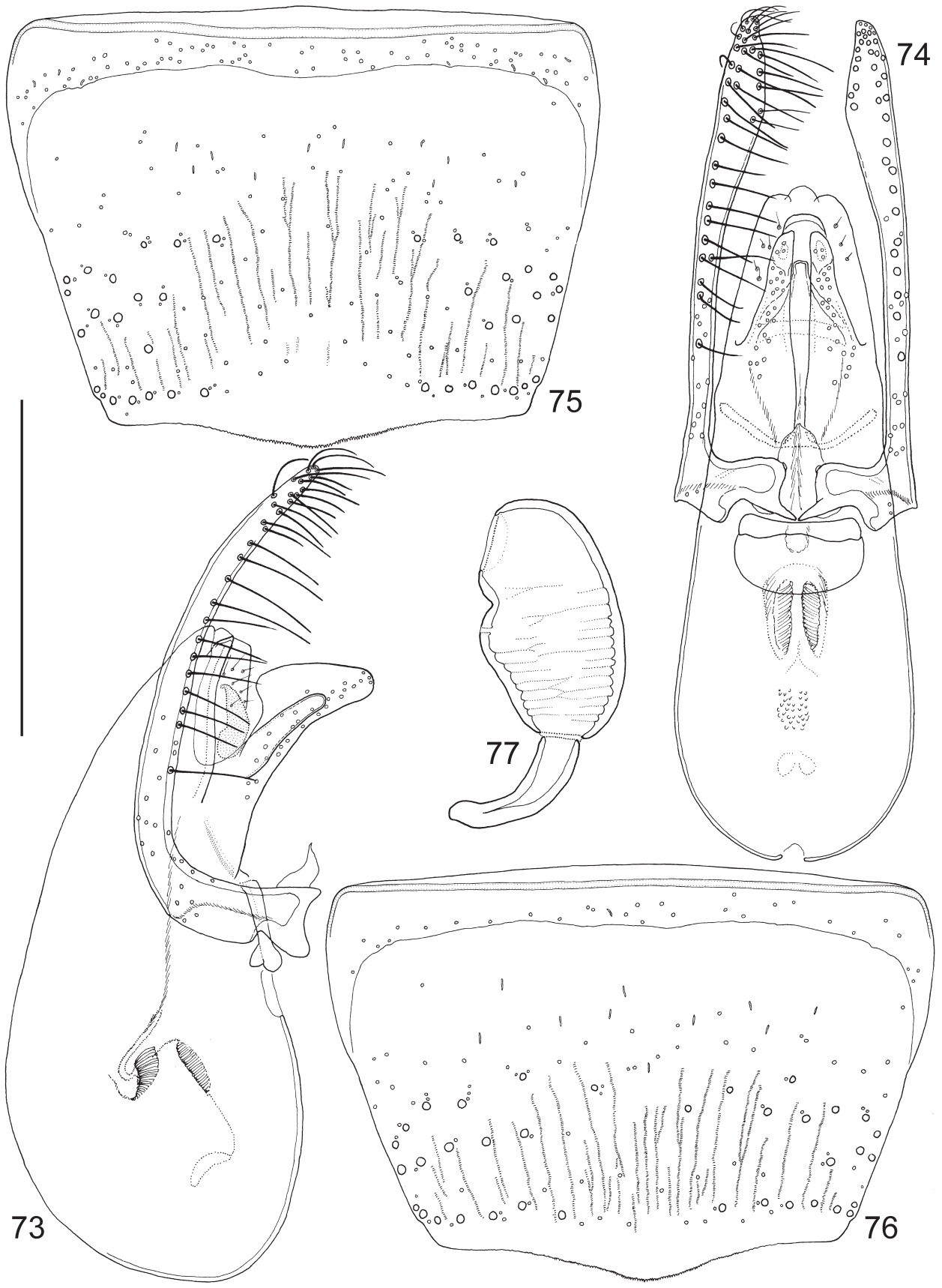

Figs 73-77. Paraploderus schwendingeri sp. n. $73=$ aedeagus, lateral view, $74=$ aedeagus, frontal view (parameral setation shown on left), $75=$ sternite VIII, male, $76=$ sternite VIII, female, 77 = spermatheca. Scales: $0.1 \mathrm{~mm}$ for Fig. 77, $0.22 \mathrm{~mm}$ for Figs 73-74, $0.3 \mathrm{~mm}$ for Figs 75-76. 
Clypeus appears almost impunctate (few tiny punctures anteriorly), with a thin anterior rim also on sides, almost no traces of microsculpture, smooth and shiny. Epistomal suture straight, roughly on imaginary line connecting supraantennal prominences. Medial portion of occipital groove almost straight (inconspicuously arching anteriorly), neck with coriaceous microsculpture (isodiametric cells). Vertex shiny without any punctures, only slight traces of them), almost totally shiny; a few smaller punctures on lateral parts and temples around postocular ridge. Faint longitudinal impressions running on both sides of vertex from epistomal suture to occipital groove, becoming rather marked posteriorly. Head surface otherwise shiny, without microsculpture. Pronotum with complete, thin marginal bead. Surface shiny, without any microsculpture but with some punctures, very shallow and scattered. Sometimes punctures more apparent and distinct in the impressed areas. Longitudinal midline marked in posterior $1 / 2$. On both sides of midline middle of disc strongly impressed to the anterior $2 / 5$ of sides. Elytra with disc almost flat, two very thin and shallow longitudinal impressions along suture behind scutellum, anterior half of disc very gently impressed in middle. Epipleural ridge present on almost entire length. Thin marginal bead with obscure connection to epipleural ridge continuing along posterior margin, not reaching sutural corner, slightly curving anteriorly before it. Along suture very fine marginal bead only conspicuous because of darker colour. Elytral punctation similar to more punctate parts of pronotum, somewhat more dense, still quite shallow, more or less equally spaced (interspaces about $2 \times$ puncture diameters) and obscured by surface unevenness. Abdomen shiny and smooth with only tiny insertion points of setae and no traces of microsculpture. Male sternite VIII as in Fig. 75, aedeagus as in Figs 73-74, female sternite VIII as in Fig. 76, spermatheca as in Fig. 77.

Distribution - The species is currently known from several localities on Sumatra (West Sumatra and Aceh provinces).

Etymology - The species in named after the collector of the holotype, arachnologist Peter Schwendinger (MHNG).

Remarks - The species has conspicuously small eyes and wide temples, and although these features appear to be rather variable, no other Oriental congener shares them in this size range.

\section{Paraploderus speculiventris (Fauvel, 1904)}

(Figs 83-87, 104)

Haploderus speculiventris FAuvel, 1904: 97.

Aploderus speculiventris Bernhauer \& Schubert, 1911: 109.

Trogophloeus oxyteloides Cameron, 1925: 175, syn. n.

Trogophloeus (Carpalimus) speculiventris CAMERON, 1928: 99.

Aploderus speculiventris SCHEERPELTz, 1933: 1093.

Paraploderus speculiventris Herman, 1970: 401, Herman, 2001: 1463.

Type material examined - (speculiventris) Lectotype ( $\delta$, here designated): “Para-; lecto-; type [light blue margined disc, curator label] \Bandoeng [06 $\left.55^{\prime} \mathrm{S}, 107^{\circ} 36^{\prime} \mathrm{E}\right]$; [W-] Java \Coll. et det. A. Fauvel; Haploderus; speculiventris; Fauv.; R.I.Sc.N.B. 17.479 \G. Fagel det., 19; Trogophloeopsis; gen. nov. m. in litt. \Syntype \Haploderus; speculiventris 

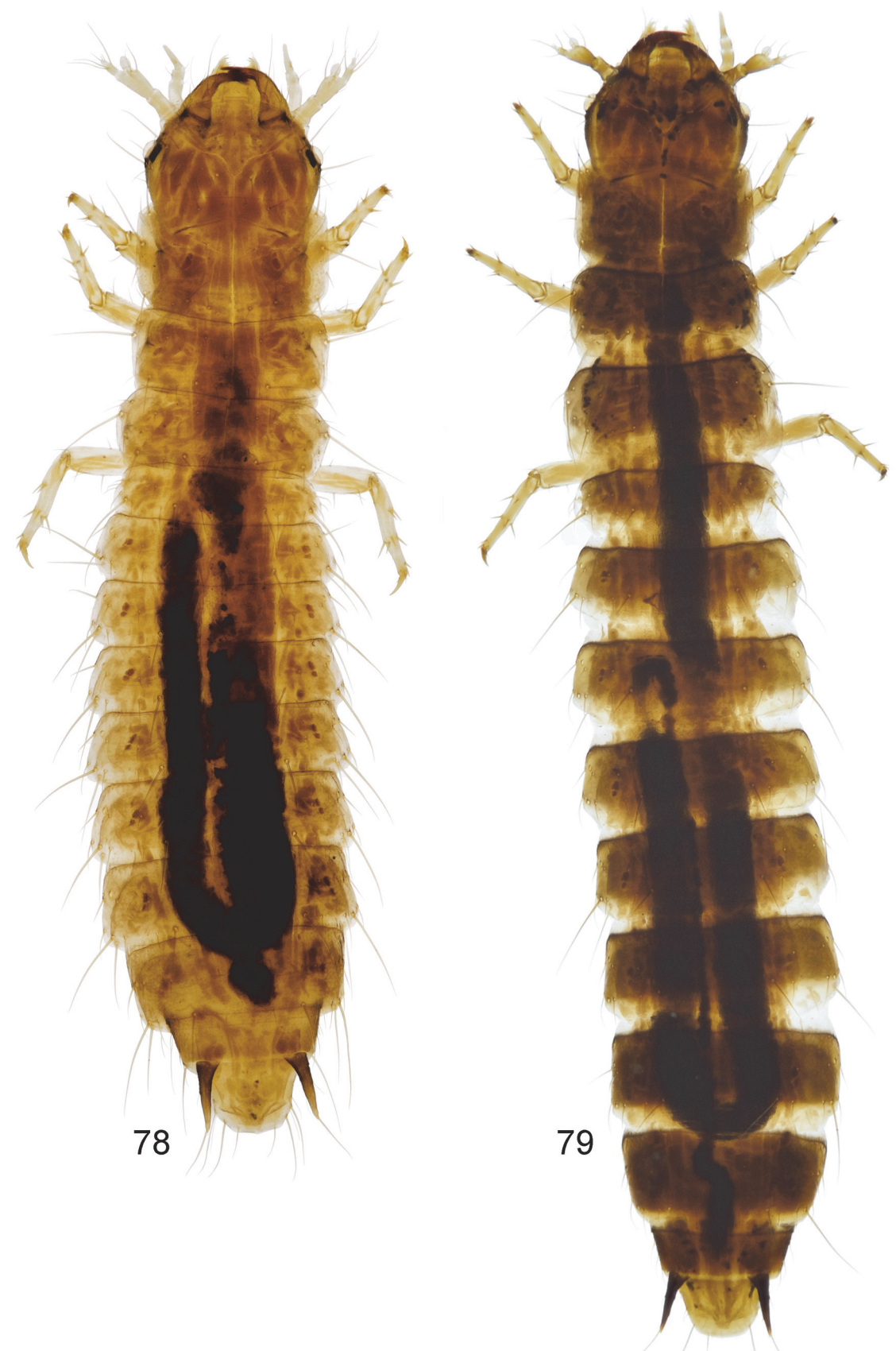

Figs 78-79. Habitus of Paraploderus rufescens sp. $\mathrm{n}$ larvae. $78=\mathrm{L}_{2}, 79=\mathrm{L}_{3}$. 


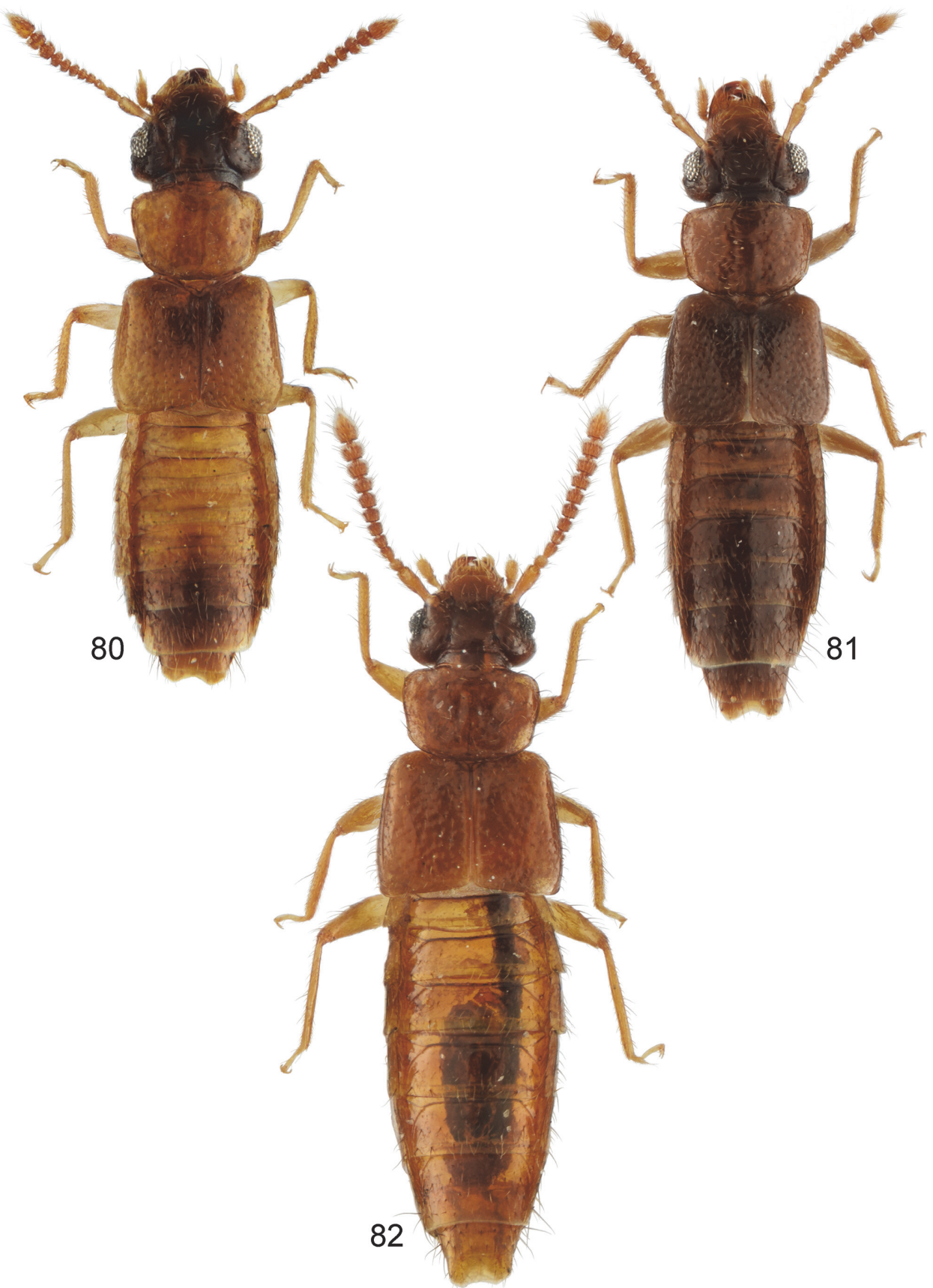

Figs 80-82. Habitus of Paraploderus species. $80=$ P. parcepunctus (Fauvel, 1905), $81=$ P. leleupi sp. n., $82=$ P. notabilis (Cameron, 1950). 
Fvl.; P.M. Hammond; det. 1972; Paralectotype $\widehat{\delta} \backslash$ Paraploderus; oxyteloides Cam.; P.M. Hammond; det. $1972 \backslash$ Lectotypus; Haploderus; speculiventris Fauvel; des. Makranczy, $2013 \backslash$ Paraploderus; speculiventris (Fauvel); det. Makranczy, 2013" (ISNB); Paralectotype (+): "Para-; lecto-; type [light blue margined disc, curator label] \Bandoeng; Java \Coll. et det. A. Fauvel; Haploderus; speculiventris; Fauv.; R.I.Sc.N.B. $17.479 \backslash$ G. Fagel det., 19; Trogophloeopsis; gen. nov. m. in litt. \Syntype \Haploderus; speculiventris Fvl.; P.M. Hammond; det. 1972; Paralectotype $q \backslash$ Paralectotypus; Haploderus; speculiventris Fauvel; des. Makranczy, 2013 \Paraploderus; speculiventris (Fauvel); det. Makranczy, 2013" (ISNB). (oxyteloides) Lectotype ( $\delta$, here designated): "Para-; lecto-; type [light blue margined disc, curator label] \ Co-; type [yellow margined disc, curator label] \[Indonesia, W-Java, Gunung] Tjibodas; 1400 M. [6³3’S, 106²0'E]; VIII. $1921 \backslash$ Trogophloeus; oxyteloides; Cam. \M. Cameron.; Bequest.; B.M. 1955-147. \ Trogophloeus; oxyteloides Cam.; P.M. Hammond; det. 1971 §̊; Paralectotype \Lectotypus; Trogophloeus; oxyteloides Cameron; des. Makranczy, 2013 \Paraploderus; speculiventris (Fauvel); det. Makranczy, 2015" (BMNH); Paralectotype (1, missing head and pronotum): "Tjibodas; 1400 M.; VIII. 1921 $\backslash$ Trogophloeus; oxyteloides; Type. n.sp. \Type [printed on red card] \Paralectotypus; Trogophloeus; oxyteloides Cameron; des. Makranczy, $2013 \backslash$ Paraploderus; speculiventris (Fauvel); det. Makranczy, 2015" (RMNH).

Other material - INDONESIA: W-Java, 2 km SE Rancabali (40 km SSW Bandung), Telaga Patenga, 1400 m, 6.VIII.1994, leg. R. Schuh (1, NHMW); W-Java, Gede-Pangrango National Park, near Headquarters, 1550 m, 3.VIII.1994, leg. R. Schuh (1 ô, 2 ㅇ, 2, NHMW, 1, SMNS, 1, NIBR, 1, FMNH), same but forest litter, 23.VIII.1994 (1 $\circ$, NHMW); West Java, [Bogor,] Col du Puncak et Cibodas, lac Telaga Warna, en haut du col et réserve de Cibodas 12.VIII.1985, leg. J. Robert (Ja-7) (10, MHNG, 5, HNHM); Sumatra, Jambi, Mt. Kerinci, 1750-1850 m, 11-12.XI.1989, leg. I. Löbl, D. Agosti, D.H. Burckhardt (11), sifting of vegetational debris in montane Lithocarpus-Castanopsis forest (1, MHNG).

Redescription - Measurements (in $\mathrm{mm}, \mathrm{n}=10$ ): $\mathrm{EW}=0.66(0.57-0.69)$; $\mathrm{TW}=0.64$ (0.54-0.67); $\mathrm{PW}=0.72(0.61-0.76) ; \mathrm{SW}=0.80(0.66-0.86) ; \mathrm{AW}=0.92(0.77-0.97) ; \mathrm{HL}=0.41$ (0.36-0.43); $\mathrm{EL}=0.16(0.15-0.17) ; \mathrm{TL}=0.11(0.09-0.13) ; \mathrm{PL}=0.49(0.41-0.53) ; \mathrm{SL}=0.76(0.60$ $0.81) ; \mathrm{SC}=0.71(0.55-0.76) ; \mathrm{FB}=1.76(1.43-1.88) ; \mathrm{BL}=3.29(2.87-3.95)$. Habitus as in Fig. 104. head and elytra dark brown with some reddish tint, epistomal suture blackish; pronotum somewhat lighter, medium to dark brown, only marginal bead darker. Abdomen with base and apex medium brownish, middle darker, dark brown with occasinal reddish lustre. Legs and antennae medium brown, mouthparts same but apices of mandibles darker, infuscate. Head transverse with rounded but slightly bulging temples a little narrower than eyes. Clypeus with scattered, small punctures only, with inconspicuous, extremely thin anterior rim also on sides, only feeble traces of microsculpture and unevenness laterally on surface. Epistomal suture between tips of supraantennal prominences. Medial portion of occipital groove slightly bending anteriorly, neck medially shiny, laterally with traces of coriaceous microsculpture with isodiametric cells. Vertex with very scattered, indefinite-bordered and variously sized punctures; punctation near temples much denser and obscures postocular ridge. Faint longitudinal impressions running on both sides of vertex from epistomal suture to occipital groove, becoming more marked posteriorly. Head surface otherwise shiny, without microsculpture. Pronotum with complete, thin marginal bead. Surface shiny, without any microsculpture but more strongly punctured than head, indefinite-bordered, mostly rather large pits (slightly umbilicate) almost everywhere on surface except along midline and narrowly along posterior margin. Longitudinal midline 


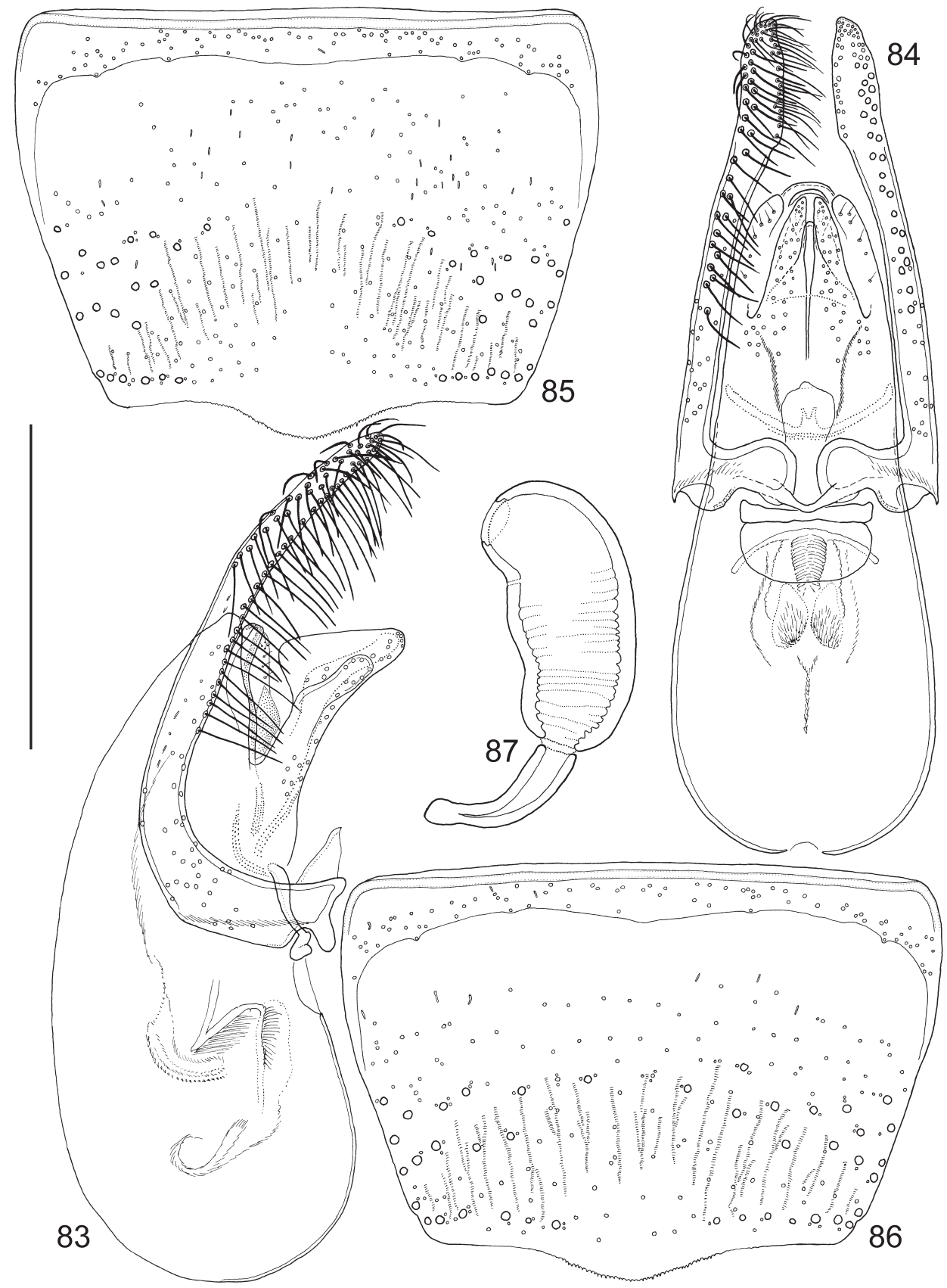

Figs 83-87. Paraploderus speculiventris (Fauvel, 1904). 83= aedeagus, lateral view, $84=$ aedeagus, frontal view (parameral setation shown on left), 85 = sternite VIII, male, 86 = sternite VIII, female, 87 = spermatheca. Scales: $0.1 \mathrm{~mm}$ for Fig. 87, $0.3 \mathrm{~mm}$ for Figs 83-84, $0.35 \mathrm{~mm}$ for Figs 85-86. 


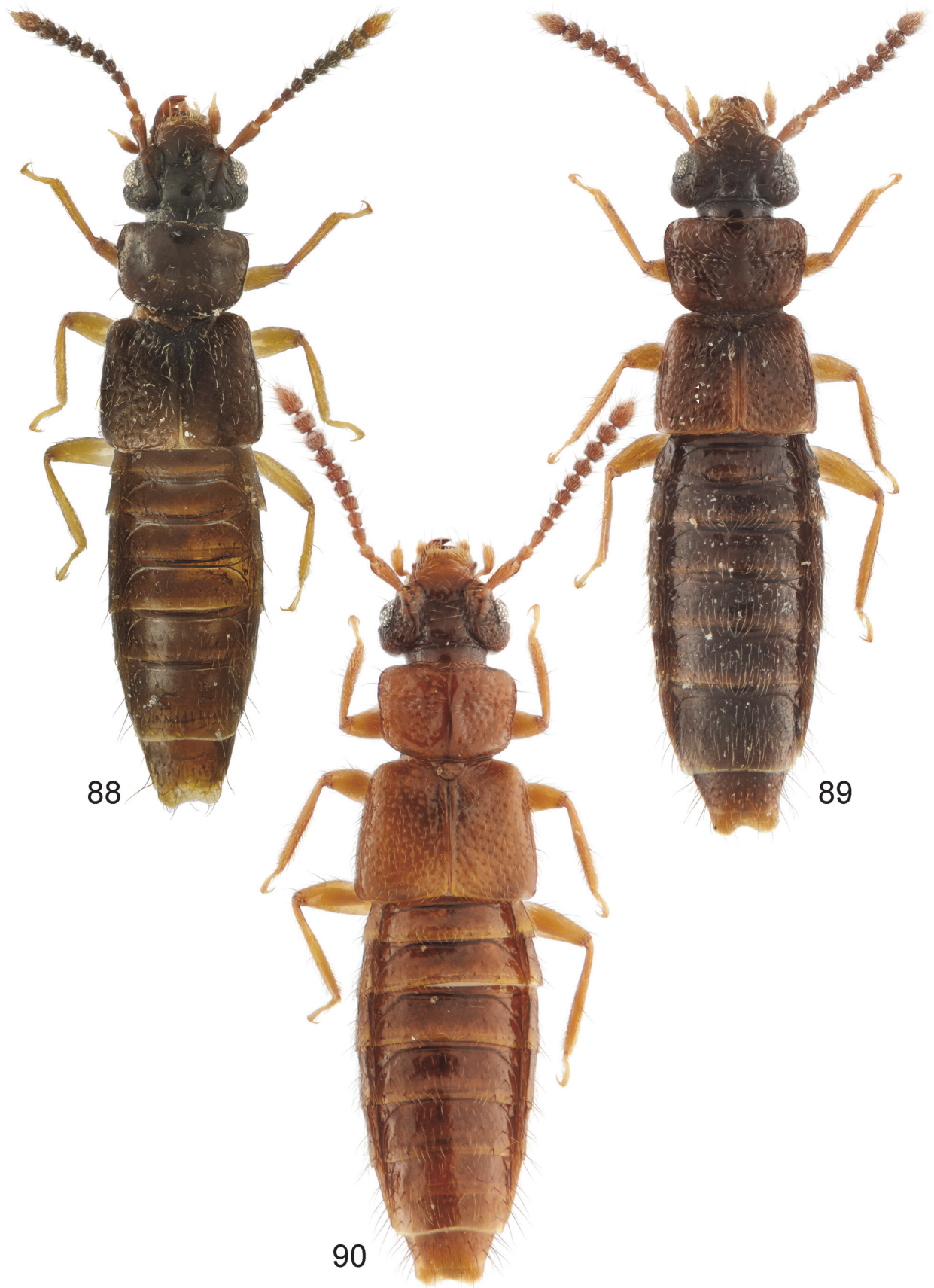

Figs 88-90. Habitus of Paraploderus species. $88=P$. nigronitens (Cameron, 1951), $89=P$. grandis $\mathrm{sp} . \mathrm{n} ., 90=P$. rufescens $\mathrm{sp} . \mathrm{n}$. 


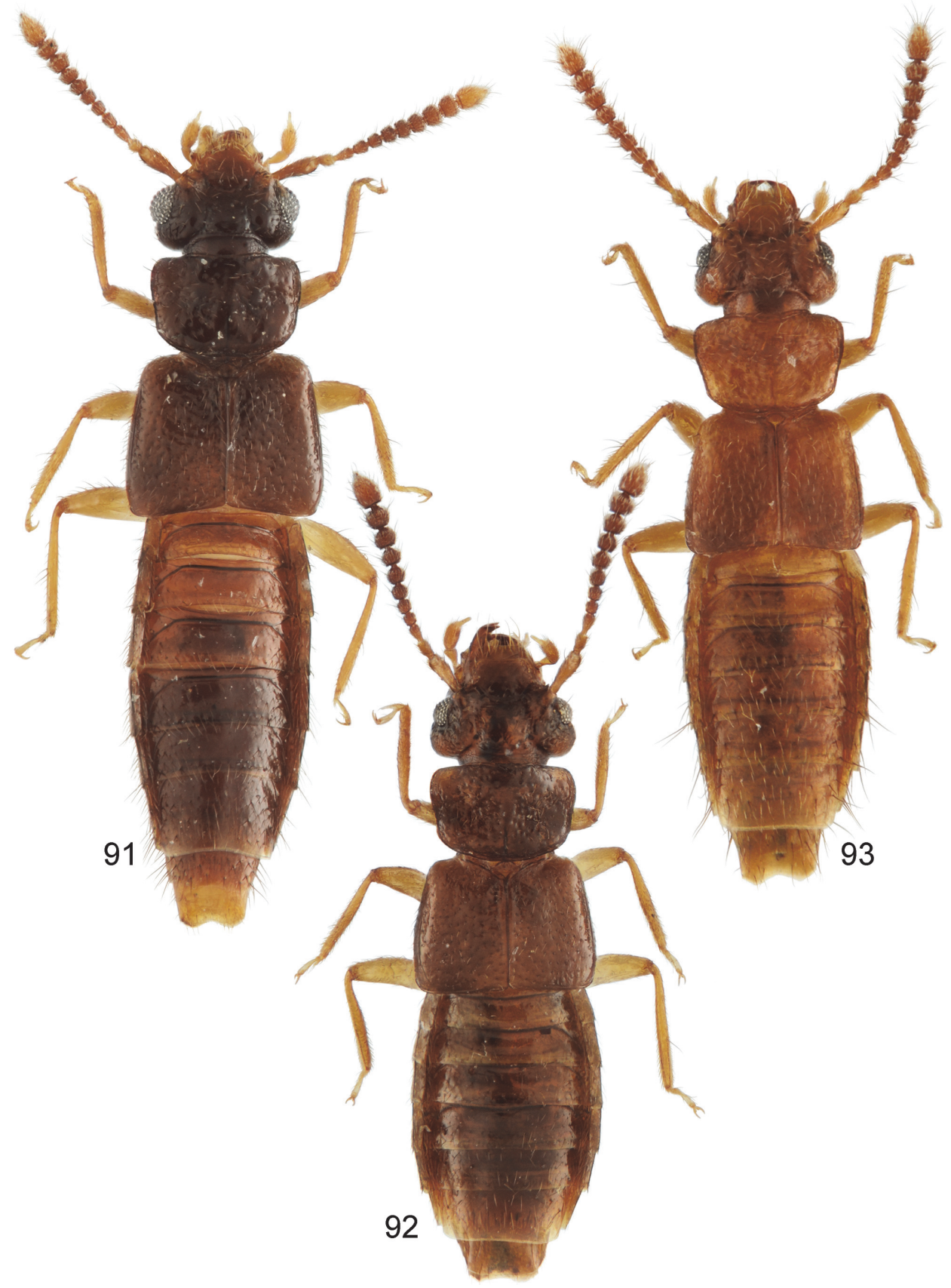

Figs 91-93. Habitus of Paraploderus species. $91=P$. wittei sp. n., $92=P$. malgaceus sp. n., $93=$ P. goergesae sp. n. 
marked as thin darker line on entire length. On both sides of midline middle of disc strongly impressed to the middle of sides. Elytra with disc very gently convex, two very thin and shallow longitudinal impressions along suture behind scutellum, anterior third of disc gently impressed. Epipleural ridge present on almost entire length. Thin marginal bead with obscure connection to epipleural ridge continuing along posterior margin, not reaching sutural corner, slightly curving anteriorly before it. Along suture very fine marginal bead only conspicuous because of darker colour. Elytral punctation mostly rather shallow, obscured by uneven surface, more or less equally spaced, moderately sparse, missing on a thin, slightly elevated stripe along suture. Abdomen shiny and smooth with only tiny insertion points of setae and extremely faint coriaceous microsculpture with isodiametric cells. Male sternite VIII as in Fig. 85, aedeagus as in Figs 83-84, female sternite VIII as in Fig. 86, spermatheca as in Fig. 87.

Distribution - All but one of the known specimens appear to be from the western part of Java, but wider distribution is possible, as there is a doubtless record from Sumatra.

Remarks - This species is remarkable in its disproportionally large aedeagus. The existing syntypical material of Haploderus speculiventris is apparently composed of two different species. P. M. Hammond identified the only male in the series as $P$. oxyteloides (leaving the conspecific female without identification, but marked a female specimen (out of the other two, non-conspecific) as lectotype (unpublished), with the clear intention to avoid the synonymy between these two published names. However, this would also give speculiventris a dubious identity (females of externally similar species cannot be distinguished). Simply sparing the introduction of a new name is not enough reason to leave the oldest name in the genus without clear identity. The label data of the non-conspecific syntypes of Haploderus speculiventris are given under the type material of $P$. fauveli sp. n.

\section{Paraploderus thailandicus sp. n.}

(Figs 94-98, 103)

Type material - Holotype (ð): THAILAND: NE Bangkok, Khao Yai Nat. Park, Khao Khieo, au-dessous d' "Air Force Check Point", versant nord, 1150 m [14 ${ }^{\circ} 22^{\prime} 03^{\prime \prime} \mathrm{N}$, 10124'21"E], 28.XI.1985, leg. D. Burckhardt \& I. Löbl (29), forêt assez sèche, tamisage de débris végétaux (MHNG); Paratypes (142): same data as holotype (95, MHNG, 1, BMNH, 1, NIBR, 1, CNCI, 1 o , MNHP, 1, AMNH, 1, NMPC, 1, FMNH, 1, SDEI, 1, SMNS); NE Bangkok, Khao Yai Nat. Park, aux environs de "Headquarters", 750-850 m, 26.XI-3.XII.1985, leg. D. Burckhardt \& I. Löbl (28b), tamisage de débris végétaux (11, MHNG, 1, NHMW); NE Bangkok, Khao Yai Nat. Park, collines E Heo Suwat waterfalls, 800 m, 1.XII.1985, leg. D. Burckhardt \& I. Löbl (30a), tamisage de débris végétaux à la lisière de la forêt, près d'un marécage et près d'un ruisselet (20, MHNG, 1, HNHM); Nakhon Rachasima prov., Khao Yai Nat. Park, 1020 m, 24.XII.1992, leg. P. Schwendinger (1, MHNG); Chanthaburi, Khao Sabap National Park, environs de Phliu Waterfalls, 150-300 m, 23-24.XI.1985, leg. D. Burckhardt \& I. Löbl (27a), tamisage de débris végétaux et de mousses à proximité de cours d'eau (2, MHNG); Chiang Mai, Doi Inthanon, ravin très humide, 1650 m, 6.XI.1985, 


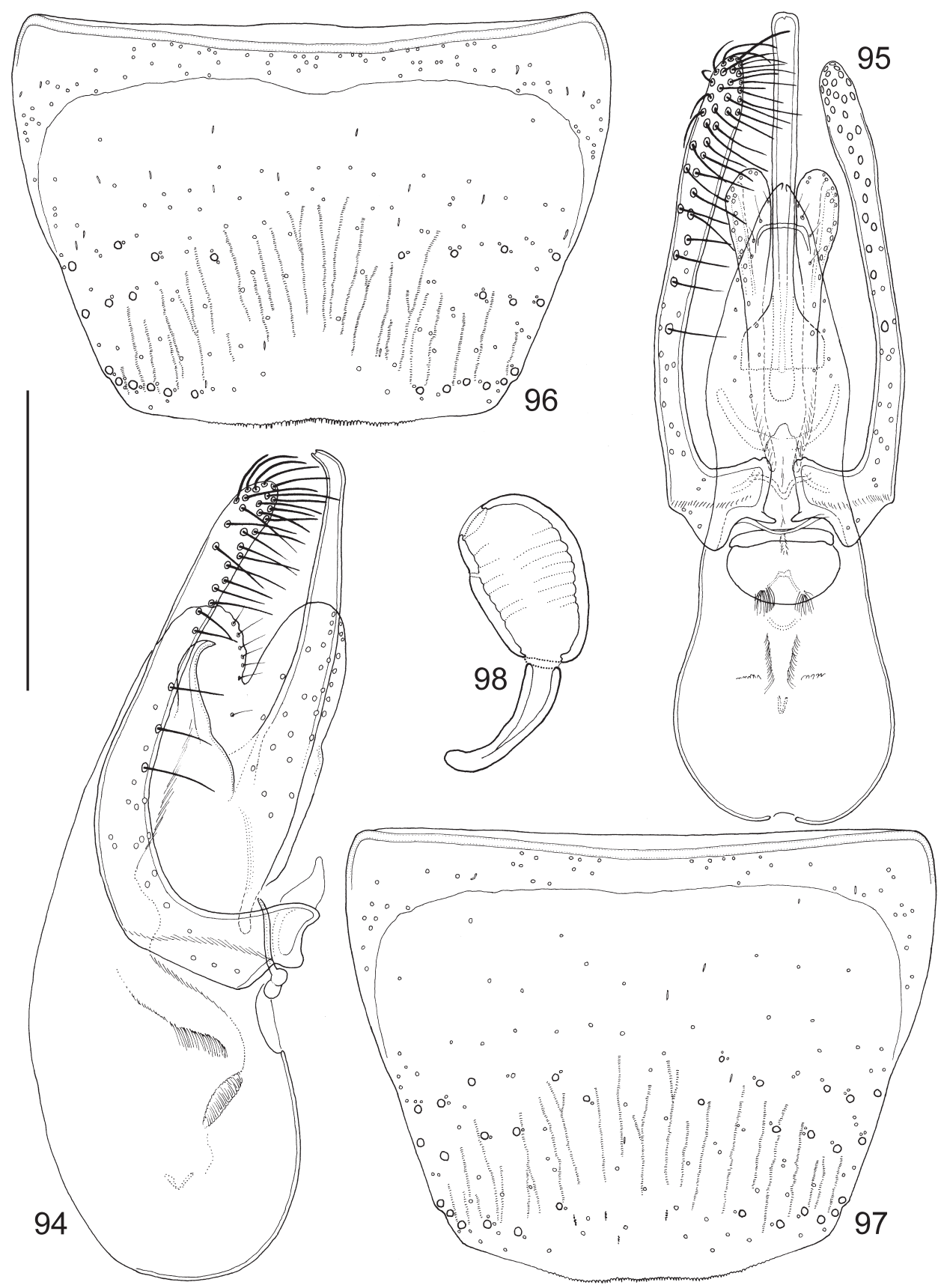

Figs 94-98. Paraploderus thailandicus sp. n. $94=$ aedeagus, lateral view, $95=$ aedeagus, frontal view (parameral setation shown on left), 96 = sternite VIII, male, $97=$ sternite VIII, female, 98 = spermatheca. Scales: $0.1 \mathrm{~mm}$ for Fig. 98, $0.18 \mathrm{~mm}$ for Figs 94-95, 0.28 mm for Figs 96-97. 


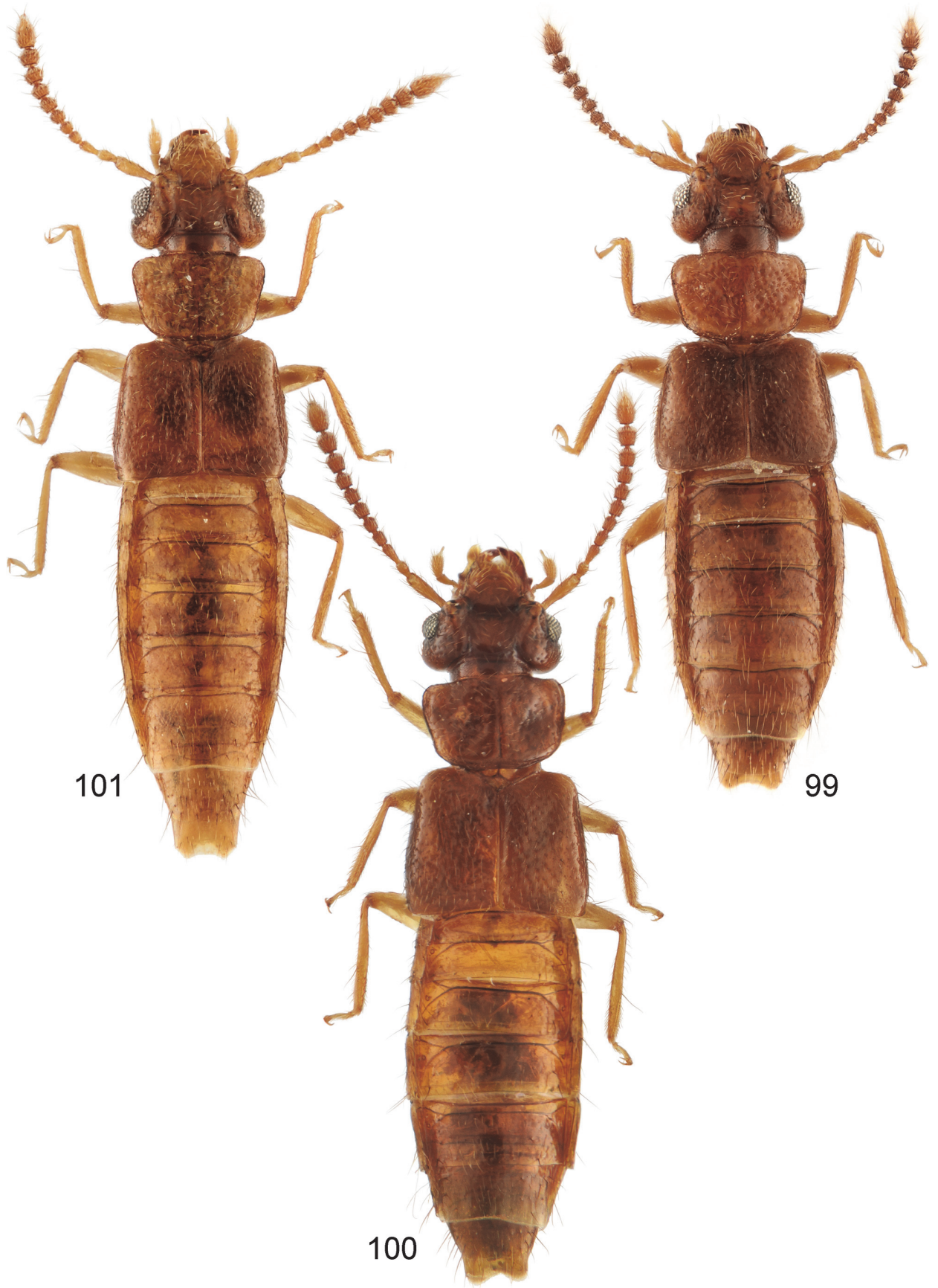

Figs 99-101. Habitus of Paraploderus species. $99=$ P. fauveli sp. n., $100=$ P. hammondi sp. n., $101=P$. loebli sp. n. 


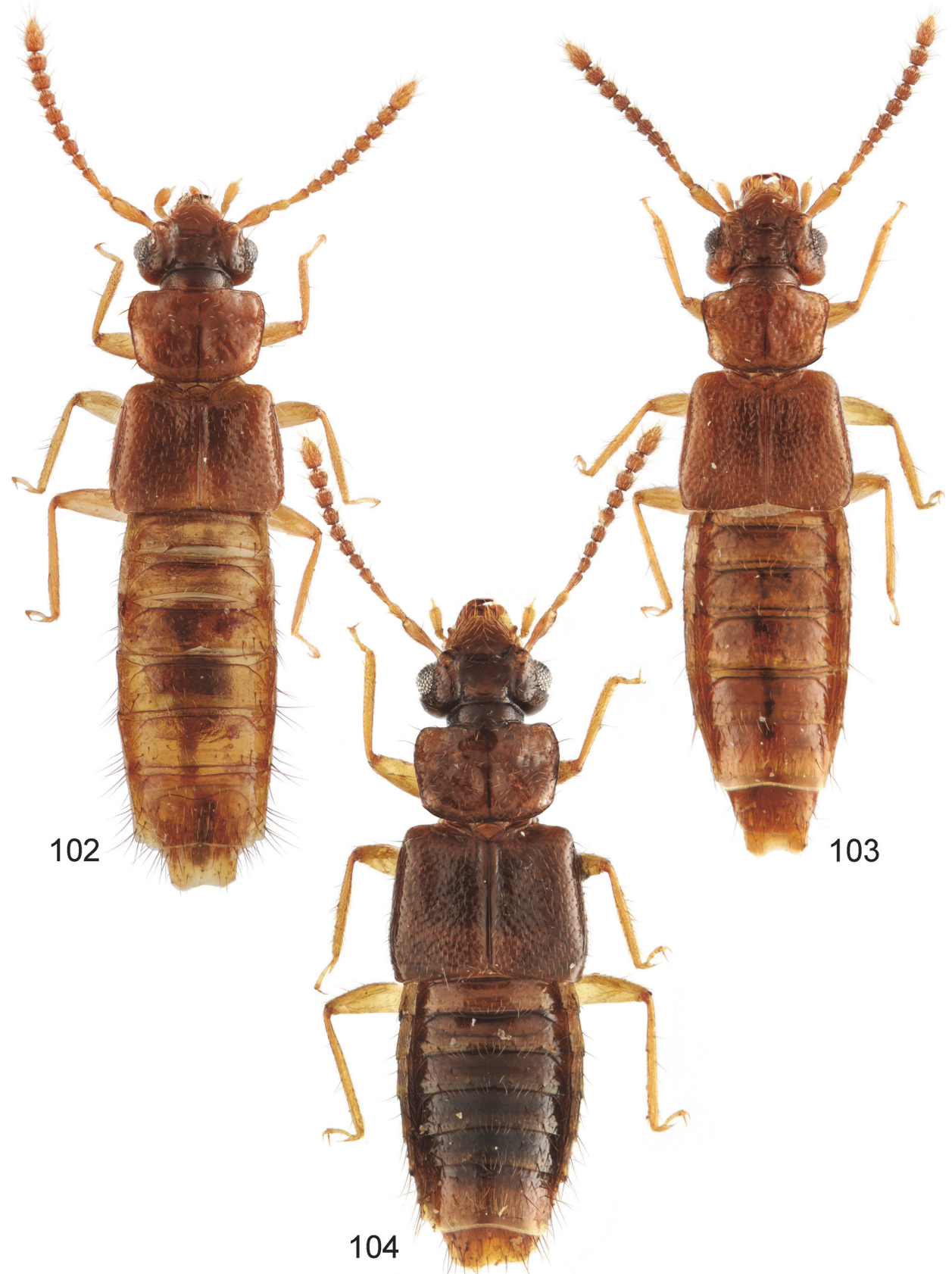

Figs 102-104. Habitus of Paraploderus species. $102=$ P. schwendingeri sp. n., $103=$ P. thailandicus sp. n., $104=$ P. speculiventris (Fauvel, 1904). 


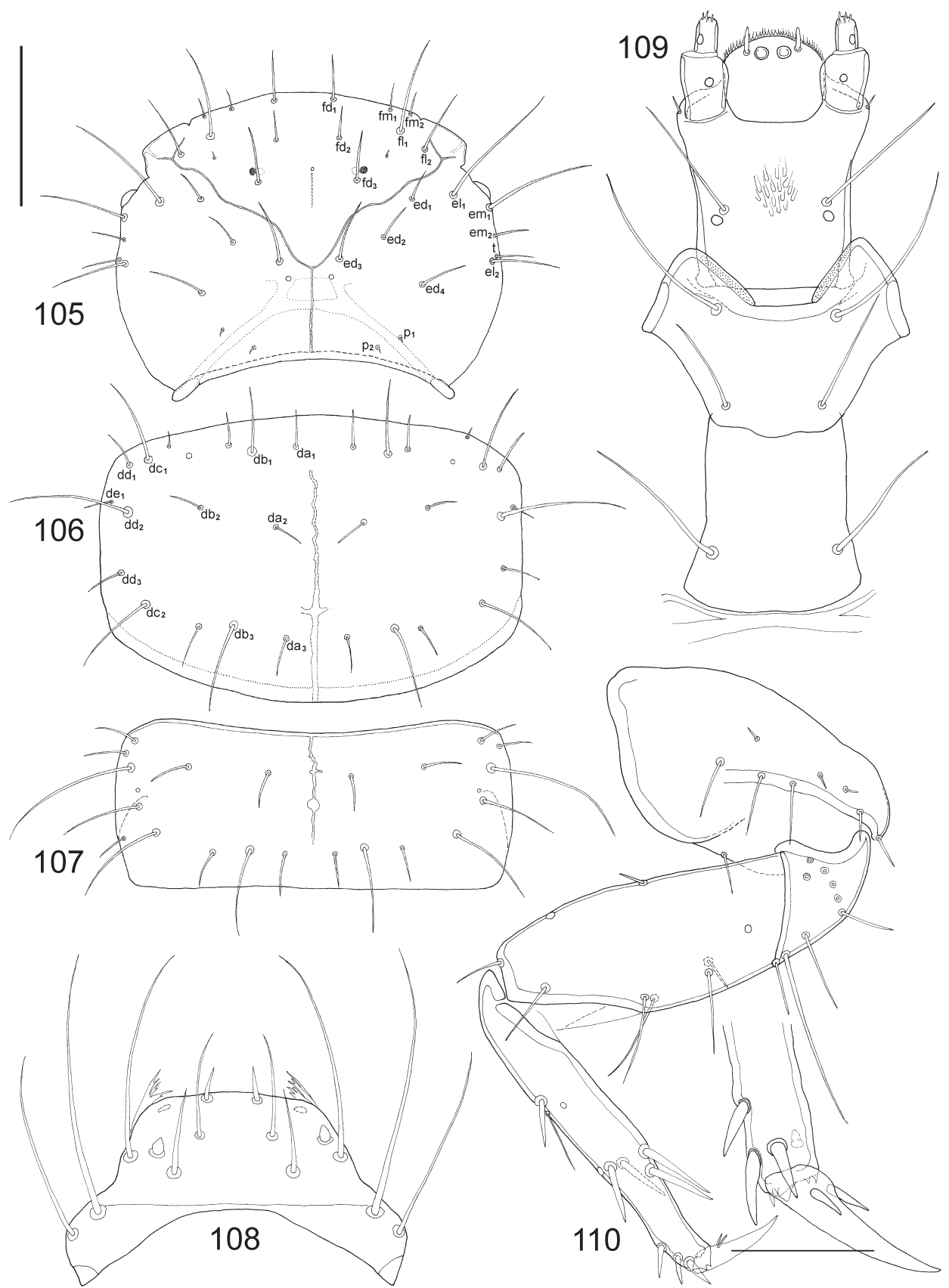

Figs 105-110. Larva $\left(\mathrm{L}_{3}\right)$ of Paraploderus rufescens sp. n. $105=$ head capsule, $106=$ pronotum, $107=$ mesonotum, 108 = labrum, $109=$ labium, $110=$ anterior leg (tarsungulus magnified

2×). Scales: $0.07 \mathrm{~mm}$ for Figs 108-109, $0.1 \mathrm{~mm}$ for Fig. 110, $0.2 \mathrm{~mm}$ for Figs 105-107. 
leg. D. Burckhardt \& I. Löbl (16), tamisage de débris végétaux et de champignons près d'un ruisselet (1, MHNG); Chiang Mai, Doi Suthep, versant nord, 1050 m, 5.XI.1985, leg. D. Burckhardt \& I. Löbl (10), ravin très humide, tamisage de bois pourri, des écorces et champignons (1, MHNG).

Description - Measurements (in mm, $\mathrm{n}=10)$ : $\mathrm{EW}=0.62(0.58-0.65)$; $\mathrm{TW}=0.60(0.56-$ $0.63) ; \mathrm{PW}=0.64(0.60-0.68) ; \mathrm{SW}=0.72(0.68-0.76) ; \mathrm{AW}=0.83(0.76-0.89) ; \mathrm{HL}=0.40(0.37-$ $0.41) ; \mathrm{EL}=0.14(0.13-0.15) ; \mathrm{TL}=0.13(0.13-0.14) ; \mathrm{PL}=0.44(0.41-0.47) ; \mathrm{SL}=0.69(0.65-0.74)$; $\mathrm{SC}=0.64$ (0.60-0.69); FB = 1.60 (1.49-1.70); $\mathrm{BL}=3.19$ (2.93-3.39). Habitus as in Fig. 103. Body more or less unicolorous, slightly reddish medium brown, head sometimes a little darker. Legs, mouthparts and antennae medium brown, apices of mandibles often darker, infuscate. Elytra the same colour as pronotum or sometimes a little darker. Head transverse with rounded, bulging temples just slightly narrower than eyes. Clypeus with very scattered, minute punctures only, with a thin anterior rim also on sides, only feeble traces of microsculpture and unevenness laterally on surface. Epistomal suture posterior to imaginary line connecting supraantennal prominences. Medial portion of occipital groove more or less straight, neck medially shinier but still with traces of microsculpture, laterally coriaceous microsculpture with isodiametric cells. Vertex with very scattered, indefinite-bordered and variously sized punctures; punctation near temples much denser and obscures postocular ridge. Faint longitudinal impressions running on both sides of vertex from epistomal suture to occipital groove, becoming more marked posteriorly. Head surface otherwise shiny, without microsculpture. Pronotum with complete, thin marginal bead. Surface shiny, without any microsculpture but more strongly punctured than head, indefinite-bordered, mostly rather large pits (slightly umbilicate) almost everywhere on surface except along midline and narrowly along posterior margin. Longitudinal midline marked in posterior $1 / 2$. On both sides of midline middle of disc strongly impressed to the anterior $1 / 3$ of sides. Elytra with disc almost flat, two very thin and shallow longitudinal impressions along suture behind scutellum, anterior half of disc gently impressed. Epipleural ridge present on almost entire length. Thin marginal bead with obscure connection to epipleural ridge continuing along posterior margin, not reaching sutural corner, slightly curving anteriorly before it. Along suture very fine marginal bead only conspicuous because of darker colour. Elytral punctation mostly rather deep, more or less equally spaced, moderately dense (interspaces just slightly less than puncture diameters), missing on a thin, slightly elevated stripe along suture. Abdomen rather shiny and smooth with only tiny insertion points of setae and no trace of microsculpture. Male sternite VIII as in Fig. 96, aedeagus as in Figs 94-95, female sternite VIII as in Fig. 97, spermatheca as in Fig. 98.

Distribution - The species is currently known from several localities in $\mathrm{N}$ Thailand.

Etymology - The name of the species refers to its being from Thailand.

Remarks - The species stands out by the aedeagus with an enormously elongate apicomedial appendage between the paired, bladelike apical opening processes. 

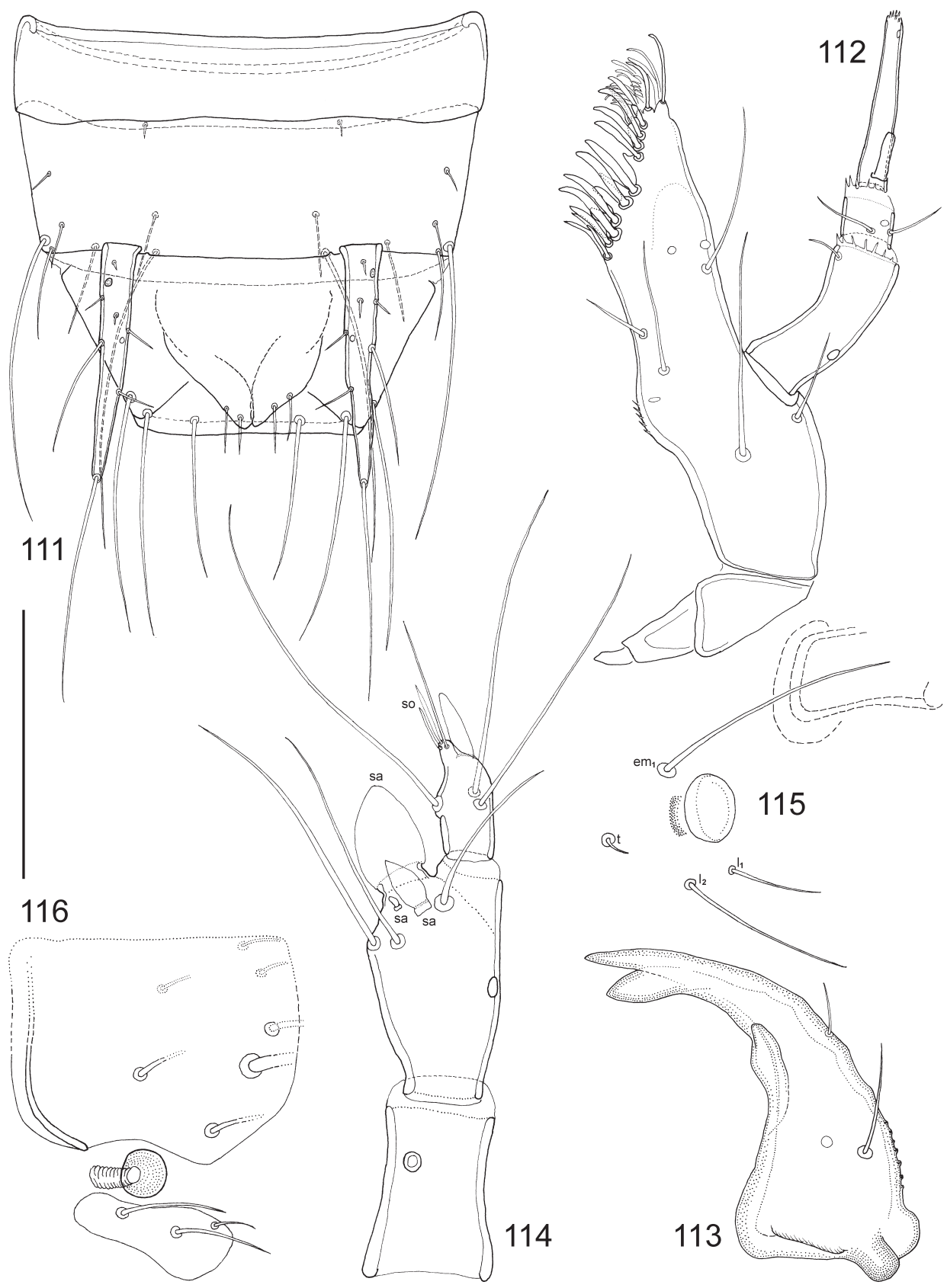

Figs 111-116. Larva $\left(\mathrm{L}_{3}\right)$ of Paraploderus rufescens sp. n. $111=$ abdominal segments $\mathrm{IX}-\mathrm{X}$, $112=$ maxilla, $113=$ mandible, $114=$ antenna, $115=$ stemma, lateral view, $116=$ lateral view of 1st tergite, pleurite and spiracle. Scales: $0.1 \mathrm{~mm}$ for Fig. 114, $0.12 \mathrm{~mm}$ for Figs 115-116, $0.14 \mathrm{~mm}$ for Fig. 112, $0.17 \mathrm{~mm}$ for Fig. 113, $0.2 \mathrm{~mm}$ for Fig. 111. 
Acknowledgements - The author wishes to express thanks to all the curators listed in the Materials section, to Al Newton and Margaret Thayer (Chicago) for their assistance with the larval description, to Lee Herman (New York) for meticulously reading through and correcting the manuscript, to Mikael Sörensson (Lund) for carrying large amount of specimens and to Harald Schillhammer (Wien) for the habitus photographs. Giulio Cuccodoro arranged my extended stay in Geneva which was instrumental in the success of this project.

\section{REFERENCES}

Bernhauer, M. (1933) Zur Staphylinidenfauna des Belgischen Kongostaates. Revue de Zoologie et de Botanique Africaines 23(3-4): 291-301.

Bernhauer, M. \& Schubert, K. 1911: Staphylinidae II (pars 29). p. 87-190. In: Junk, W. \& Schenkling, S. (eds): Coleopterorum Catalogus, Volumen V. W. Junk, Berlin, Germany, 988 pp.

Cameron, M. (1925) New Staphylinidae from the Dutch East Indies. Treubia 6(2): 174-198.

Cameron, M. (1928) Fauna sumatrensis. Staphylinidae (Col.). Entomologische Mitteilungen 17(2): 90-110.

Cameron, M. (1950) New species of Staphylinidae (Col.) from Angola. Publicações Culturais Companhia de Diamantes de Angola (Diamang) 7: 109-121.

Cameron, M. (1951) New species of Staphylinidae (Col.) from Angola. Publicações Culturais Companhia de Diamantes de Angola (Diamang) 13: 45-51.

Fauvel, A. (1904) Staphylinides exotiques nouveaux. 2e Partie. Revue d'Entomologie (Caen) 23: $76-112$.

Fauvel, A. (1905) Staphylinides exotiques nouveaux. 3e Partie. Revue d'Entomologie (Caen) 24: 113-147.

Gildenkov, M. Yu. (2004) Osobennosti morfologii Paraploderus punctus, predstavitelya maloizvestnogo roda [Morphological features of Paraploderus punctus, representative of a little-known genus]. Pp. 341-344. In: Nauchnye chteniya pamyati professora V. V. Stanchinskogo, Vol. 4 [A tribute to prof. V.V. Stanchinsky, the 4th International Proceeding]. Publishing house [of the] Smolensk State Pedagogical University, Smolensk (Russia).

Herman, L. H. (1970) Phylogeny and reclassification of the genera of the rove-beetle subfamily Oxytelinae of the World (Coleoptera, Staphylinidae). Bulletin of the American Museum of Natural History 142(5): 343-454.

Herman, L. H. (2001) Catalog of the Staphylinidae (Insecta: Coleoptera). 1785 to the end of the second Millennium. Bulletin of the American Museum of Natural History 265: 1-4218. doi: 10.1206/0003-0090(2001)264<0003:NCITSI>2.0.CO;2

Makranczy, GY. (2006) Systematics and phylogenetic relationships of the genera in the Carpelimus group (Coleoptera: Staphylinidae: Oxytelinae). Annales historico-naturales Musei nationalis hungarici 98: 29-119.

Makranczy, Gy. (2013) Description of a new Anotylus species from Madagascar and the female of Anotylus flavipennis from Laos (Coleoptera: Staphylinidae: Oxytelinae). Acta Zoologica Academiae Scientiarum Hungaricae 59(3): 187-195.

Makranczy, Gy. (2014a) Review of the genus Parosus Sharp, 1887 (Coleoptera: Staphylinidae, Oxytelinae). Revue suisse de Zoologie 121(1): 77-133. 
Makranczy, Gy. (2014b) Review of the Thinodromus circulus species group (Coleoptera, Staphylinidae, Oxytelinae). Acta Entomologica Musei Nationalis Pragae 54(2): 539-554.

Makranczy, Gy. (2014c) Revision of the genus Ochthephilus Mulsant \& Rey, 1856 (Coleoptera: Staphylinidae, Oxytelinae). Revue suisse de Zoologie 121(4): 457-694.

Staniec, B. (1997) A description of the developmental stages of Aploderus caelatus (Gravenhorst, 1802) (Coleoptera: Staphylinidae). Deutsche entomologische Zeitschrift 44(2): 203-230. doi: 10.1002/mmnd.19970440209

StAniec, B. (1999) A description of the egg and mature larva $\left(\mathrm{L}_{3}\right)$ of Aploderus caesus (Erichson, 1839) (Coleoptera: Staphylinidae). Genus 10(3): 361-370.

Staniec, B. (2003) Description of the egg, larva and pupa of Platystethus alutaceus (Thomson, 1861) (Coleoptera: Staphylinidae). Genus 14(1): 27-41.

Scheerpeltz, O. (1933) Staphylinidae VII (pars 129). [Supplementum I.] Pp. 989-1500. In: Junk, W. \& Schenkling, S. (eds.): Coleopterorum Catalogus, Volumen VI. W. Junk, Berlin, Germany, 1881 pp.

Received August 31, 2015, accepted September 16, 2015, published March 16, 2016 